\title{
A STUDY OF
}

\section{SCHOOL CROSSING PROTECTION}

SEPT. 1961
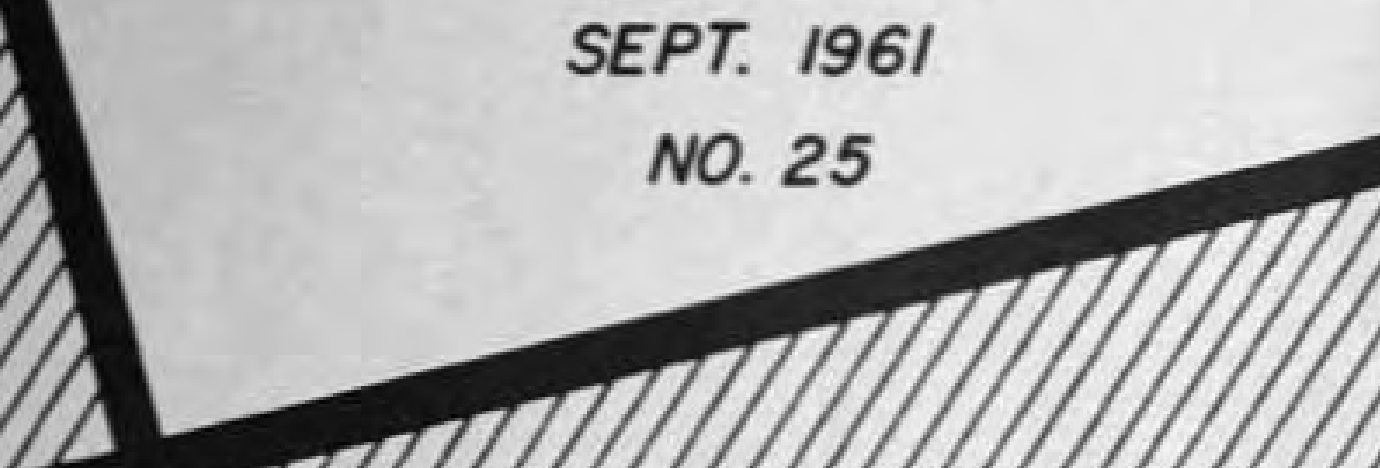
IInal Report

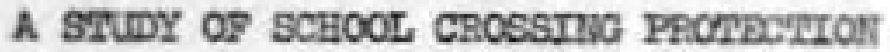

TO:

X. B. Hoods, Director Jolnt Hichny Plesearch Project

moat:

II. L. Itichael, Associate DIrector Joint Hidruay Rescarch Projest
Sopteaber 27, 1961

Me: 8-4-22

Project: C-36-17u

A Pinal reported entilied "A Stuily or Bchool Croseinz Protection" authored by Forwest D. Huler, greduste asolstant on our staff, is attached. Fhis revourch roport vas also used by He. Nuler os his thesis In partiel fulfilleat of the VSCB degree end was proparod unitar the direction of Professor 7 . L. Mehecl.

This resourch 1mvestigetes onc of the most arficult to handie, fren the viav point of public relations, of all trurfic encinaering problens. It aleo is one of the arees uhere controle are not unfforn. The stuidy dacerminod the erfect on speed of fourteou combinations of sigrs and flashers used as school crossing protection and prosents fuctual data on theso effecte. The stuly also investigeted the problem of school croseing protection relative to the totel. trafric ascident problen.

The report is presented for the recond and to the mantoors for information. The cooperstion and assistance of the DIvisicn of Trafac Freineering in this study has been excellent and is Bratoluliy aclinouleaged.

Respectruty subnitted,

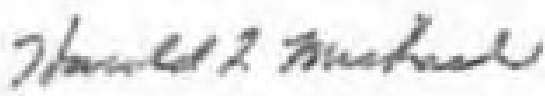

IarajA I. Mahael

Becretauy

IIIt:lene

Attachnent

ec: $\mathbf{Y}$. L. Ashbaucher

J. I. MeIaughlin

J. R. Cooper

R. D. Kiles

H. L. Dolch

R. B. Vu11s

W. I. Coots

II. B. Seott

7. P. Hever

J. V. Aeythe

7. B. H1212

G. R. Teonards

J. I. Neitre

B. J. Yodar 

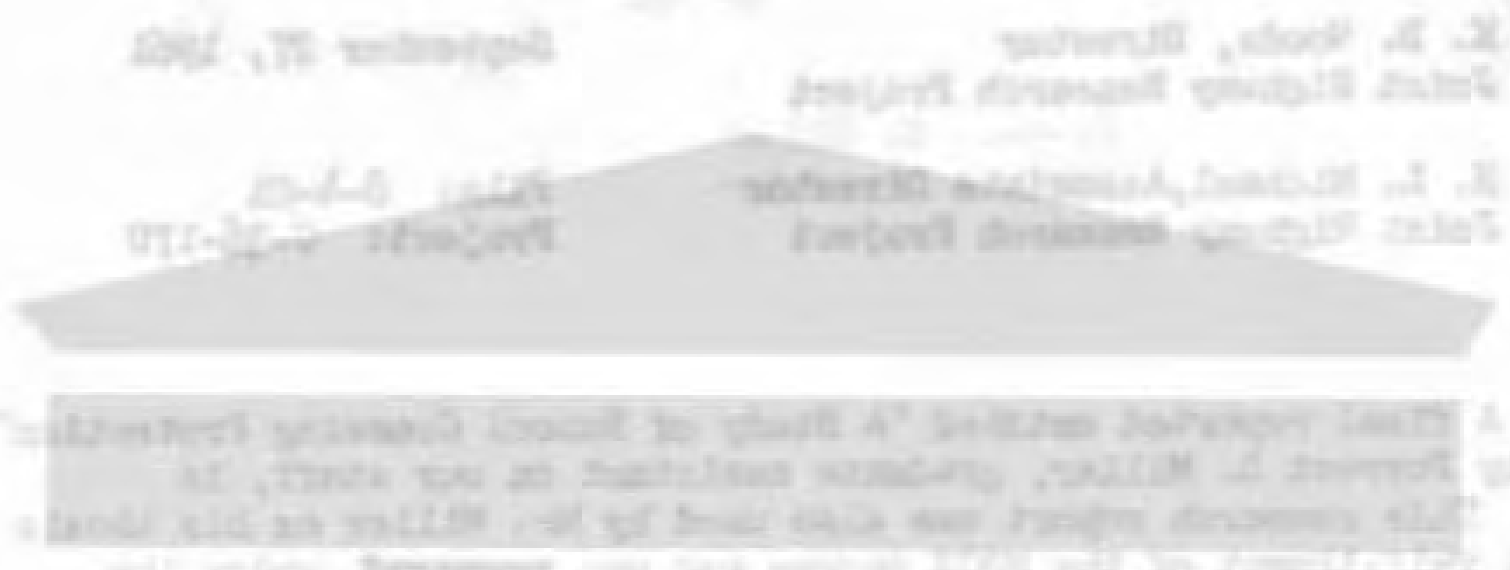

Digitized by the Internet Archive in 2011 with funding from

LYRASIS members and Sloan Foundation; Indiana Department of Transportation
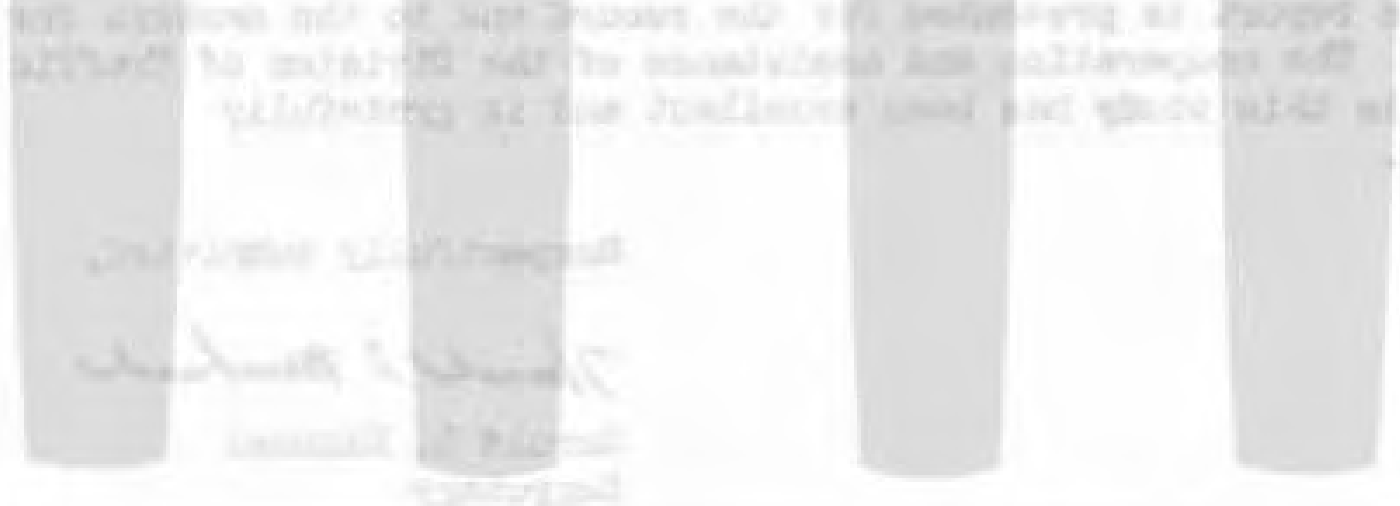

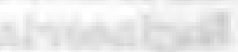

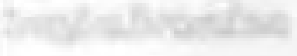

(1)
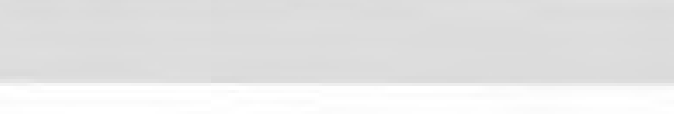
Final Report

A STUDY OF SCHOOL CROSSING PAOTBCHION

BY

Porrest D. MHer

Grachute Assistant

Joint Highvay Research Projoct

File $110 .: 8-4-21$

Project IIo: C-36-170

Purdue thiversity

Iafayette, Inotiann

September 27, 1961 


\section{ACKNOWLEDGMENTS}

The author wishes to express his appreciation for the invaluable assistance rendered him by Professor Harold L. Michael, Associate Director, Jolnt Highway Research Project, in all phases of the study and in the preparation and review of the manuscript; to Dr. Irving W. Burr, Department of Mathematics, for his advice on the statistical design and analysis of the data and for his review of the manuscript; to Dr. Virgil L. Anderson, Department of Mathematics, for his advice on the statisticsl analysis of the data and for his review of the manuscript; to Professor Robert D. Miles, Joint Highway Research Project, for his review of the manuscript; to members of the State H1ghway Department of Indlana for their cooperation in the study; to the staff of the Joint Highway Research Project for their assistance in performing the study; and to members of the statistical computing laboratory for their assistance in pedestrian accident computations.

Acknowledgment is also made to the Indiana State Police for supplyIng the pedestrian accident records; to the Police of Lafayette for supplying accident records; to the Pollce of West Lafayette for their assistance with the operation of the signals used in the study and for supplying accident records; and to two property owners along Northwestern Avenue, West Lafayette, for granting permission for the use of their driveways. 


\section{TABLB OF CONTENTS}

Page

LIST OF FIGURES

LIST OF TABLES

ABSTRACT ......................... v11

INTRODUCTION ........................... 1

School Crossing Protection .................. 1

School Crossing Protection Devices ............... 2

School Crossing Safety ................. 4

PRBVIOUS INVESTIGATIONS ................ 7

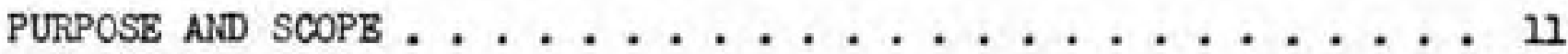

Purpose ......................... 11

Limits of Study ................... 11

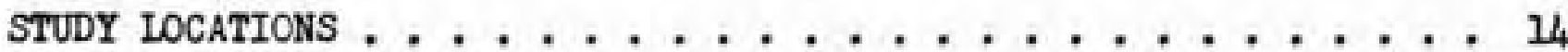

General ....................... . . . . . . . . .

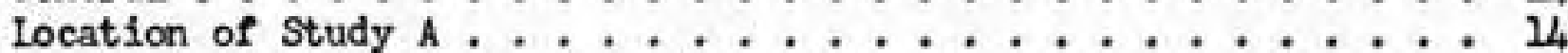

Iocations for Study B ............... 18

Locations for Study C.................. 24

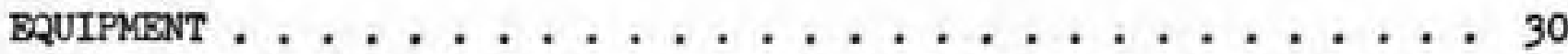

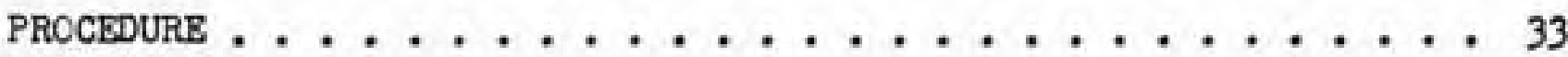

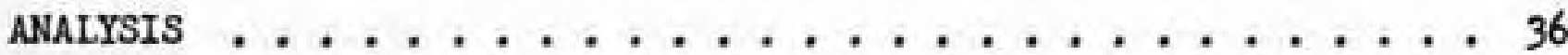

Statistical Analysis of Speed Parameters . . . . . . . . 36

Arithmetic Analysis of Speed-Delay ........... 39

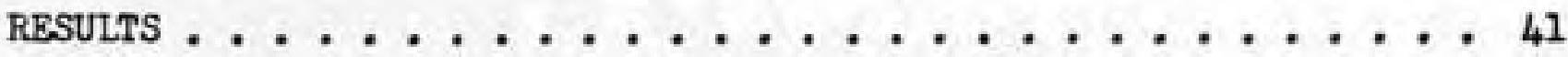

Study A ...................... 41

Study B..................... 49

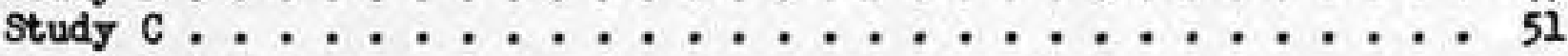

ACCIDENT STUDY OF THB SCHOOL-AGB PEDESTRIAN .......... 54 
CONCLUSIONS AND RBCONONDATIONS 56

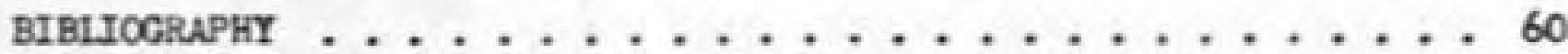

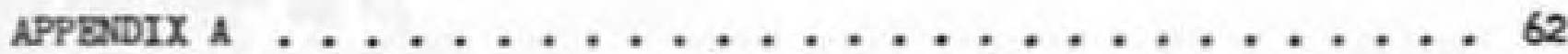

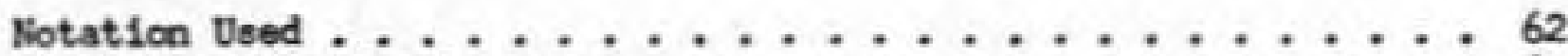

Glossary of Statistical Terms .............. 64

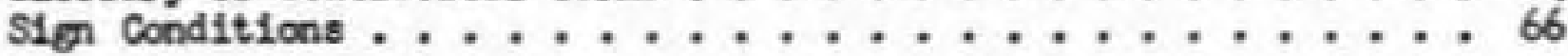

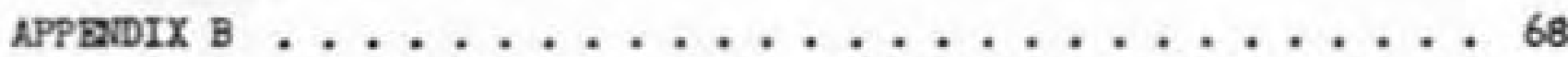

Sumary of Data ................. 68

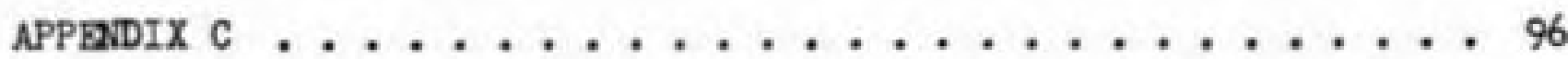

Illustrative Examples .................. 96 


\section{LIST OP PIGURES}

Flgure

Page

1. Student Injuries by Location ............... 5

2. Study Locations ................... 15

3. Photo Mosaic of Location A . . . . . . . . . 16

4. Types of Traffic Control Devices Used at Location A . . . 19

5. Views at Locations $\mathrm{Bl}$ and $\mathrm{B} 2 \ldots \ldots 22$

6. Views at Locations $\mathrm{Cl}$ and $\mathrm{C} 2 \ldots . . \ldots 25$

7. Views at Locations $\mathrm{C}_{3}$ and $\mathrm{C}_{4} \ldots \ldots . \ldots 27$

8. Views at Locations $\mathrm{C5}$ and $\varnothing 6 . \ldots . \ldots$

9. Radar Speed Meter Setup ................. 31

10. Scatter Diagram of Standard Deviation and Sample Size of Location A ............. . . 38

11. Children-SIgn Condition Interaction ...........43

12. Children and Sign Condition Versus Speed .......... 44

13. Time-SIgn Condition Interaction ............ 46 
IIST OF TABLES

Table

Page

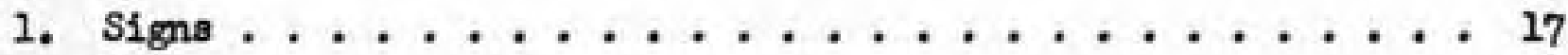

2. Sign Conditions and Location of Signs ........... 18

3. Analysis of Variance Table ............... 42

4. Multiple Comparisons ................ 48

5. Sumary of Data: Speed Parameters ........... 68

6. Summary of Data: Nean and 85th Percentile Speeds . . . . 82

7. Preliminary Study: Speed Parameters ........... 90

8. Sumary of Data: Traffic Delay Resulting from PedestrianActuated Signals ................ . . 91

9. Sunmary of Data: Pedestrian-Actuated Signals at School Crossings .................. 92

10. Summary of Data: School Crossing Overpasses and Underpasses 93

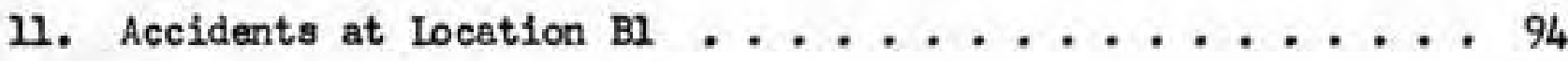

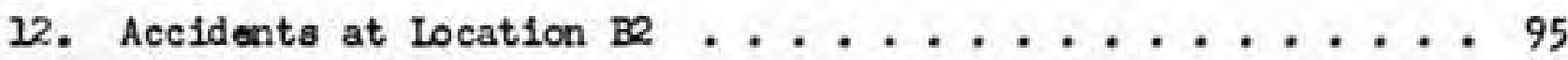




\section{ABSTRACT}

Miller, Forrest Dewayne. MSCE., Purdue University, January 1962. A STUDY OF SCHOOL CROSSING PROTBCTION. Major Professor: Harold L. Michael.

The problem of providing school crossing protection is a highly sensitive one, even though school children are involved in very few accidents going to and from school as compared to other locations. Although national standards on school crossing protection exist, one finds that many state and local jurisdictions express their own individuality as to the type as well as the operation of traffic control devices at school crossings. Uniformity in the use of these devices, an important requirement for safety, certainly does not exist.

The effect of various types of school crossing protection at school crossings was evaluated in this study. At one location the 85 th percentile speeds obtained under each of fourteen different sign conditions in a rural-suburban area were statistically anslyzed to determine the effect on 85th percentile speed. They were also correlated with three other factors-1) the direction of travel, 2) the time of the day, and 3) the presence of children at the crossing. The effect of a pedestrian-actuated signal at a school crossing was studied at two locations by observing how the children used it and by a study of the delay to traffic as a result of the signal. The effect of overpass and underpass school crossIngs was studled at six locations by observing how children use these facilities. The seriousness of the school crossing problem in Indiana was evaluated by analyzing the pedestrian accidents of school children during the hours they go to and from school. 
The study indicated that different combinations of sign condition, direction of travel, time of day, and presence of children significantly affected the 85 th percent1le speed at the school crossing. The presence of children at the edge of the roadway significantly lowered the 85th percentile speed under each sign condition. It was also found that the use of any of the traffic sign conditions studied had a rather small effect on 85 th percentile speed, with the several best sign conditions reducing the speed by a maximum of only five miles per hour.

The study indicated that a pedestrian-actuated signal operated by an adult school guard was superior to one operated by children. The operation of the signal was also less efficient to vehicular traffic when operated by children because it resulted in more delay to them. Overpass and underpass school crossings were much more effectively used by elementary school children than high school children. Underpass school crossings were found to be less desirable than overpass school crossings because they have greater potential for nulsance use and even crime. Enforcement of use was found to be necessary to obtain maximum use from most underpasses or overpasses. 


\section{INTRODUCTION}

\section{School Crossing Protection}

"Protective care for the 8 chool child pedestrian is a highly sensitive subject."(3)* Many more traffle control devices--signals, signs, guards, etc.--would have to be provided if all the demands of parents and others were to be met. Such demands, however, are often of an emotional nature and therefore, may be unfustified and if satisfied, may even increase the hazards. ". . (S)chool crossing protection seems to demand time, attention, manpower, and materials all out of proportion to the magnitude of the problem as measured by any factual basis . . ."(3) It is true that everyone wants to protect children, but at times there is a tendency to overprotect them while going to and from school. Excessive protection at school crossings will not equip children with the degree of self-reliance and personal responsibility they need at unprotected crossings and at other times of the day.

The basic rule of school crossing protection was well stated by Sielski (14) when he said, "It is the responsibility of the child aided by the school safety patrol member, to select proper gaps in traffic. If there is less than one safe gap per minute, it is the responsibility of the community to establish restrictive controls to create adequate gaps." The type of control to be used depends largely on the volume of traffic, the nature of the crossing, and other existing conditions.

\footnotetext{
"Numbers in parentheses refer to listings in the bibliography.
} 


\section{School Crossing Protection Devices}

Uniformity in the use of traffic controls at school crossings is an important requirement for safety (3). Although uniformity is the preva11Ing practice in the fleld of traffic, uniformity in school crossing protection is almost non-existent. There are nationally recommended standards given in the Manual on Uniform Traffic Control Devices for Streets and Highways (18), but there are a tremendous number of deviations from these standards (2). Many state and local jurisd1ctions express their own Individuality as to the type as well as the operation of traffic controls at school crossings. Such variations certainly confuse the driver of the motor vehicle.

The type of traffic control to be used at a schopl crossing depends on several conditions. Perhaps the most effective protection at school crossings is that of police protection. However, in most cases this is not practical or economical; particularly, where police departments are undermanned. There are a minimum number of locations, however, where pollce protection is warranted and should be used. The adult school crossing guard can provide protection almost equal to that of a policeman, if properly trained and supervised. The duty of the adult guard, as well as the pollceman, is to provide adequate gaps in traffic when such gaps do not exist, so as to allow children to cross safely. Since adult guards work only a few hours per day, they are more economical than employing additional police to provide the protection. However, budgets usually allow only limited use of adult guards, thus, not fulfillIng the need for guards at all crossings where they are warranted, 1.e., where safe gaps do not exist and where traffic control signals are not warranted. 
Traffic control signals when warranted should be used to provide gaps for groups of children at school crossings. Basically, there are two types of signal control that are used: pretimed and traffic-actuated signals, with or without pedestrian signals (18). Pretimed and trafficactuated signals should be installed only where traffic and/or pedestrian volumes warrant such installations (18). If warranted (18), traffic actuation may be by means of pedestrian push-button detectors. For school crossing protection, the push button may be supervised by someone, such as an adult guard, to provide satisfactory operation; otherwise, ch1ldren may misuse it mischievously.

Another type of traffic control used to provide protection for children at school crossings is that of signs. Precaution should be used, however, against unwarranted use and placement of too many signs, for this breeds contempt and the signs fail to accomplish their purpose (14). Signs which are portable should be used only during the hours when a school crossing is being used and should never be placed in the roadway (18). Standard warning signs are diamond-shaped with black legend on yellow background and carry the message "SCHOOL CROSSING." The flashing beacon 1s frequently used in confunction with the warning sign pertaining to the school crossing. Its purpose is to attract attention and emphasize the warning message on the sign.

Some use has been made of a stop sign at school crossings even though such signs are not recommended (18). As indicated by an Illinols study $(2,3)$, 1t 1s doubtful if such a stop regulation is very effective when a high percentage of the vehicles must stop for an empty crosswalk. Statutory or advisory speed limit signs are also used at many crossings. Studies, however, have shown that if speed limits are too low, motorists tend to disregard their cautionary intent by ignoring them $(4,11)$. 
School safety patrols should not be used to create gaps by regulating traffic, but to control children until there is an adequate gap. They are, however, often used at locations where there are traffic control devices, and they play an important role in protecting children at school crossings $(3,15)$.

The installation of an underground or overhead crossing facility is a most positive form of protection for school children safety. Such protection, however, has been limited to locations where many children have to cross at a particularly hazardous location. The underpass and the overpass have a relatively high initial cost, may be difficult to locate in developed urban areas, and often require barriers to channelfze the movements of school ch1ldren $(2,9)$. In regard to overpasses 1 t has been found that ramps are more preferred by pedestrians than stairs. Generally, it will be found that the overpass has certain distinct advantages over the underpass for 1ts construction and maintenance costs are usually lower and it does not encourage nuisances and crimes as much as an underpass (3).

\section{School Crossing Safety}

Although much stress and effort is placed on school crossing protection, school children are involved in very few accidents going to and from school when compared to other locations. According to the National Safety Council (19) only five per cent of student injuries occur when going to and from school (see Flgure 1). Of this five per cent the principal infury source is motor-vehicle accidents, yet they are only one third of the total number.

The safety record at protected school crossings is extremely good and can be attributed in part to the school safety patrol. The school 

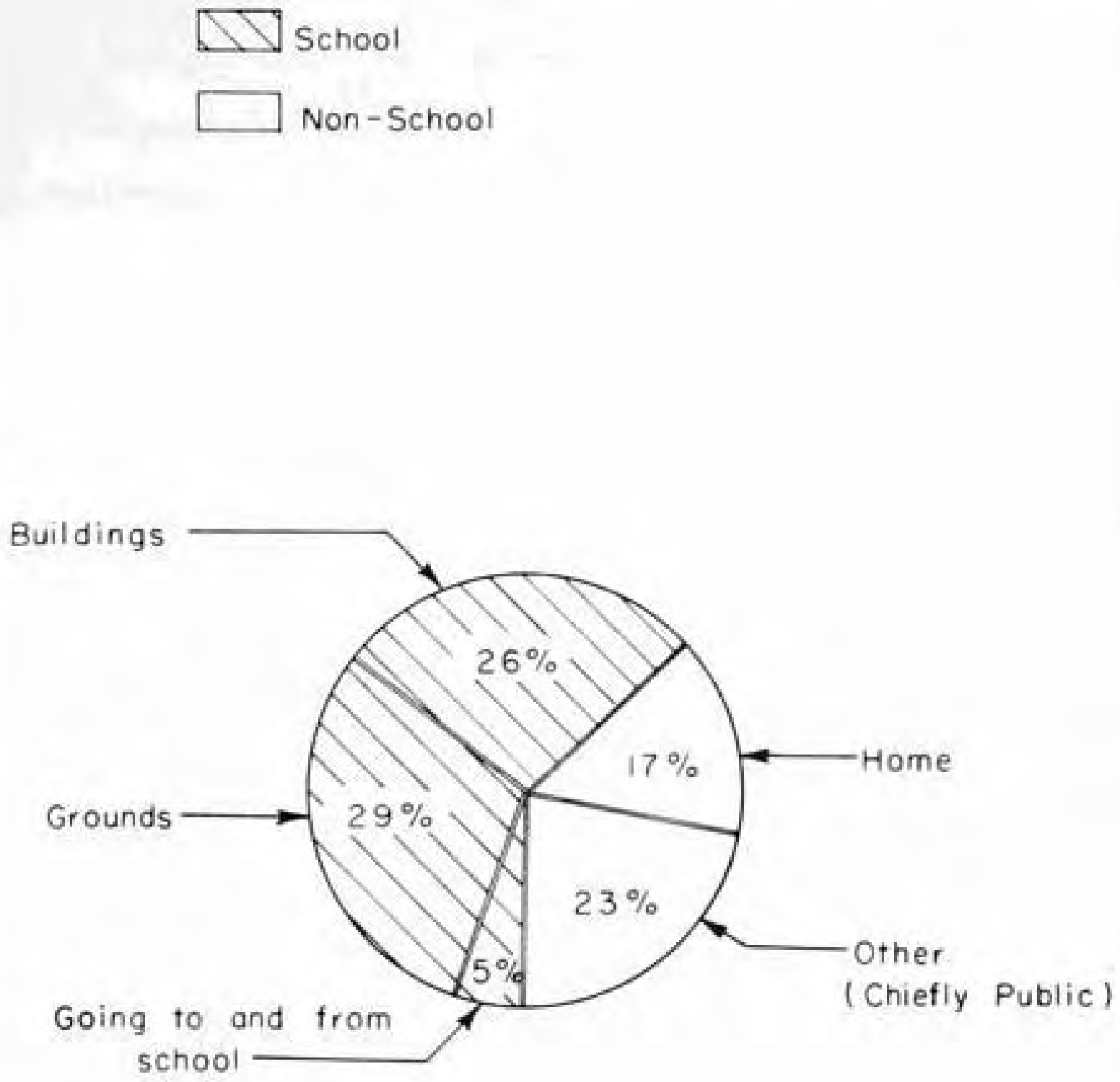

Injuries requiring doctor's attention or causing absense of $1 / 2$ day or more

Source School systems reporting to National Safety Council (19) 
patrol helps children select a safe gap in traffic in which to cross the roadway. It is not known just how offective school patrols are, but it 1s known that there has been a sharp reduction in the school child death rate since about 1930 where the 5- to 14 -year age group is served by school safety patrols (15). 


\section{PREVIOUS INVESTIGATIONS}

Various traffic control devices for school crossing protection have been evaluated as to their effectiveness in attempts to adopt uniform practices for their use on a state or national level.

Collection of data on national practices for the operation and protection of school zones and crossings was performed in 1951 by the Subcomittee on Traffic Control Devices of the Committee on Traffic of the American Association of State Highway Officials (2). In their report (published in 1952), containing information from fifty-two highway agencies (the present fifty states, District of Columbia, and the Territory of Puerto Rico), they concluded that the existing national standards for signing school crossings were inadequate. They also recommended that the diamond-shaped warning sign with the legend "SCHOOL CROSSING" be used for advance notice of the presence of a school crossing and that the color specification of a black legend on a highway yellow background be used at all times for such school crossing warning signs. The Subconmittee disapproved the use of life-size figurines or facsimiles of school children in the roadway. These "signs," they stated, are conducive to being mistaken for live children or may obscure their presence.

A Cinncinat1 traffic engineer, George Howle, has given much thought toward the development of a new, distinctive design of a pedestrian protection sign in an attempt to devise a more effective approach to the problem of pedestrian protection (15). He states that the diamond-shaped 
pedestrian protection sign may not be an effective means of protecting the pedestrian because the usual psychological reaction of the motorist to the diamond-shaped $81 \mathrm{gn}$ is one of self-protection. Since one of the primary features most apparent to the driver is the shape of the sign, Howle further states that the pentagon is the only practical shape not being used for some other purpose. "I think it is admirably suited as a pedestrian protection $s i g n$ because the pentagon $s i g n$, viewed from some little distance, does actually resemble, to some extent, the silhouette of a man." (15) Although he did not conduct a fleld study, he recomended that a sign of this shape be tried.

Experiments were conducted by Crawford, Brooks, and Bldridge at the University of Illinois, under the supervision of Professor C. C. W1ley, on various methods of operating traffic signals which had been placed solely for school children protection (15). As a result of this study, they recommended push-button operation of school crossing signals. The two-color face (red and yellow) gave fairly good performance, but their studies indicated that the standard three-color face was more effective. Flashing red, operating during the period when children used the crossing, was found to be unsultable. Flashing yellow, used as an off-cycle indication, did not seem to be very effective.

Two field investigations have been made concerning the effect of various school signal devices on vehicular and pedestrian actions. One of these surveys, conducted by the Illinois Division of Highways, included fifty-nine signalized school crossings at which one of three different methods of warning were used $(2,3)$. These methods of warning were a flashing-red indication; a push-button actuated, yellow, advance indicat1on followed by a flashing-red interval; and a push-button actuated, 
advance, yellow indication followed by a steady-red indication. The study showed that violations of the stop regulation, even considering the rolling stop as obeyance, amounted to four per cent for the single flashing red signal as compared to about one half of one per cent for the pedestrian-actuated flashing or steady red indication supplemented by the advance yellow. This indicates that any control requiring a high percentage of the vehicles to stop for an empty crosswalk will result in a large number of violations. Push-button control, however, can eliminate most of the unnecessary stopping.

In another study, similar to the one in Illinois, the Nebraska Bureau of Highways observed approximately 2,000 vehicles at a single location adjacent to a school bullding to determine the relative effectiveness of four different types of traffic control devices at school crossings (2). Each device required the motorist to stop. These devices included portable-type school crossing stop sipns, fixed-type school crossing stop signs, a school crossing stop sign with a red flashing beacon, and a school crossing stop sign with alternately flashing twin beacons. Although the sample size was small, the percentages of the violations of the stop regulation compared quite closely with those reported in the Illinois study. Results showed that regardless of the type of device used, only about fifty per cent of the motorists came to a complete and voluntary stop.

In 1949 a study was made in California of the protection provided at locations where school children cross state highways in rural-suburban areas (3). The number of accidents was obtained from each location and compiled according to the type and amount of protection provided. It was found that 28 out of a total of 588 accidents occurred at school crossings. 
of the 28,19 accidents occurred where children did not use the facilities provided for their protection. The results indicated that the degree of traffic risk for school children rises sharply the first two years of their school career and then decreases with age. One may conclude from this study that the problem of protecting school children at crosswalks is not only that of providing more effective traffic control devices, but also that of educating the children to use the facilities which are provided for their protection.

Although some research has been conducted concerning school crossing protection, further study needs to be made. Carefully controlled studies of the effects of various devices suggested for school crossing protection would contribute much toward solving the problem of school crossing safety and obtaining uniformity in the use of traffic control devices at school crossings. It was for these reasons that the research reported in this study was undertaken. 
PURPOSE AND SCOPE

\section{Purpose}

The purpose of this research was to evaluate some effects of various devices used for school crossing protection at school crossings. For various traffic control signs, the effect on speed was evaluated; for separated crossing structures, the use of the facillty was investigated; and for pedestrian-actuated signals, the use by school children and the effect on vehicular traffic were studied. It was hoped that from the study an effective device (or devices) for school crossing protection could be recormended for use as standard practice in Indiana,

\section{Limits of Study}

The major portion of this research was devoted to a study of the effect on speed of various combinations of traffic control signs at one school crossing. Because of the great amount of speed data required, the distance from Purdue University to the study site was of major interest in the selection of the site. In addition, it was desired to have a study site where traffic volumes and speeds as well as numbers of children crossing required school crossing protection. A site on US 231 in West Lafayette, Indiana, fulfilled these requirements and was selected.

For the purpose of studying overpasses and underpasses, all those sites known to be in existence on state highways in Indiana, and one underpass which was located near a state highway were studied. Because the use of pedestrian-actuated signals at school crossings is very limited In Indiana, only two sites were studied for this portion of the research. 
Passenger cars were the only type of vehicles considered in the study of traffic control signs because speed limits are primarily based upon speed data obtained for these vehicles. Truck traffic was also rather light at the study site because through traffic is bypassed around the city.

Because this particular study was concerned with the effect of various traffic control signs at the school crossing, the residence of each vehicle was considered in planning the study because a local driver may react differently to a type of school crossing control than a nonlocal driver. The usual way of handling this factor is to classify each vehicle as local or non-local, local generally defined as those vehicles registered in the county in which the study is performed. A problem, however, arose in this study due to the operation by Purdue University students of many vehicles not registered in the local area. Moreover, through traffic bypasses the city, and almost all of the vehicles passing the study site were from the local area. Therefore, no local or nonlocal classification was made of the vehicles in this study.

In all studies, data were collected only during the hours that children were going to and from school. In the study of overpasses and underpasses data were collected during two periods of one day and then repeated at a later date. In the study of pedestrian-actuated signals, data were collected during the afternoon period when chlldren were leavIng school on two separate days. For the sign study at the West lafayette school crossing, data were collected during each of the four time periods of a day when children use the crossing. In order to eliminate the variable of the day of the week, data were collected for this study on two weekdays whlch were plcked at random for each series of speed studies. 
All data collection was done when the pavement was dry and when optimum atmospheric conditions (i.e., no fog or haze) were present. However, during the winter months some of the speed studies encountered darkness during the early part of the first time period.

From information obtained in a preliminary study (11) which had been conducted in early 1960, a desirable sample size was determined for the speed study. Data were collected from October, 1960, to June, 1961, for this research. 


\section{STUDY LOCATIONS}

\section{Genoral}

This research on school crossing devices consisted of the three separate studies wh1ch have been discussed, and for purposes of 1dentification they are designated studies A, B, and C. The study concerning the effect of various traffic control signs at school crossings 1s Study A; the study of pedestrian-actuated signals at school crossings is Study B; and the study of overpasses and underpasses is Study C. The locations where these studies were performed are shown on a map of Indiana in Pigure 2.

\section{Location of Study A}

The location of Study A is a school crossing on Northwestern Avenue (US 231 and Business US 52) at Garden Street in West Lafayette. Southbound traffic approaches the school crossing from a h1gh speed area. From the intersection of US 52 and US 52 Bypass to Iindberg Road (see Figure 3), the highway changes from a four-lane divided facility with a 30-foot median strip to one with a 5-foot median strip of concrete. A golf course borders the west side of the highway in this area while only scattered development borders the east side, and the road is zoned with a 50 mile-per-hour speed limit. Beginning at Lindberg Road and continuing toward downtown West Lafayette for approximately $0.7 \mathrm{mile}$, the speed Ifmit is 40 miles per hour and the highway is four-lane undivided. The school crossing 1o located within this highly developed residential area 


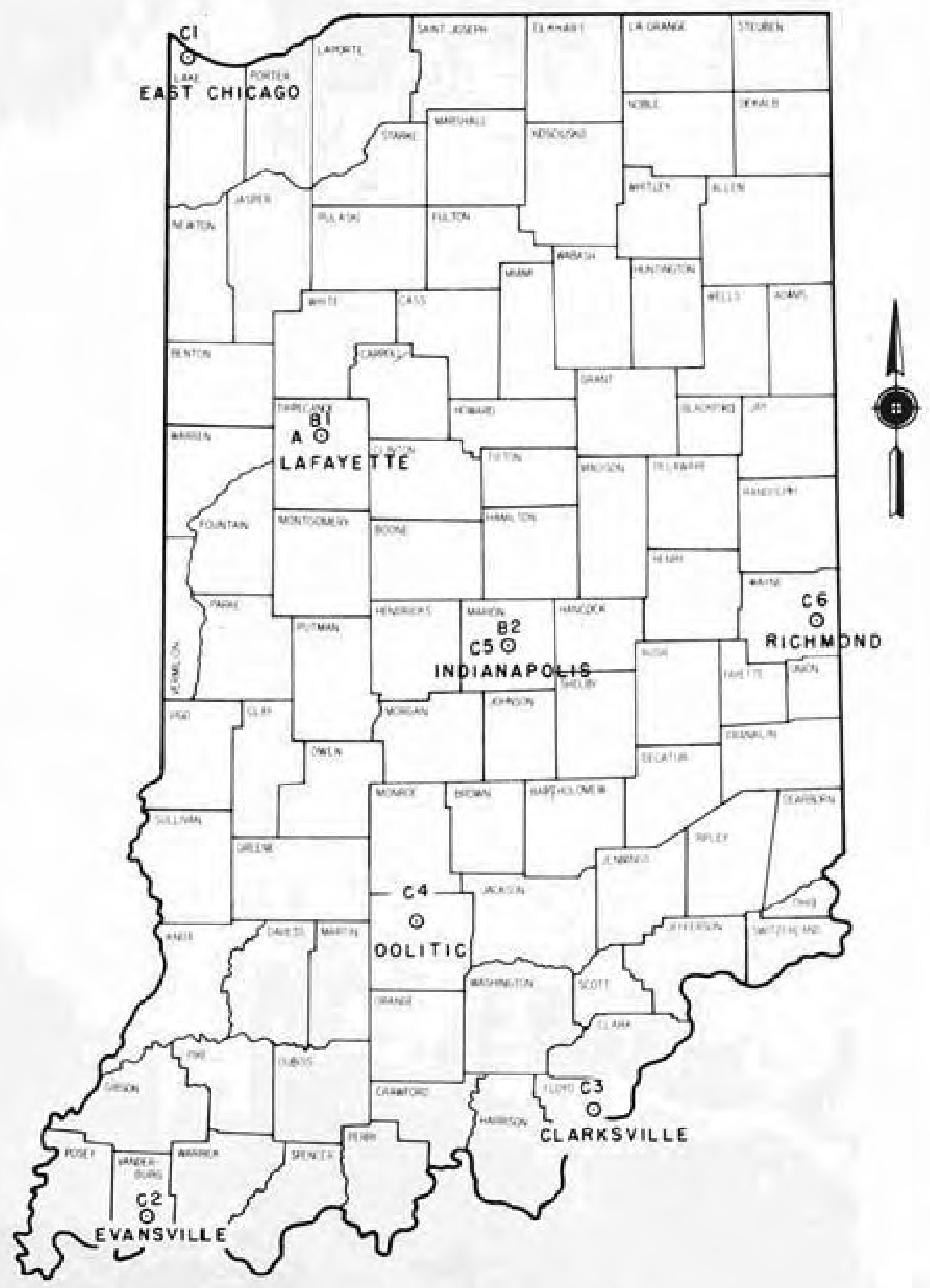

STUDY LOCATIONS

FIGURE 2 


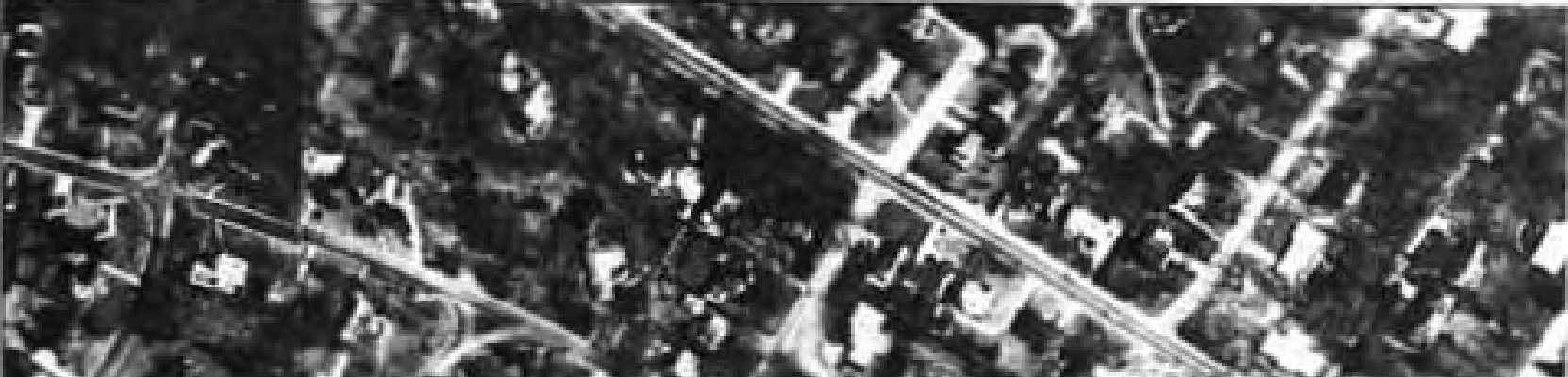

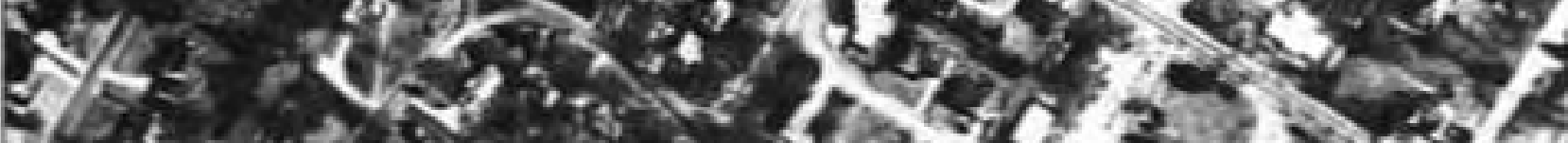

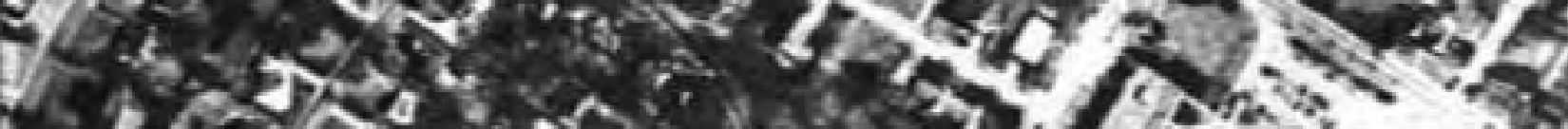

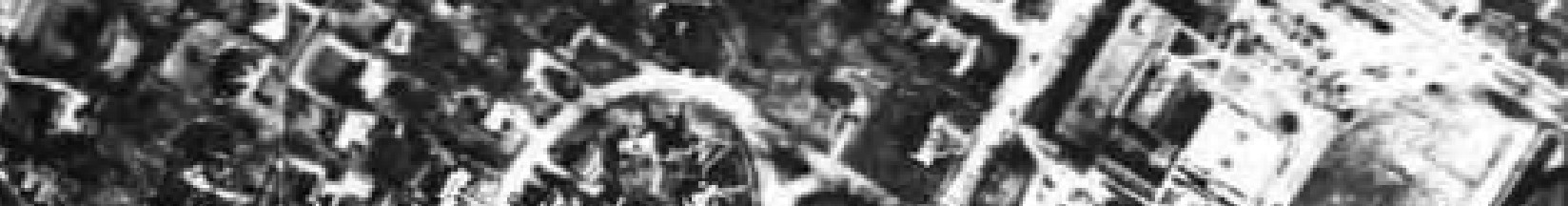

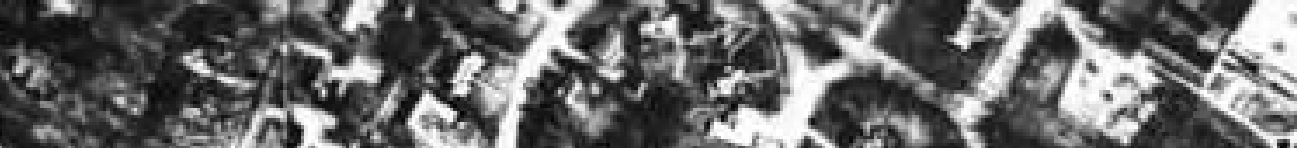

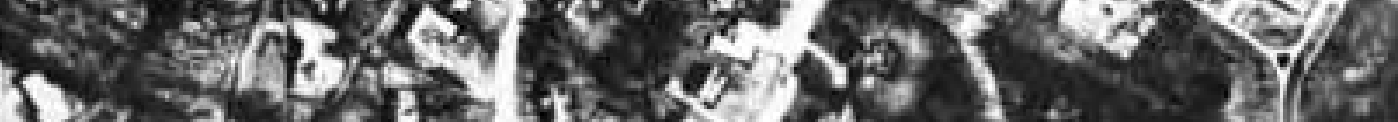
ons r t

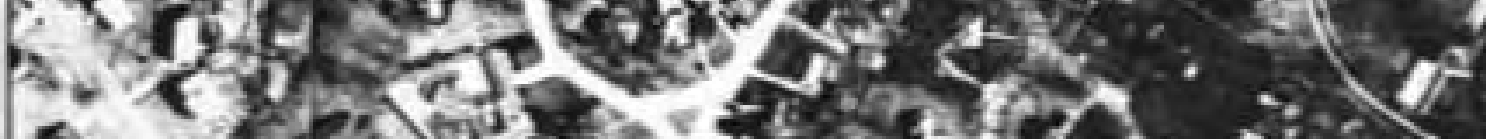

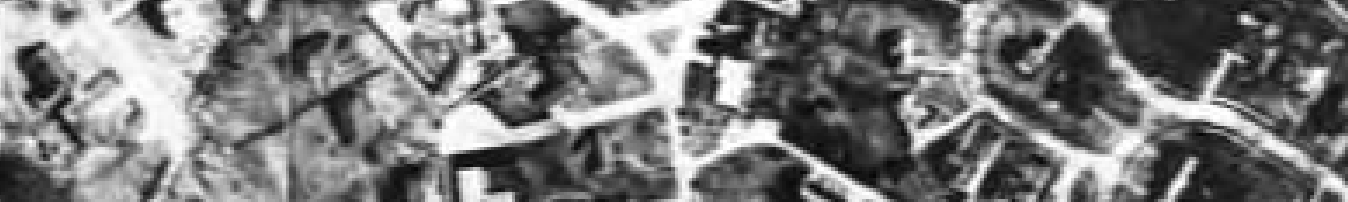

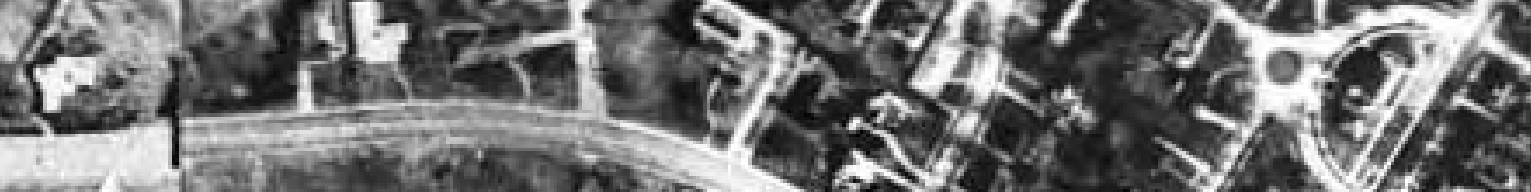

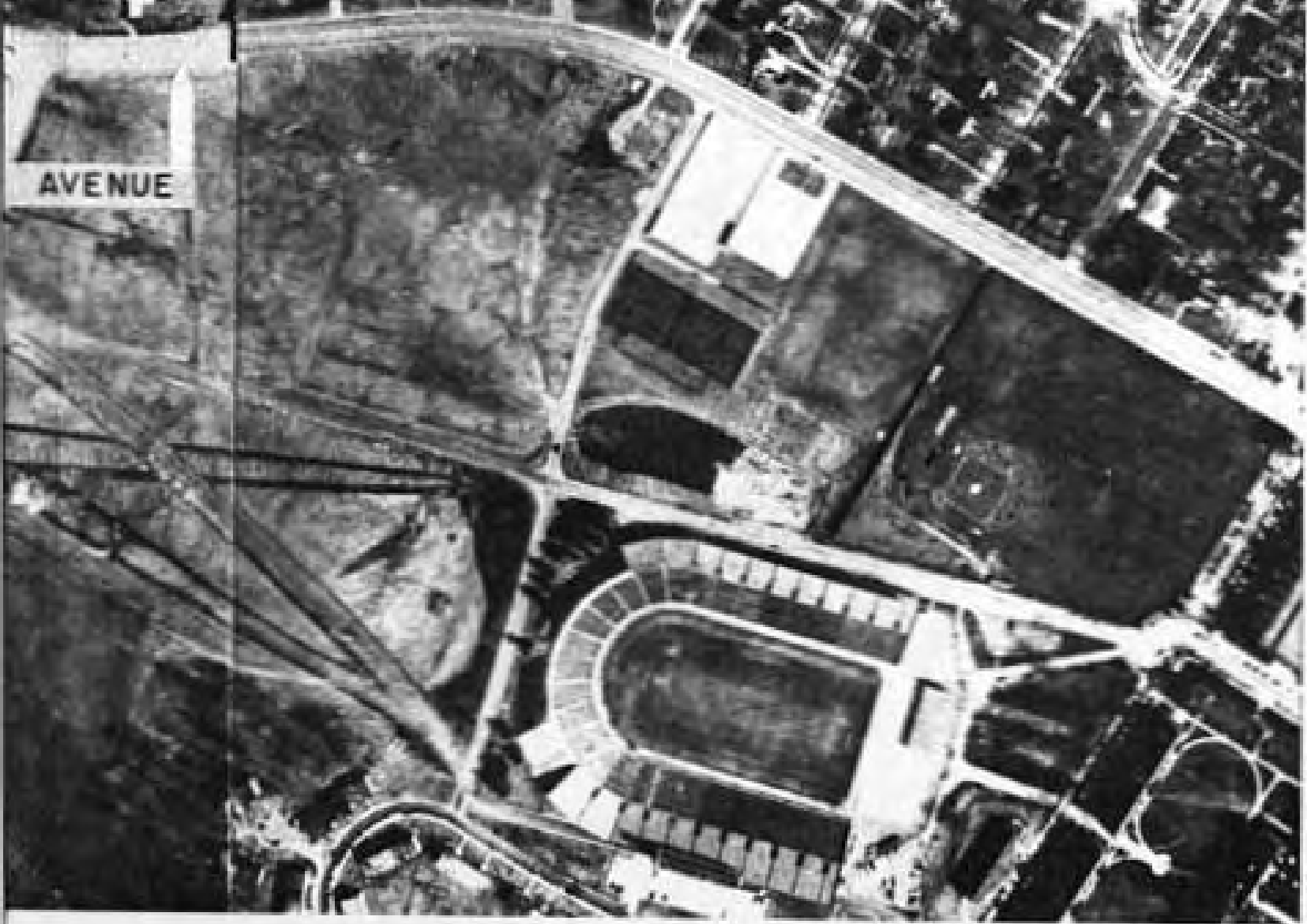




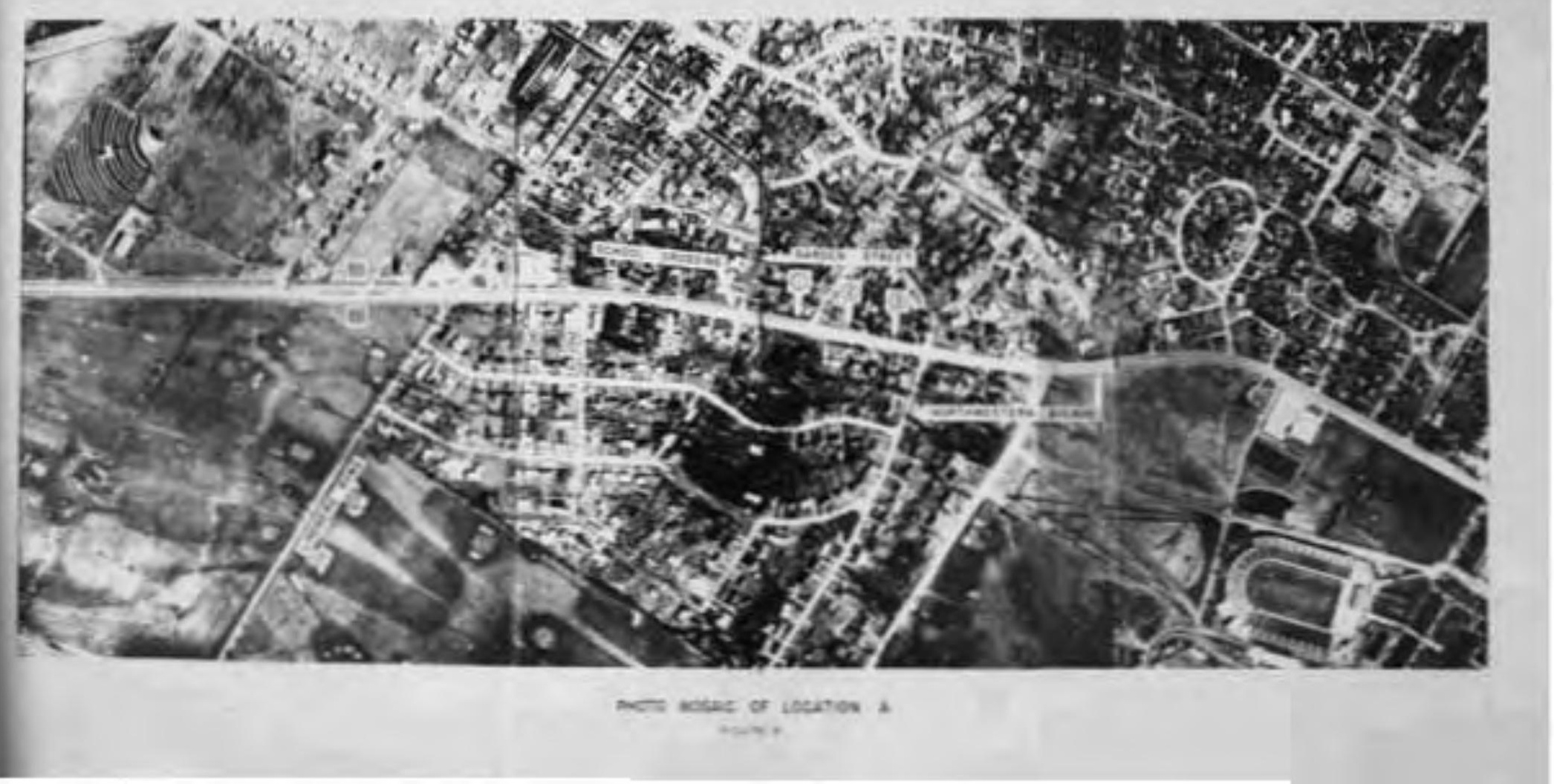


and 1s approximately 1300 feet south of Lindberg Road. The annual average daily traffic (AADT) at the crosswalk is approximately 6600 vehicles per day.

Since this highway had been reconstructed from \& two-lane facility to one of four lanes in the fall of 1958, no school crossing signs had been placed prior to this study. Thus, this location was ideal for studying the effect of various traffic control devices at a school crossing in a rural-suburban area.

The several types of traffic control signs and beacons which were used in this study are listed in Table 1 and are shown, but not always individually, in Figure 4. These signs and bescons were used in fourteen combinations wh1ch are listed in Table 2 and detailed further in Appendix A. The distances between sign locations and the school crossing are also given in Table 2 and the numbers on Pigure 3 indicate the locations of the sign posts for this study.

Table 1

SIGNS

\begin{tabular}{cl}
\hline Identification & \multicolumn{1}{c}{ Description } \\
\hline A & 30" warning sign, "SCHOOL CROSSING" \\
B & 36" warning sign, "SCHOOL CROSSING" \\
C & "SPEED LIMIT 25 wHEN CHILREN PRES- \\
ENT" sign \\
D & $\begin{array}{l}\text { portable "SCHOOL CHILDREN CROSSING" } \\
\text { sign }\end{array}$ \\
B & $\begin{array}{l}\text { single flashing beacon placed di- } \\
\text { rectly above a sign }\end{array}$ \\
F & $\begin{array}{l}\text { horizontal alternate flashing bea- } \\
\text { cons directly above a sign } \\
\text { vertical alternate flashing beacons, } \\
\text { G } \\
\text { one directly above and one directly } \\
\text { below a sign }\end{array}$ \\
\hline &
\end{tabular}


Table 2

SIGN CONDITIONS AND LOCATION OF SIGNS

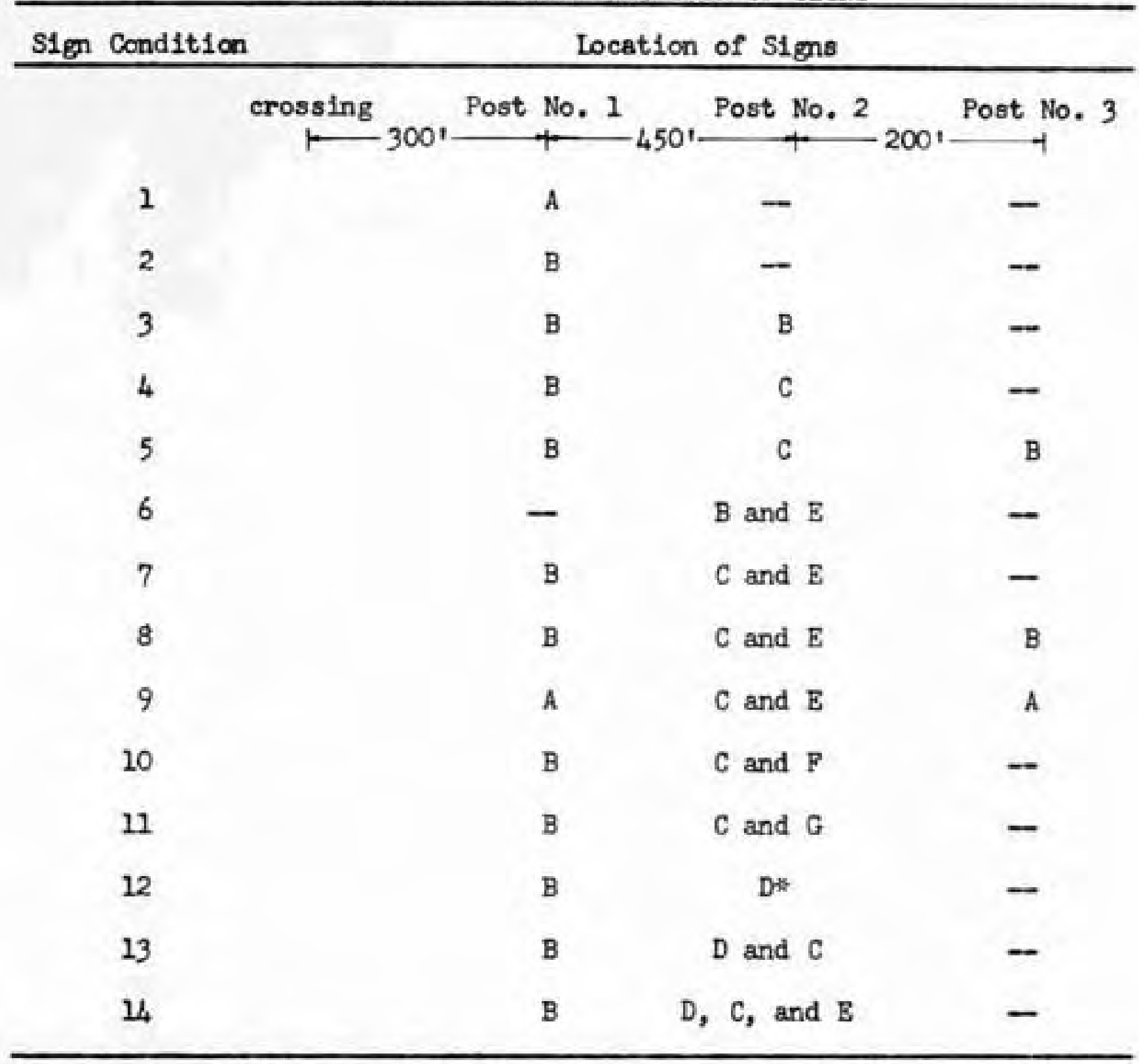

HD located across from Post No. 2 in center of roadway.

\section{Locations for Study B}

A study of pedestrian-actuated signals at school crossings was made at locations $\mathrm{Bl}$ and $\mathrm{B2}$, shown in P1gure 5. Location Bl is a school crossIng on Union Street at 26th Street in Lafayette. Union Street, a two-way through facility (38 feet wide with parking both sides west of the intersection and 18 feet wide esst of the intersection) is in a highly developed residential district. Twenty-sixth Street is a minor street on which 


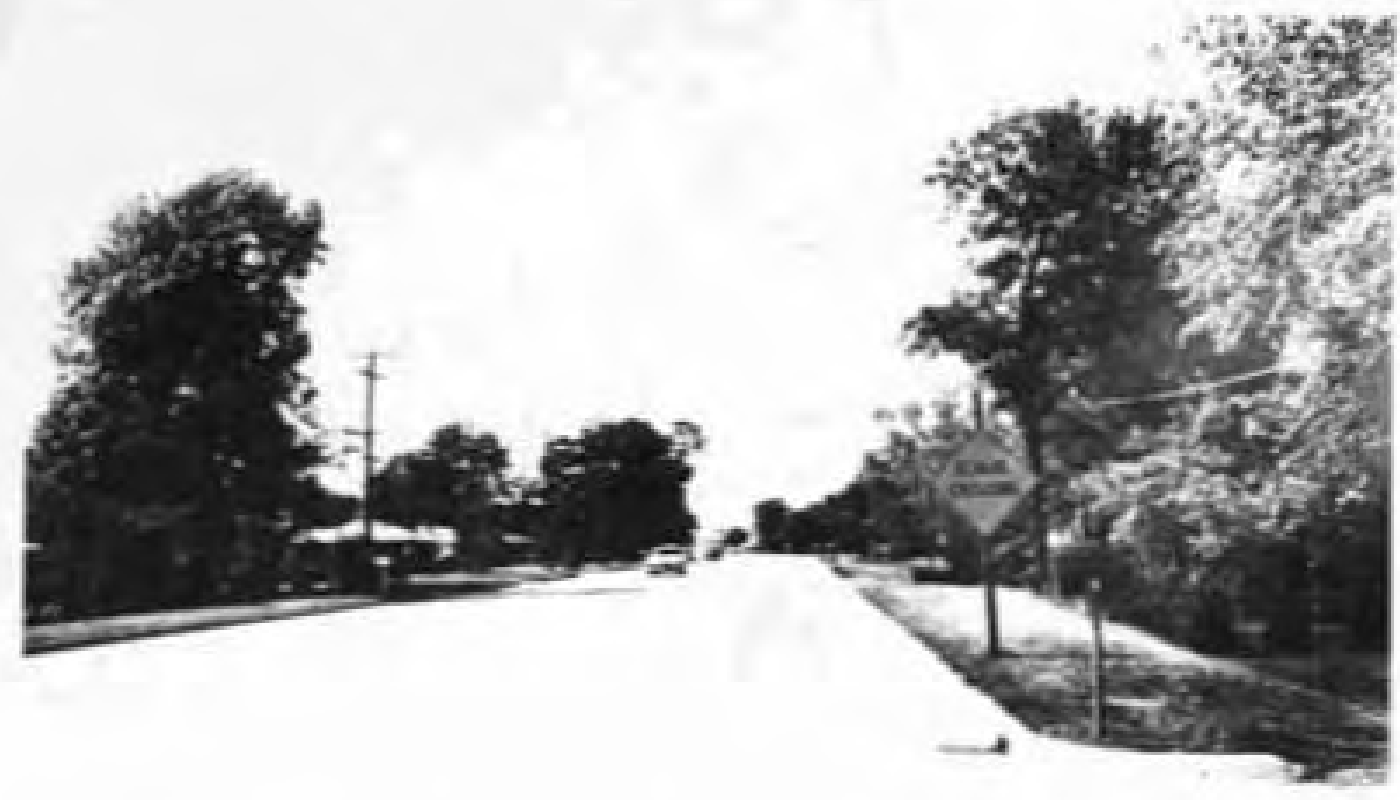

Thirty-six inch warning sign "SCHOOL CROSSING"

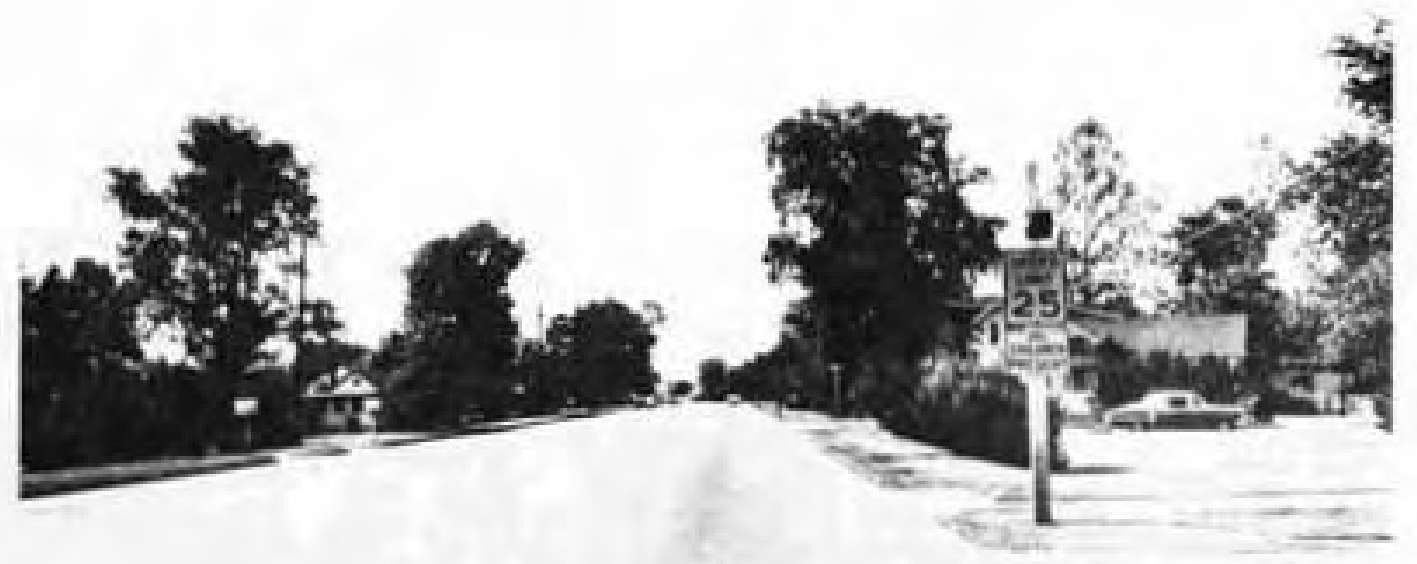

"SPEED LIMIT 25 WHEN CHILDREN PRESENT" sign with a single flashing beacon

TYPES OF TRAFFIC CONTROL DEVICES USED AT LOCATION A FIGURF 4 


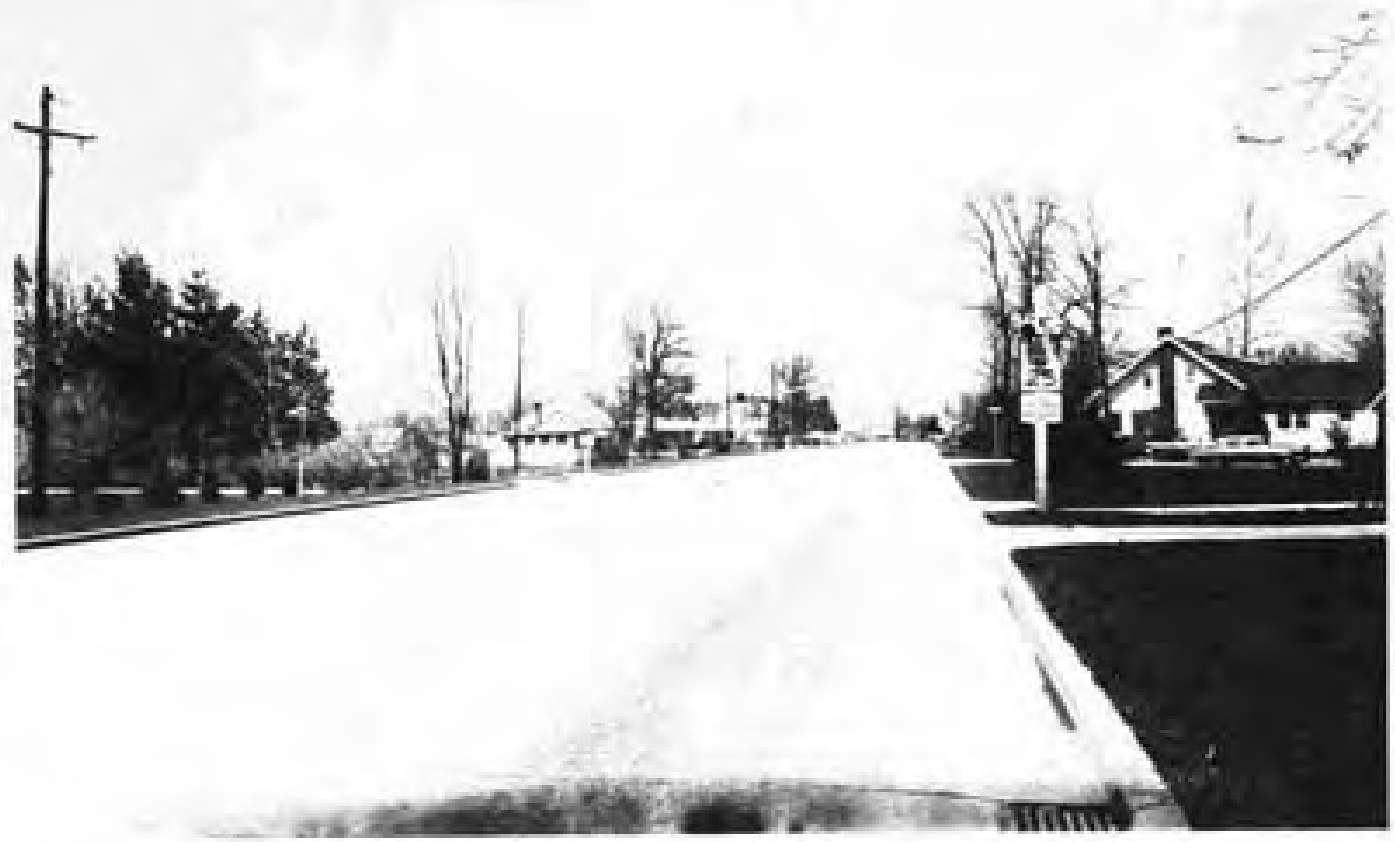

SPEED LIMIT 25 WHEN CHILDREN PRESENT" sign with horizontal alternate flashing beacons

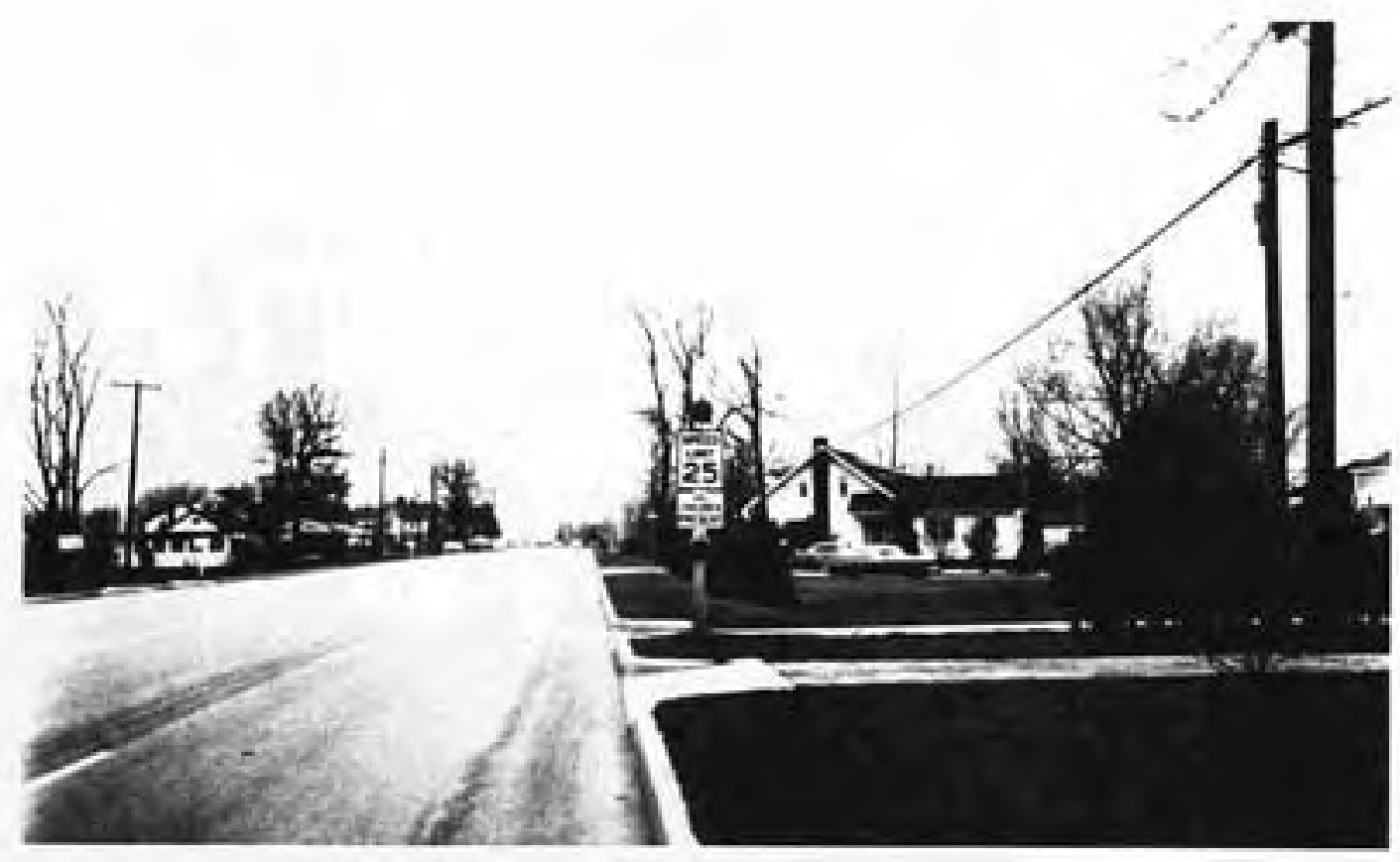

"SPEED LIMIT 25 WHEN CHILDREN PRESENT" sign with vertical alternate flashing beacons

TYPES OF TRAFFIC CONTROL DEVICES USED AT LOCATION FIGURE 4, CONTINUED 


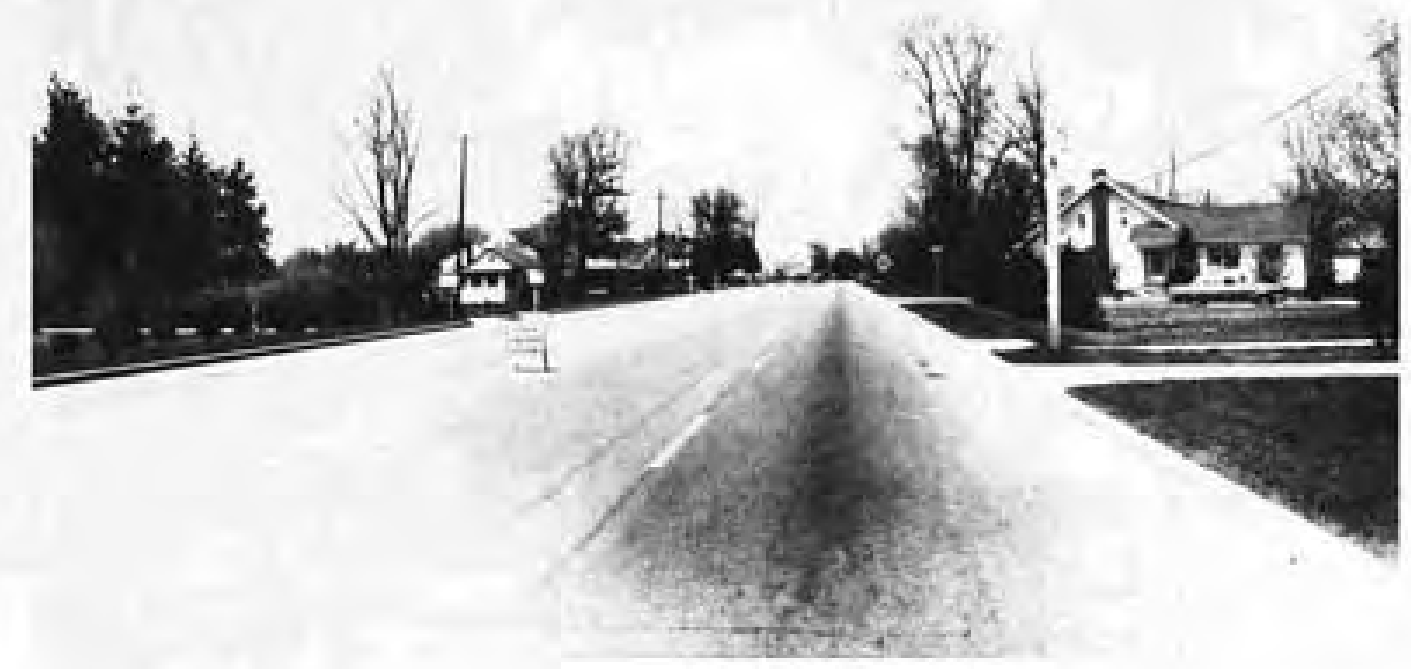

Portable "SCHOOL CHILDREN CROSSING" sign

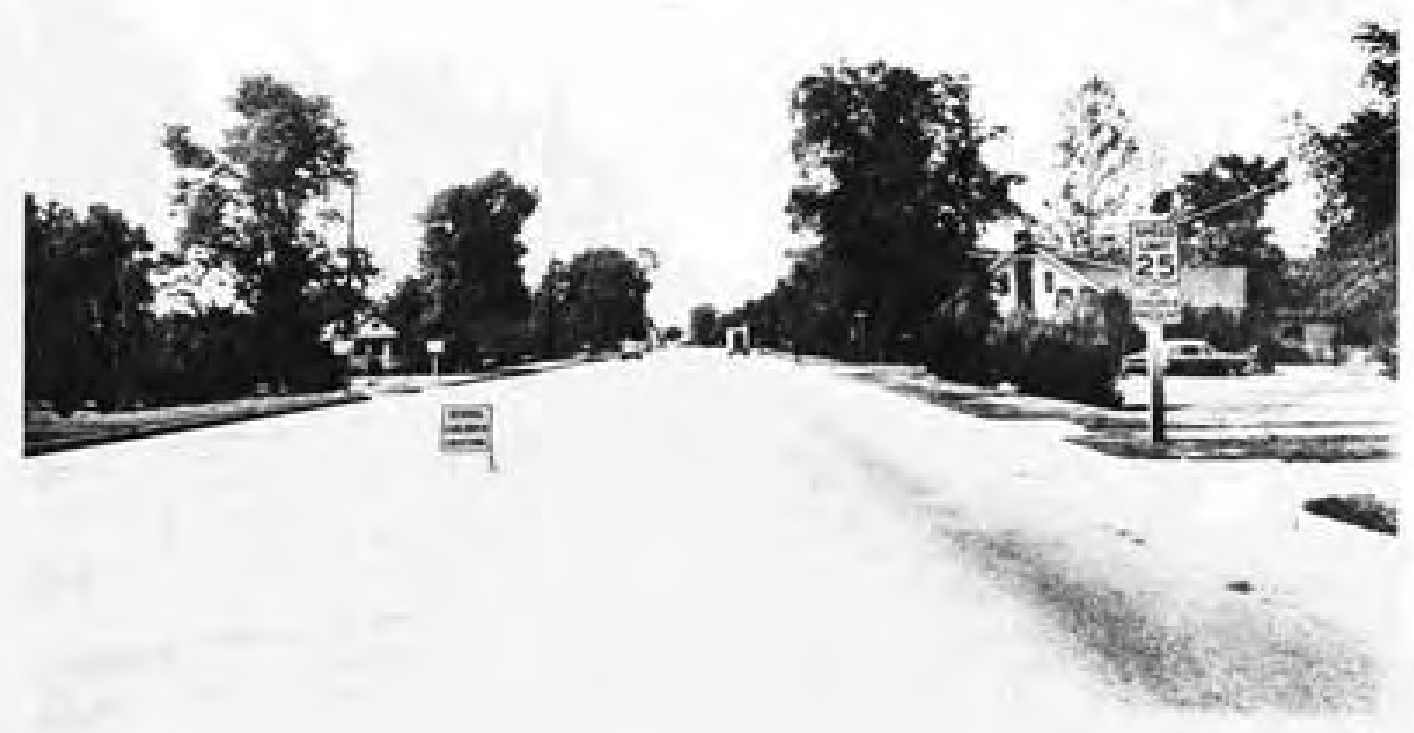

Portable "SCHOOL CHILDREN CROSSING" sign and "SPEED LIMIT 25 WHEN CHILDREN PRESENT" sign with a single flashing beocon TYPES OF TRAFFIC CONTROL DEVICES USED AT LOCATION A FIGURE 4, CONTINUED 


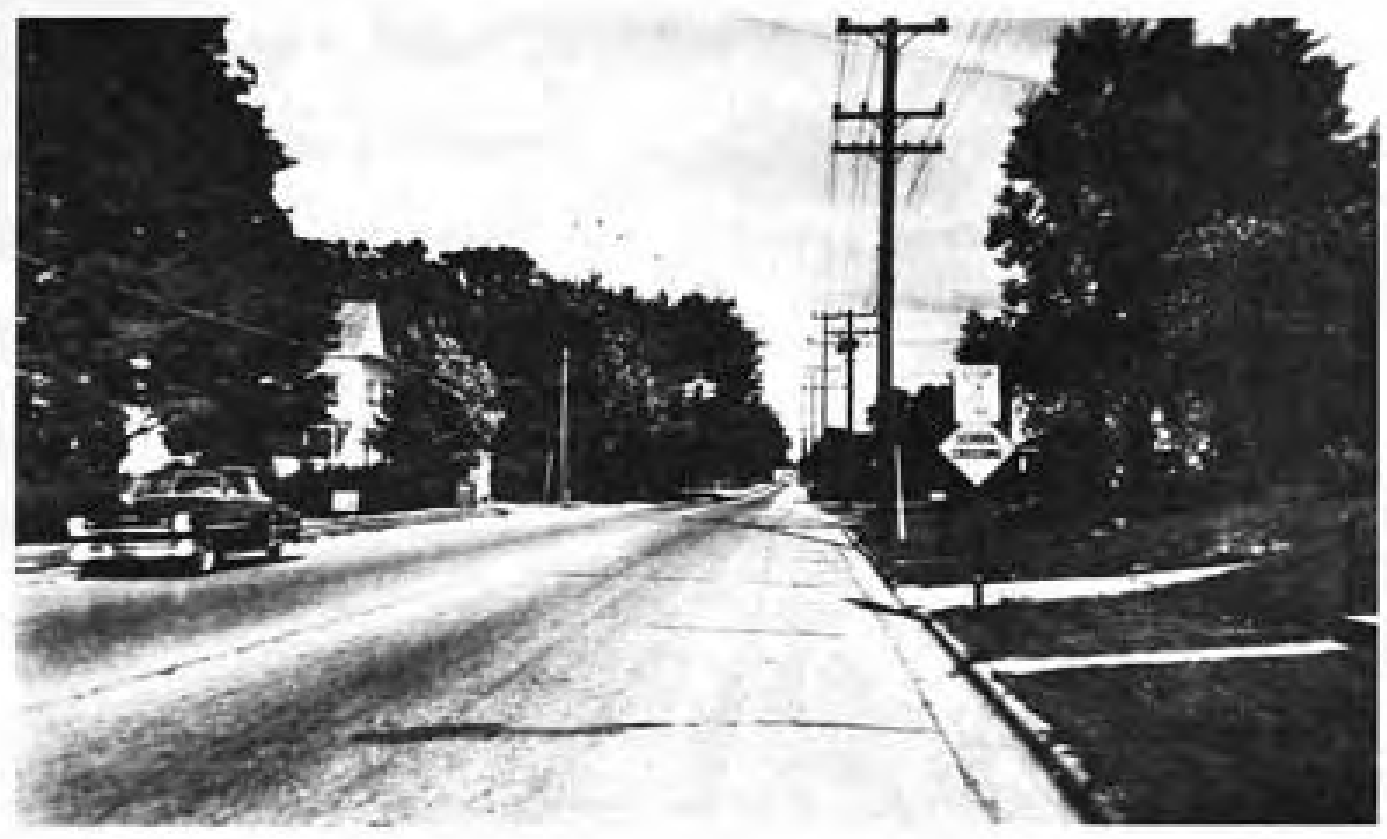

Pedestrian-actuated signal at location BI

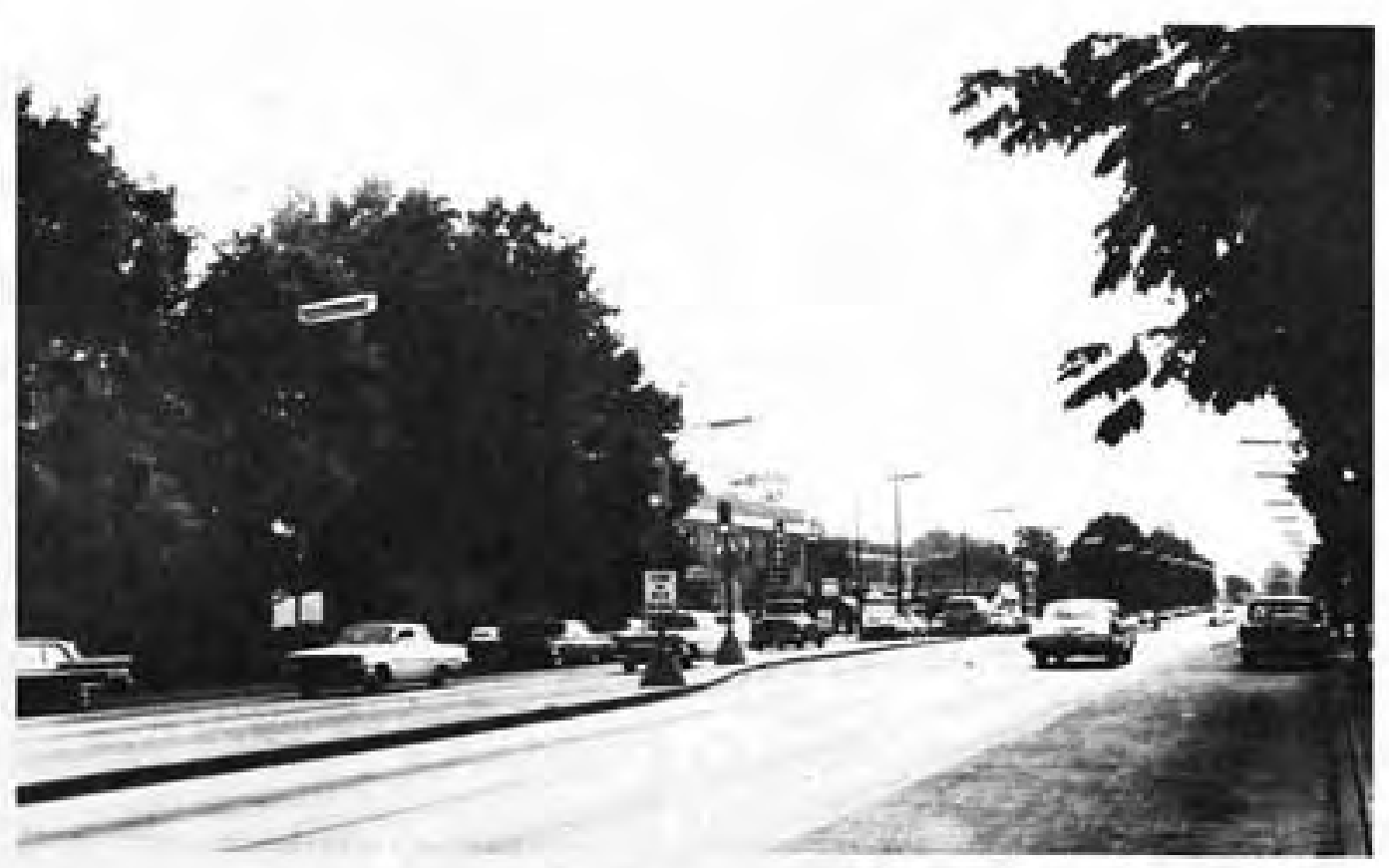

Pedestrian-actuated signal at location $\mathrm{B2}$

VIEWS AT LOCATIONS BI AND B2 FIGURE 5 
vehicles are required to stop at the intersection with Union Street. A heavy turning movement occurs as northbound vehicles on 26th Street turn left or right onto Union Street. Those vehicles turning left cross the school crossing at the intersection. At the intersection a pedestrianactuated signal, which is connected to a mechanical controller, provides protection to school children crossing Union Street. A push button is provided on either side of the crossing. This signal is a two-face type, wh1ch when actuated, indicates yellow for a few seconds and then a steady red for about 25 seconds in all four directions. At all other times the signal does not present an indication of any type. Advance warning signs indicate the presence of the crosswalk and the signal. The speed limit In this area is 30 miles per hour.

Location B2 is a school crossing on 38th Street (SR 67 and US 36) between Park Avenue and Broadway Street in Indianapolls. Thirty-eighth Street is a four-lane divided facility (concrete median) with parking on both sides and provision for left turns in separate lanes. The crosswalk is on the border between a residential district to the west and a commercial district to the east, both highly developed. The crosswalk lies between the main door of the school and an alley across the street. The three pedestrian-actuated signals, one on the center island and one on each side of the street, are connected to a mechanical controller. A push button is located on either side of the crosswalk and is under the supervision of an adult guard during the period when a majority of the children cross. The signals are the standard three-face type with pedestrian signals and indicate green to vehicular traffic unless actuated. When actuated, a short yellow followed by 30 seconds of red are displayed to vehicles and the pedestrian "walk" cycle is actuated for school children. 
Intersections are located one half of a block either direction from the crosswalk on 38th Street and one of them is signalized. The speed limit in this area is 30 miles per hour.

\section{Locations for Study C}

A study of overpass and underpass school crossings was conducted at locations $\mathrm{Cl}$ through C6. Location $\mathrm{Cl}$ (see Figure 6) is an underpass for school children on East Columbus Drive (US 12) at Alder Street in East Chicago. Bast Columbus Drive is a two-lane urban highway carrying a normal volume of traffic, but since there are an extraordinary large number of children needing to cross, a sufficient number of safe gaps do not exist. The tunnel under the highway solves the problem. The underpass is an old concrete structure with doors that are kept locked during the night to prevent crime and nuisance use. City police lock and unlock the doors to this structure. The only enforcement used to force the children to use the facility is the threat of severe pun1shment by school officials to those who disobey. An adult guard at a nearby intersection watches for violators.

Location C2 (see Flgure 6) is an overpass for school children on US 41 at colin Avenue in Evansville. A large volume of traffic is carried on US 41 , a two-lane urban highway. Colin Avenue forms a $T$ intersection with US 4l. The overpass $1 \mathrm{~s}$ an old steel structure with two flights of steep stairs on either side. A fence on the school side channels school traffic to the structure. The portion of the structure directly over the highway is covered by a roof. School patrol guards are stationed at each end of the covered portion of the structure during the time that children go to and from school. 


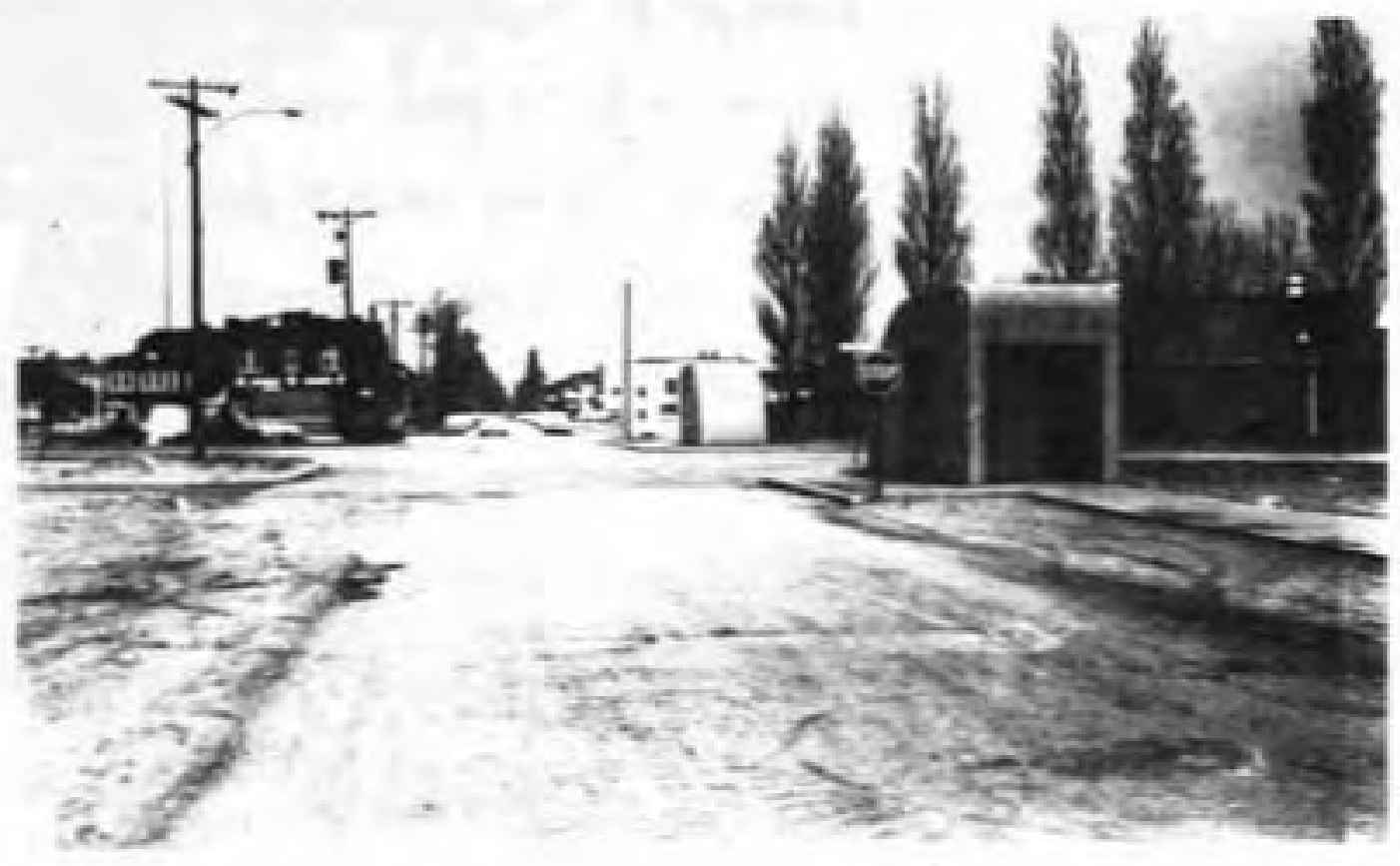

Underpass school crossing at location Cl

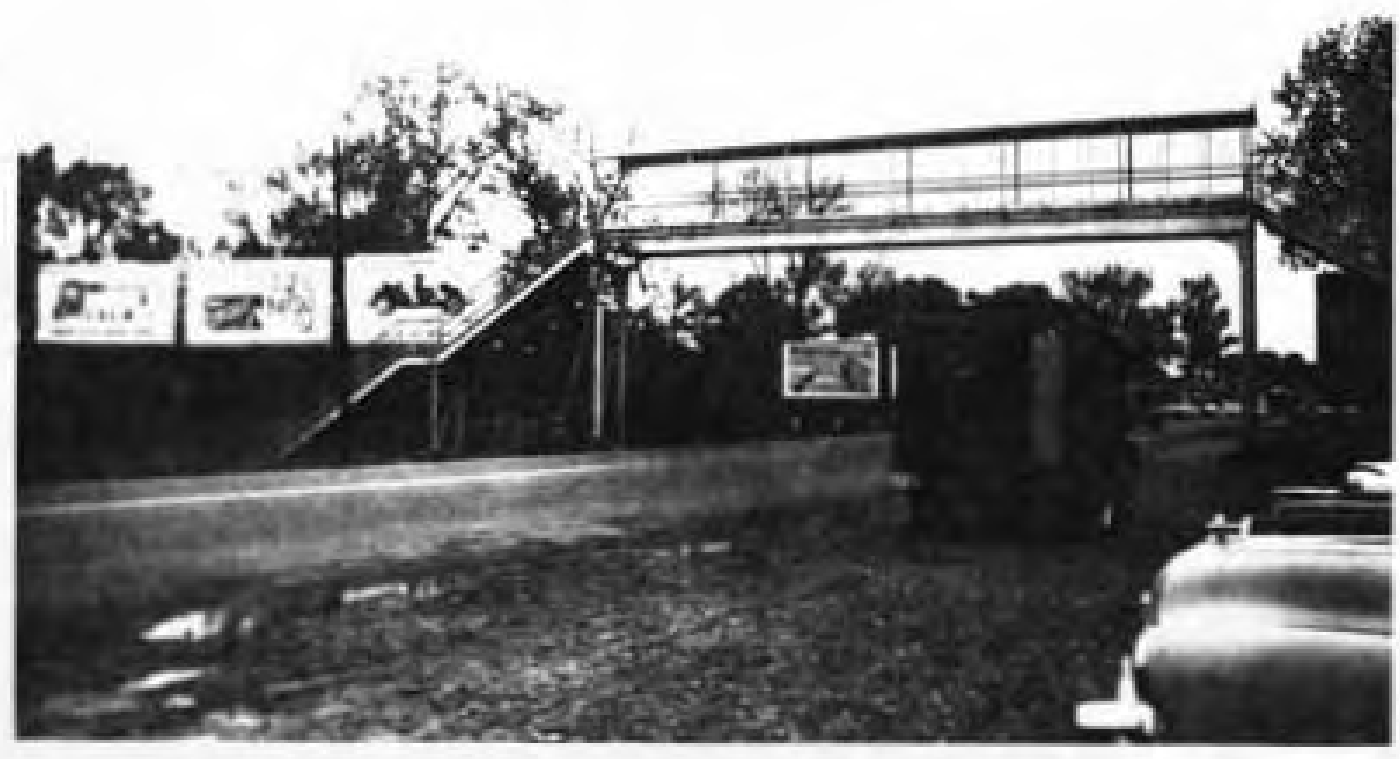

Overpass school crossing at location C2

VIEWS AT LOCATIONS CI AND C2

FIGURE 6 
Location C3 (see Flgure 7) is an overpass school crossing on SR 62 in Clarksville. State Road 62 is an expressway (partial 1imited access) which is four-lane divided and has a speed limit of $40 \mathrm{miles}$ per hour. Access to the highway in the vicinity of the overpass may be gained approximately one block on either side of the overpass. The intersection to the east is signalized while the one to the west is not. The overpass Is a concrete structure with low gradient rams which terminate on streets which dead end on either side. The guard fence on either side of the structure is connected to the fence along the limited access highway.

Location $\mathrm{CL}_{4}$ (see Figure 7) is an overpass for elementary school children on SR 37 in Dolitic. State Road 37 is a two-lane highway. The overpass is situsted on the border between the urban and rural areas. The topographic features are a bit unusual in that the crosswalk is situated near the crest of a hill and near a curve. This results in poor visibility at this location and would make it very difficult for children to cross the highway at grade level. The overpass is a concrete structure with low gradient ramps and no channelizing fence on either side. The school is located opposite the structure.

Location C5 (see Figure 8) is an overpass school crossing on Madison Bupressway Just south of street 1500 South in Indianapolis. Madison Expressway is a six-lane divided facility with full limited access beginning at 1500 South and extending southward. Although Madison Avenue intersects the street at 1500 South at grade, it is below grade at the crosswalk. The overpass is a concrete structure at ground level with a fence on elther side connected to the fence along the expressway. A peculiar situation exists in that the approach to the school crossing overpass is crossed by a rall line. Thus, rail traffic conflicts with the school crossing at times. 


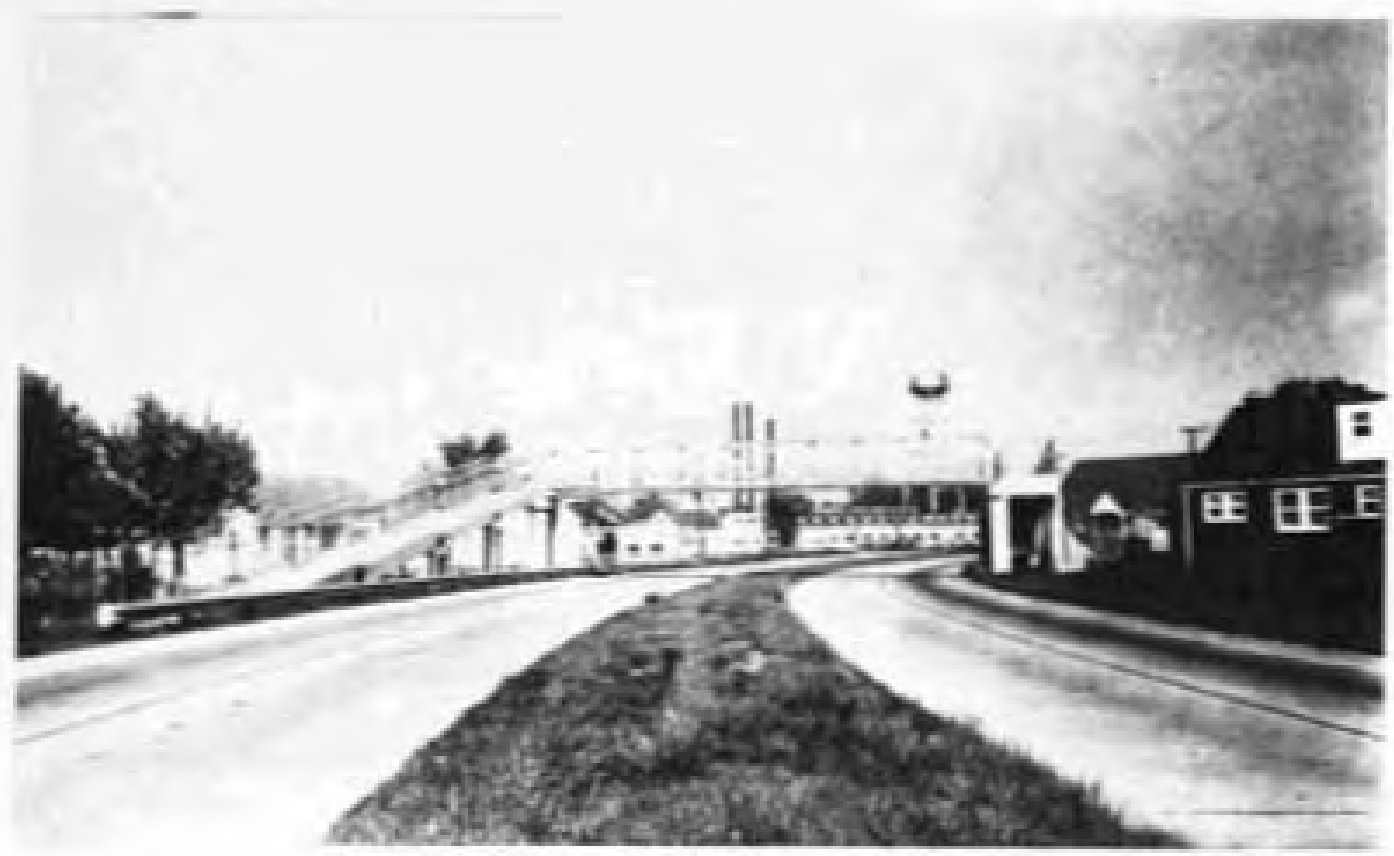

Overpass school crossing at location C3

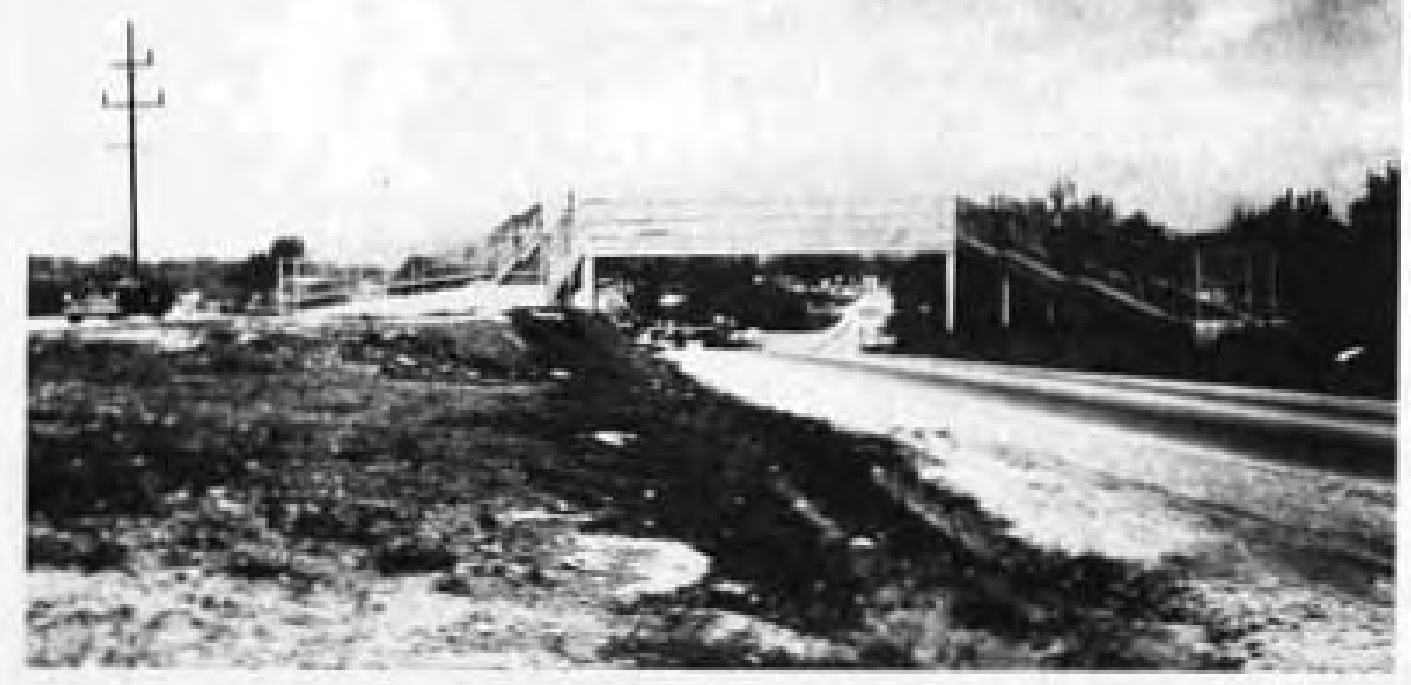

Overpass school crossing at location C4

VIEWS AT LOCATIONS C3 AND C4

FIGURE 7 


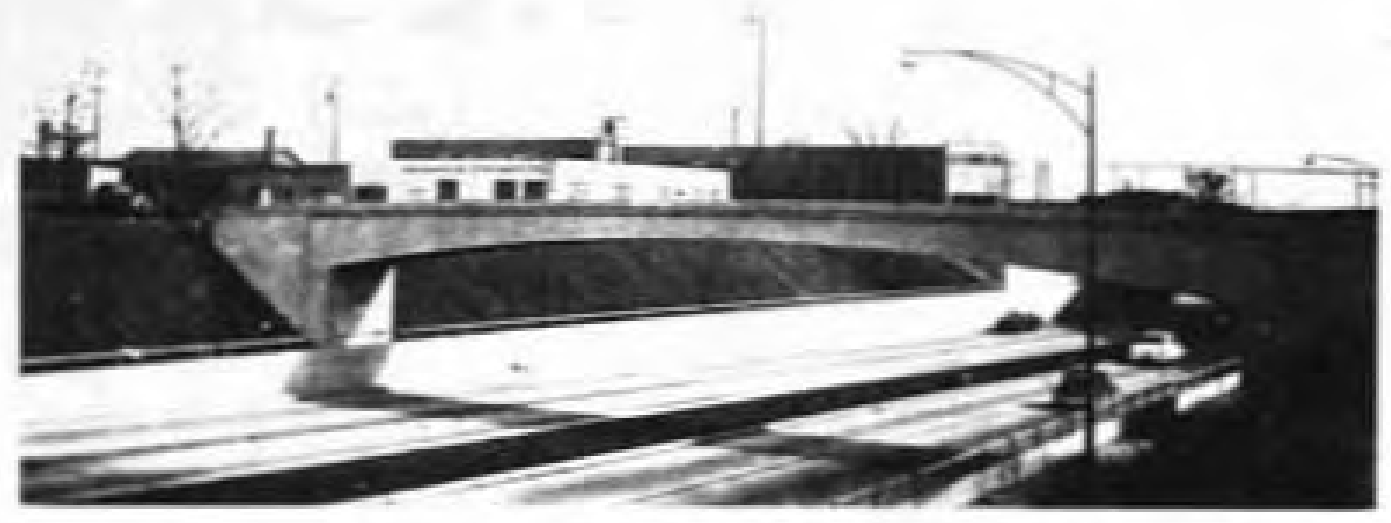

Overpass school crossing at location C5

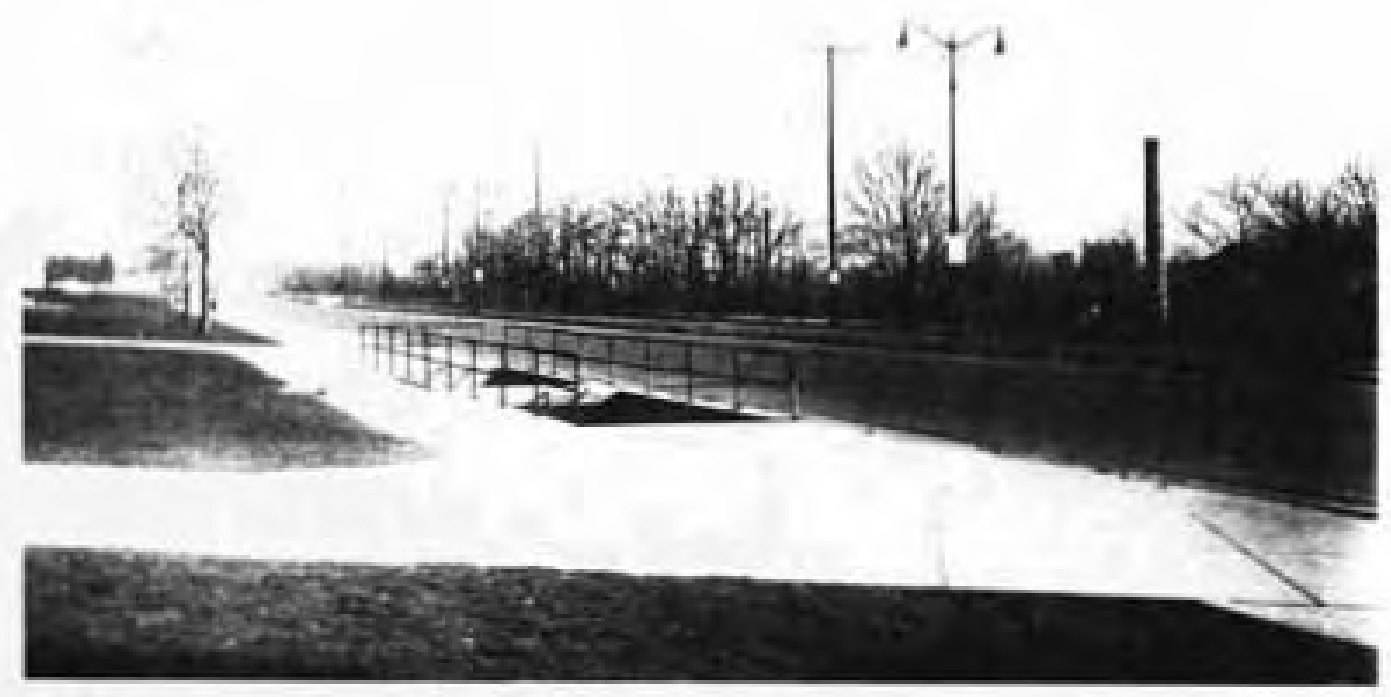

Underpass school crossing at location C6

VIEWS AT LOCATIONS C5 AND C6

FIGURE a 
Location C6 (see F1gure 8) is an underpass school crossing for high school students on Whitewater Boulevard between G Street and US 40 in R1chmond. Whitewater Boulevard is a four-lane divided facility bordered on one side by a river and on the other by the hiph school. The tunnel has been abandoned because of nuisance use, and it is now closed with a heavy wire fence. 


\section{EQUIPMENT}

All speed data for this study were obtained by the use of an ElectroMatic Radar Speed Meter powered by a 12-volt automobile storage battery.

The radar meter $(7,13,17)$ utilizes the Doppler effect to measure speeds. Radio waves of constant frequency $(2,455$ megacycles $)$ are broadcast continuously by the transmitter-receiver unit in a cone-shaped beam of approximately $20^{\circ}$. These waves change frequency when reflected from a moving object in proportion to the component of speed in the direction of the waves. The difference in frequency between the transmitted and received waves, or the Doppler frequency shift, induces a potential that is converted to miles per hour on a speed indicator, a voltmeter linearly calibrated in scale divisions of two miles per hour.

The effective range of the speed meter increases with 1ts height above the roadway, the optimum height being about three feet. At this height the effective range of the conical beam is about 175 feet for passenger cars. In order to achieve the optimum height and facilitate aiming, the transmitter-receiver unit was supported on a stool which was leveled by means of flat stakes laid beneath the legs (see Figure 9).

The beam had to be angled into the traffic stream because it was necessary to set the unit several feet from the edge of the roadway in order to conceal the meter as much as possible. As a result, the indicated speed represented only a component of the true vehicle speed. The true speed is equal to the indicated speed divided by the cosine of the angle 


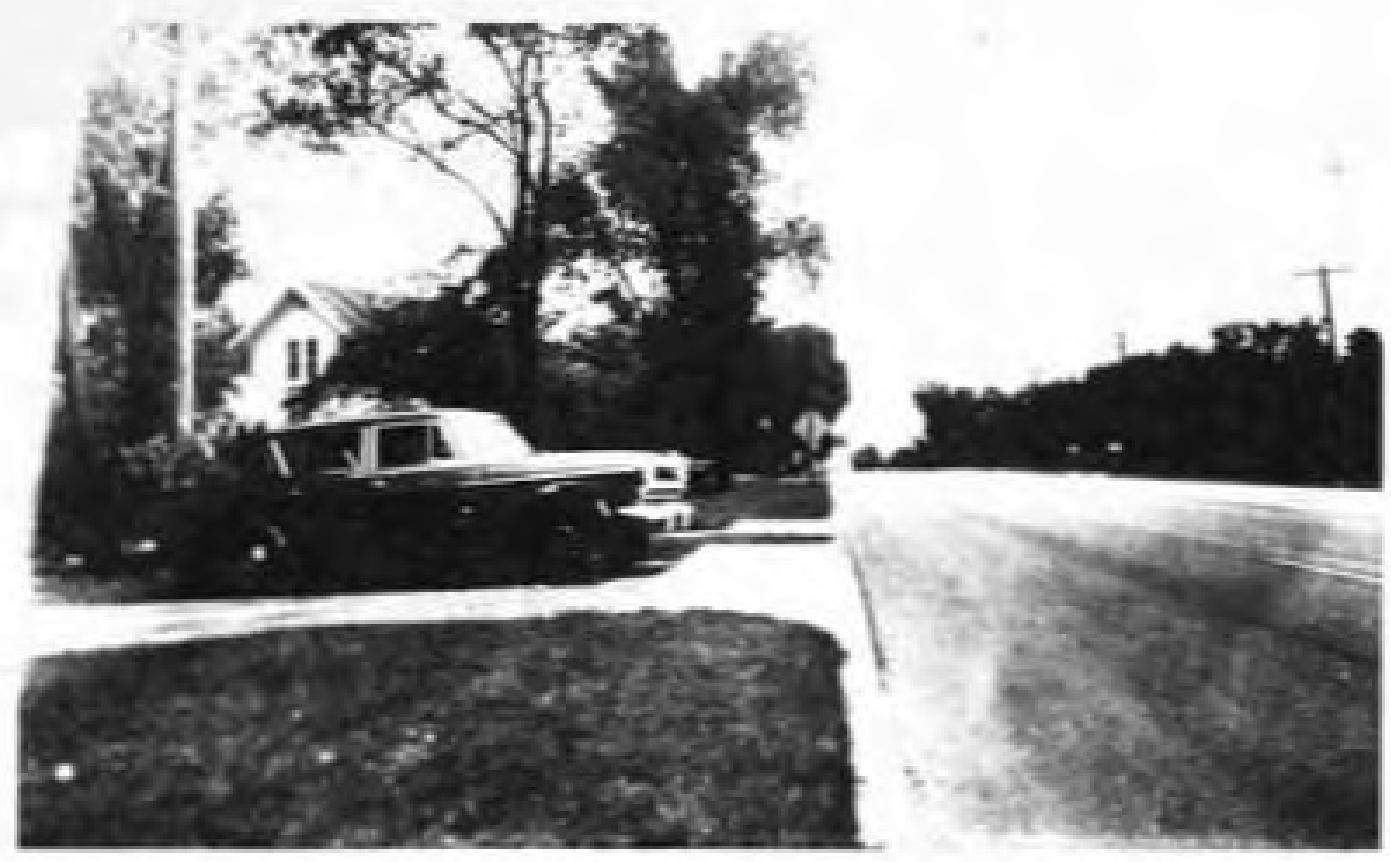

Recording speed of northbound traftic

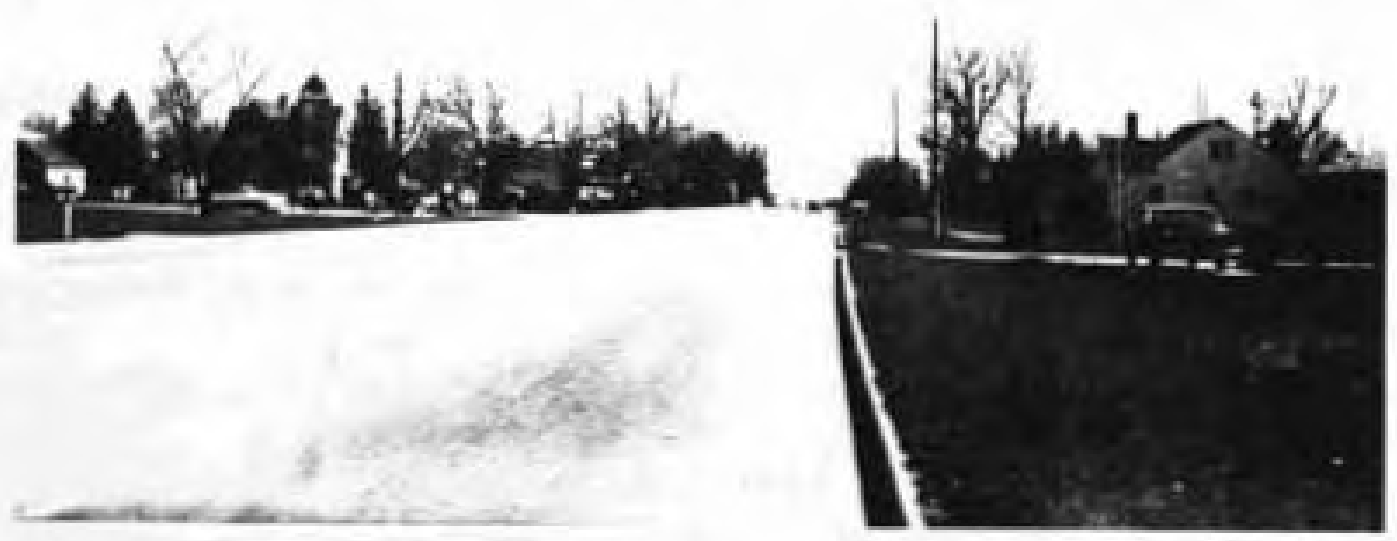

Driver's view for southoound traffic

\section{RADAR SPEED METER SETUP}

FIGURE 9 
between the beam and the edge of the road. If, however, the angle is small (less than $10^{\circ}$ ) the angular error is insignificant.

Speed readings are also affected by voltage variations in the battery. Several hours of continuous operation is sufficient to discharge a battery to the point where the speed meter is no longer rellable; however, no battery was in continuous operation for more than two hours before being recharged. Precaution was also used by checking the voltage of the battery periodically during its operation. A battery was replaced if the voltage dropped to 11.5 volts, even though the speed meter will operate reliably within the range of 11 volts D.C. to 14 volts D.C. This procedure was used to eliminate any error due to the discharge of a battery.

A tuning fork was used periodically during each speed study to check the calibration of the speed meter. This tuning fork has a vibration frequency which registers 60 miles per hour on the indicator.

The speed meter was also checked by the control car method. The speedometer of a Purdue University vehicle was calibrated from 30 to 60 miles per hour in increments of ten miles per hour. Test runs were made before and after the study to deternine if any difference exdsted between the true speed as given by the vehicle and that shown on the indicator of the speed meter. Slight differences of up to $0.5 \mathrm{mile}$ per hour occurred between the true speeds and the indicated speeds. The difficulty in sustaining exact speed with the vehicle and the accuracy in reading the meter indicator could account for these small differences and no corrections to the Indicated speeds were made. 


\section{PROCEDURE}

Traffic control devices at school crossings have an effect on a number of things including speed, safety, appearance of the roadway, cost, practicality, and acceptance by local residents. The effect on speed and safety were the primary concerns of the study conducted on Northwestern Avenue in West Lafayette (Study A).

Before the actual collection of speed data was undertaken, a preliminary study (11) was made at this location, from which an estimate was made of the average standard deviation to be encountered. This value was used in determining the sample size that would be required for statistical comparisons. However, due to the variables involved, the sample size could not be held constant.

The radar speed meter was set on a stool near the edge of the pavement and aimed at the crosswalk, thus, obtaining the speeds of vehicles as they crossed the crosswalk. Since the highway is four-lane, the transmitter-receiver unit was aimed so that the speeds of vehicles in the two nearest lanes could easily be read on the indicator without getting interference from vehicles going the opposite direction. For southbound traffic the unit was placed behind a mailbox while the observer sat in a parked car in a driveway (see $F_{1 \text { gure }} 9$ ). Since there was no mailbox in the proper location for northbound traffic, the unit was shlelded from distant view by the observer's car which was parked in an alley, but away from the edge of the road. It is believed that the speeds 
of the observed vehicles were not influenced by the presence of the observer nor the equipment as they were relatively well concealed. anly free-moving vehicles were recorded in this study. For the purposes of this study, a free-moving vehicle was defined as one whose speed was not seriously affected by the immediate presence of other vehicles in its path. Thus, only the first vehicle in a platoon was recorded, and vehicles accelerating or decelerating due to entering or leaving the roadway were not recorded.

The school crossing on Northwestern Avenue, which was the location studied, is also guarded by an adult guard. This guard was present throughout the study and stopped traffic when necessary to create gaps for ch1ldren to cross the roadway. At other times she stood near the edge of the road when children were present and away from the road when children were not present. Vehicles which were stopped or slowed by this adult guard were not included in the study.

Speeds were checked under fourteen different sign conditions during the time children were going to and from school. These sign conditions are detailed in Table 2 and Appendix A. A one-week waiting period during which no data were taken followed each new sign condition in order to give motorists time to adjust to the new condition. Pour weekdays were required to collect speed data for each sign condition-two separate days for each direction were used to minimize the effect of the day of the week. The order of these four days of data collection vere picked at random for each sign condition.

The time periods during which data were collected es th day were $7: 30$ 8:30 a.m., 11:00-12:00 noon, 12:15-1:15 p.m., and 3:00-L:00 p.m. During 
each time period, speeds were recorded as to whether children were present at the roadside or not.

The study of pedestrian-actuated signals at school crossings, made at locations $\mathrm{BI}$ and $\mathrm{B} 2$, was conducted on two different days. The number of children using the signal, children not using 1t, children misusing 1t, and vehicles disobeylng it were noted. At the same time the volume of vehicles passing over the crosswalk was also recorded each fifteenminute interval from 3:00-4:00 p.m. Time did not allow the collection of data during other periods of the day when children were going to and from school. The volume of vehicles was also recorded for an hour when the signal was not in use. On two other days, speed-delay studies were made at each of the two crossings. A car was driven through the crossIng at the average speed of traffic, for a distance of two blocks on either side of the school crossing. The time required to travel this measured distance was recorded in seconds for each trip. These trips were made for periods when the signal was in use and when it was not. Each period was one hour in length and divided into fifteen-minute intervals.

At the overpasses and underpasses included in this study, children were observed during two crossing periods on each of two non-consecutive days. A record was made of the number of children using the facillty, those not using it, and adults using 1t. The type of enforcement was also recorded. 


\section{ANALYSIS}

\section{Statistical Analysio of Speed Parameters}

Only data collected in Study A warranted a statistical analysis. The field data were processed to yield values of speed parameters by sign condition, direction, time period, and the presence of children at the school crossing. These parameters were a measure of the magnitude and the dispersion of the speed distribution. The mean speed, median speed, and the 85 th percentile speed were parameters of magnitude while the variance (square of the standard deviation) was the parameter of dispersion.

The 85th percentile speeds obtained for each of the fourteen sign conditions were statistically analyzed to determine the effect on traffic speeds of 1) the sign condition, 2) the direction of travel, 3) the time of the day, and 4) the presence of children at the crossing.

A statistical method termed "analysis of variance" (ANOVA) was utilized in analyzing the speed data. The assumptions which underlie this method include: a normal distribution of speed, observations that are random samples, and homogeneity of variances. Although a moderate departure from normality does not seriously impeir the validity of the test procedure, a test was performed on some of the data obtained under the first two sign conditions to determine if speeds were normally

*Definitions of statistical terms used in this report are included In Appendix A. 
distributed. The Chi-Square $\left(x^{2}\right)$ Test of Normality (10) indicated that speeds were normally distributed as is generally assumed. The 85th percentile speed was the parameter used in the ANOVA, and it was assumed to have a normal distribution.

Violation of the assumption of homogeneity of variance is more serious. The effect of unequal cell variances is small when the number of observations per cell are equal, but larger when the number of observations are unequal (6). If the cell variances increase as the number of observations decrease, a marked discrepancy in probability in the direction of overestimation of significance will occur. However, if the cell variances increase as the number of observations per cell increase, the discrepancy in probability results in underestimation of significance. The speed data showed that heterogeneity of variances did exist. From the scatter diagram of Figure 10 it can be concluded that the standard deviation was independent of the sample size.

Had the same number of measurements been made for each sign condition, 1.e., the same number of replications per cell, the analysis would have been simplified. However, this was not possible for several reasons. Traffic volumes differed from day to day to some extent, and for each one-hour time period. Volumes also depended on the direction of traffic and the length of time that children were present at the school crossing. The large number of conditions and the limited amount of time did not allow the required number of repeated studies to be made in order to obtain the same minimum sample size for every condition as determined by the data obtained from the preliminary study.

Since the number of repllcations per cell were unequal, a special method (21) was used in the analysis. The summation of the sum of squares 


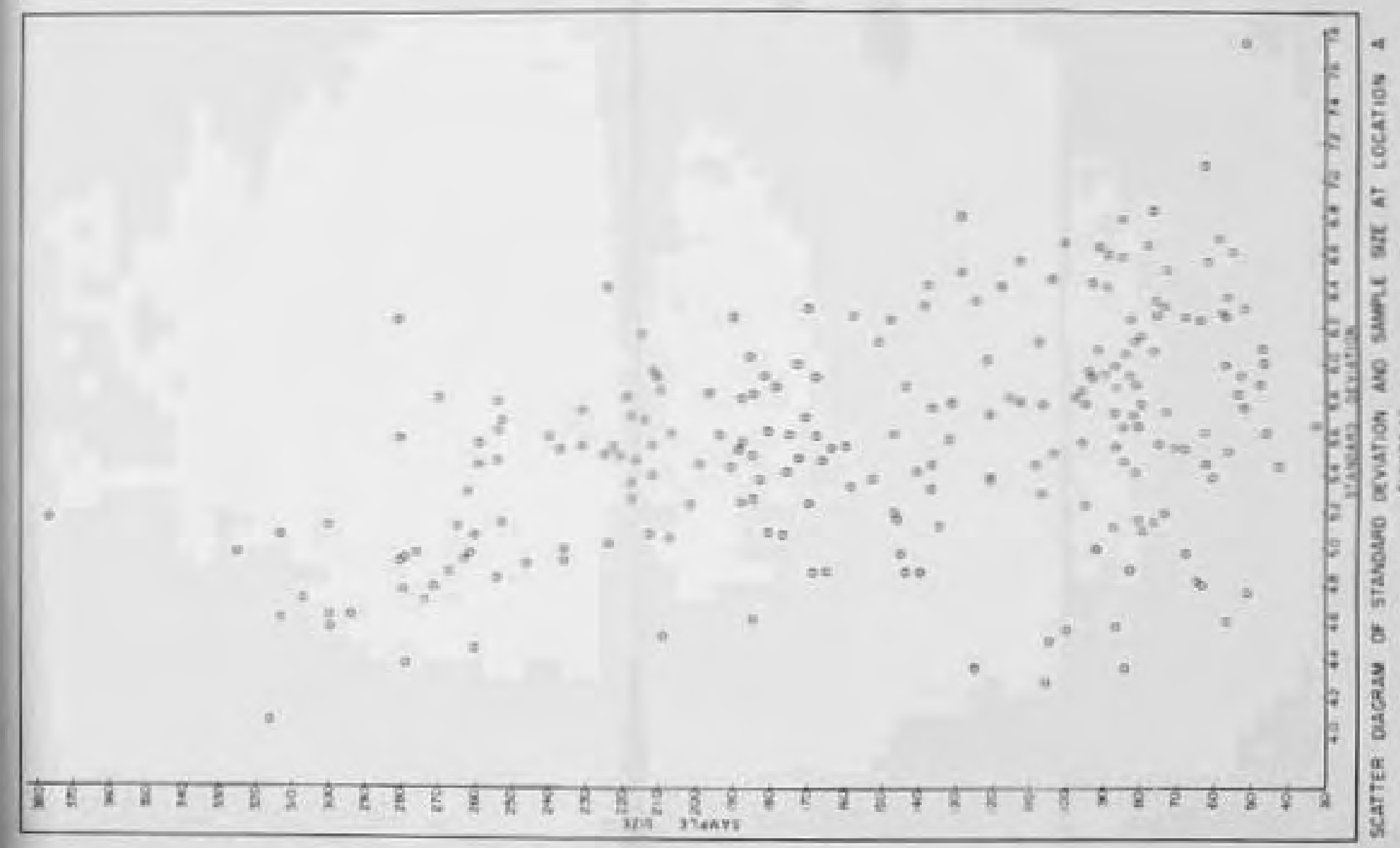


within each individual cell had to be divided by the average sample size or harmonic mean (5) to obtain the total sum of squares within all cells. The harmonic mean was the correction factor that was applied.

Since the 85th percentile speed was used for analysis instead of the mean speed, a second correction factor (16) had to be applied. The error mean square was calculated as it would have been for mean speeds and then multiplied by the second correction factor to obtain the error mean square for 85 th percentile speeds. A more detailed description of the method used in performing the analysis of variance is given in the form of an example in Appendix C. A tabulated sumary of the results of the analysis of variance is given in Appendix C, showing significant or not signifleant differences between all the various factors involved.

After the analysis of variance was completed, multiple, non-independent significance tests were made on differences between pairs of 85 th percentile speeds, with the 85 th percentile speeds based on varying $n_{1}$ (replications per cell). The Schefft Test (20) was used to make the comparisons because it controls the level of signiflcance over all types of comparisons and is adaptable to unequal $\mathrm{n}_{1}{ }^{\prime s}$. Graphs were drawn of children versus sign condition and time versus sign condition to determine which specific conditions interacted. Those with interaction could not be analyzed in this test.

\section{Arithmetic Analysis of Speed-Delay}

An arithmetic analysis was made of data obtained from locations BI and B2. Data concerning the use of the pedestrian-actuated signals at school crossings were summarized and put in table form. This analysis also included the effect that this type of protection had in regard to 
the delay of traffic. Delay was considered to be the difference in the time required to travel a measured distance during the periods when the signal was not being used and when it was being used.

The economic cost of delay to the motorist was based on figures obtained from a report (1) by the American Association of State Highway officials. Although the values given in th1s report are for rural conditions, they were used because values for urban conditions were not available. It is felt that the values used approximate those which would be typical under the urban conditions at the signals included in this study. In calculating user costs for the vehicle while in motion, both locations were assumed to be tangent two-lane highways with restricted operation. Although location B2 is four-lane divided, it was classified two-lane because of the low speeds which occur.

Extra cost resulting from a stop delay was also considered. The total cost per vehicle due to the delay caused by the presence of the signal may be expressed by the following equation:

$$
c_{T}=c_{1}-c_{2}+[\text { number of stops per vehicle] [cost per stop] }
$$

where

$\mathrm{C}_{\mathrm{T}}=$ total economic cost (cents per veh1cle) to each vehicle user due to delay

$c_{1}=$ user cost based on running speed during period when signal is being used over length of road where speed might be affected by signal

$c_{2}=$ user cost based on running speed during period when is not being used over same length of road. 


\section{RESULTS}

\section{Study A}

The results of the analysis of variance shown in Table 3 revealed significant differences among the four factors, including significant interaction. This may indicate that different combinations of sign condition, direction of travel, time of day, and the presence of children significantly affected speed at the school crossing. Another factor, which was not included in the analysis, became obvious as the study proceeded. There was an indication that speeds also depended on which side of the road the children were present. Speeds were slower (1-5 miles per hour) when children were on the near side of the road from traffic, than they were when children were on the far side. Although this was true for a four-lane highway, it may not be true for a two-lane highway.

The interaction between the presence of children at the school crossing and the traffic sign condition 1s 11lustrated in Figure 11 . Different interaction between the presence of children and sign condition is illustrated by the crossing lines. Figure 12 also shows the effect on 85th percentile speeds of the presence of children for each of the fourteen sign conditions.

Each 85th percentile speed (coded) which is plotted on Figures 11 and 12 is 256 less than the sum of the eight 85th percentile speeds which were taken for a sign condition with or without children present as appropriate. One can convert each plotted speed on Figures 11 and 12 
Table 3

ANALYSIS OF VARIANCE TABLE

\begin{tabular}{|c|c|c|c|c|c|c|}
\hline Source & $\begin{array}{l}\text { Sum of } \\
\text { Squares }\end{array}$ & d.f. & $\begin{array}{l}\text { Mean } \\
\text { Square }\end{array}$ & $\begin{array}{c}\text { Varlance } \\
\text { Ratio }\end{array}$ & $\mathrm{F}_{0.05}$ & $\begin{array}{c}\text { Conclu- } \\
\text { sion }\end{array}$ \\
\hline Children & 835.46 & 1 & 835.46 & $1,329.3$ & 3.84 & s \\
\hline Time & 119.75 & 3 & 39.92 & 63.5 & 2.60 & s \\
\hline D1rection & 7.34 & 1 & 7.34 & 11.7 & 3.84 & s \\
\hline S1gns & 472.50 & 13 & 36.35 & 57.8 & 1.72 & s \\
\hline $\mathrm{TxC}$ & 3.93 & 3 & 1.31 & 2.1 & 2.60 & NS \\
\hline TxS & 59.48 & 39 & 1.53 & 2.4 & 1.42 & $\mathrm{~s}$ \\
\hline $\mathrm{T} \times \mathrm{D}$ & 165.13 & 3 & 55.04 & 87.6 & 2.60 & s \\
\hline Cxs & 22.45 & 13 & 1.73 & 2.8 & 1.72 & s \\
\hline$C \times D$ & 6.27 & 1 & 6.27 & 10.0 & 2.84 & s \\
\hline SxD & 41.59 & 13 & 3.20 & 5.1 & 1.72 & s \\
\hline CxTxS & 46.97 & 39 & 1.20 & 1.9 & 1.42 & $s$ \\
\hline$C \times T \times D$ & 40.95 & 3 & 13.65 & 21.7 & 2.60 & $s$ \\
\hline$C x S x D$ & 16.96 & 13 & 1.30 & 2.1 & 1.72 & s \\
\hline$T \times S x D$ & 40.54 & 39 & 1.04 & 1.7 & 1.42 & $s$ \\
\hline$C x \mathbb{T} \times D x S$ & 40.16 & 39 & 1.03 & 1.7 & 1.42 & $s$ \\
\hline Brror & $21,357.02$ & 33,980 & 0.6285 & & & \\
\hline Total & & 34,203 & & & & \\
\hline
\end{tabular}

Notation used:

$S$ Significant difference of a source of variation on a 5 per cent significance level

NS Insignificant difference of a source of variation on a 5 per cent significance level

to an 85 th percentile speed by adding 256 to the plotted value and dividIng by eight. The data were plotted in the manner indicated to provide easier visual analysis of the data. 


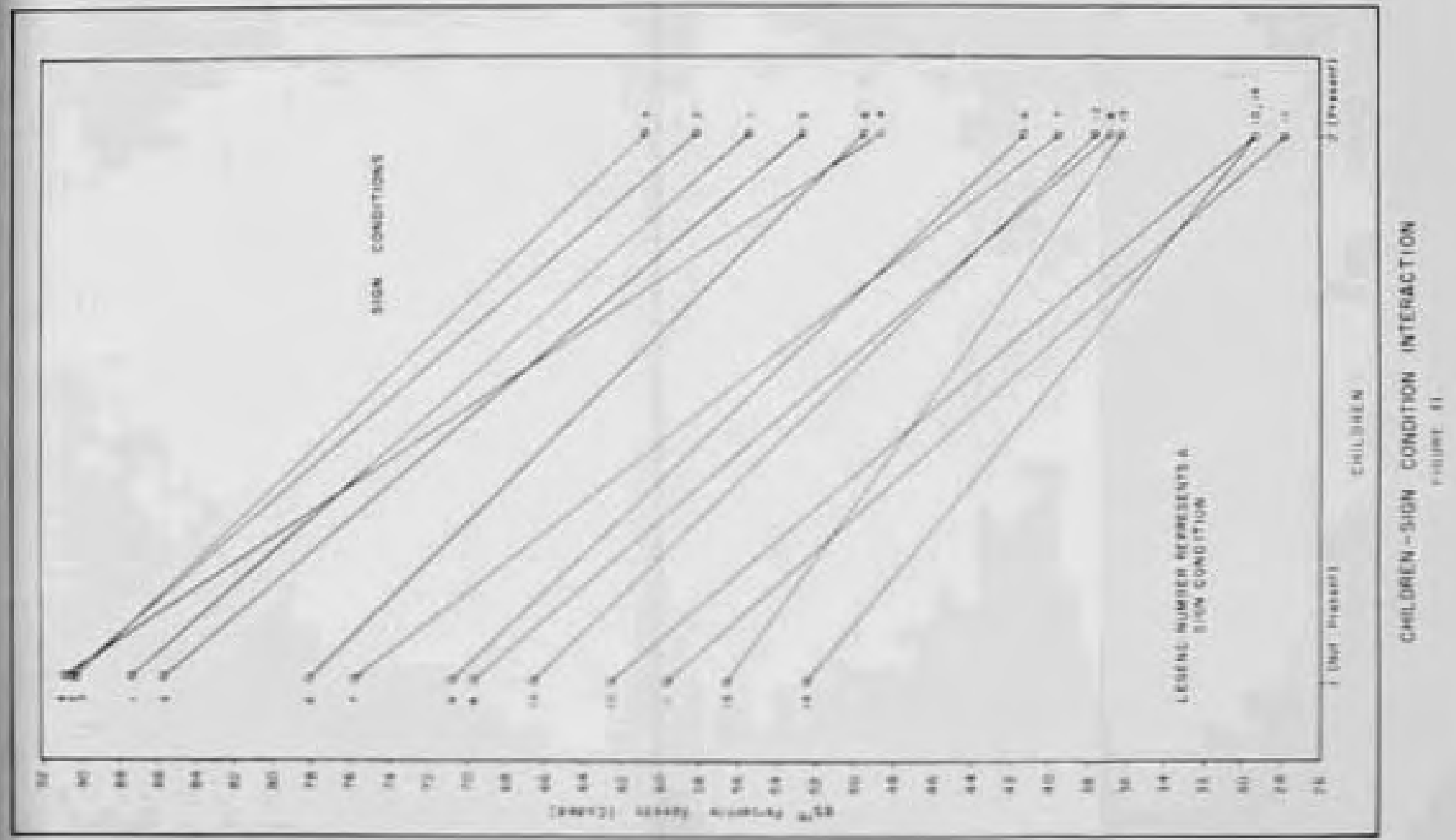




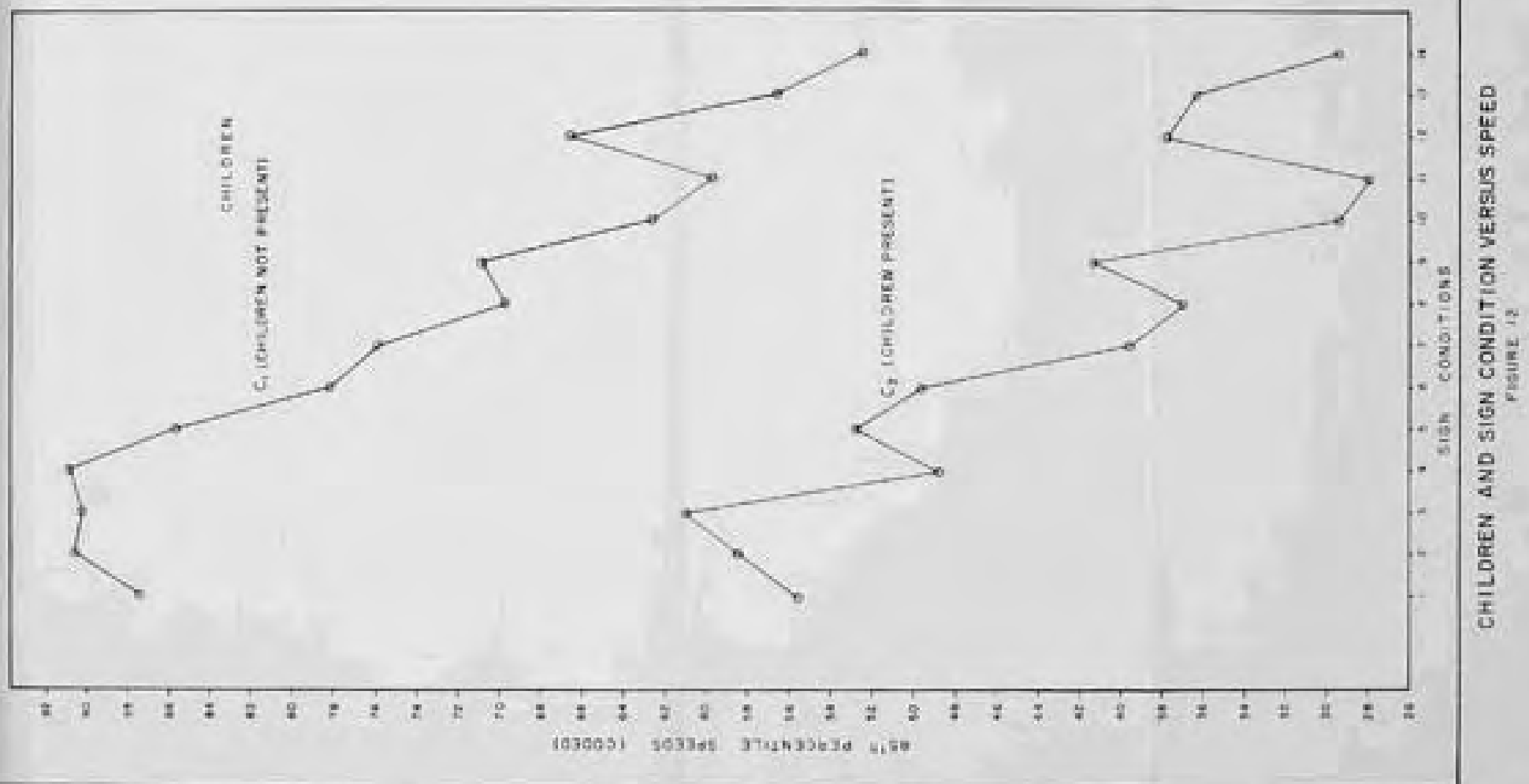


For each sign condition the 85th percentile speed decreased significantly when children were present at the edge of the roadway as conpared to when they were not present. The decrease in speed was much larger for sign condition $4\left(\mathrm{~S}_{4}\right)$ * than for any of the other sign conditions. The 85th percentile speed also decreased considerably when children were present for $S_{7}, S_{10}$, and $S_{11}$. All three of these sign conditions are similar in that each is the $S_{4}$ condition plus a flashing beacon(s), the location of the latter varying among the three. Considering only when children are present, the sign conditions fall into three separated groups of speeds (see F1gure 11), with $\mathrm{S}_{10}, \mathrm{~S}_{11}$, and $\mathrm{S}_{14}$ giving the lowest speeds.

The interaction between the time of the day and the sign condition 1s illustrated in Figure 13. The coded 85th percentile speed on this figure is 128 less than the sum of the four 85 th percentile speeds taken for each sign condition and a time of day. The 85th percentile speed was the lowest in the morning when children go to school $\left(\mathrm{T}_{1}\right)$ for all sign conditions except $\mathrm{S}_{8}$. Generally, speeds were lower during $\mathrm{T}_{1}$ and $T_{3}$, when children were going to school and people were going to work and slightly higher during $\mathrm{T}_{2}$ and $\mathrm{T}_{4}$, when children were coming home from school. Speeds increased each consecutive time period throughout the day for $S_{9}$ and $S_{14}$. The lowest 85th percentile speeds were those for $S_{14}$ In the morning, $T_{1}$. Although the speeds for $S_{8}$ followed the pattern of that for other sign conditions (low for $T_{1}$ and $T_{3}$ and high for $T_{2}$ and $T_{4}$ ), the changes in speed by time of day were higher than for other sign conditions. Sign condition 11 and $\mathrm{S}_{13}$ also deviated from the general time effect pattern, but in another way. Their effect on speed was about the same regardless of the time period.

* See Appendix A for listing of sign conditions and other variables. 


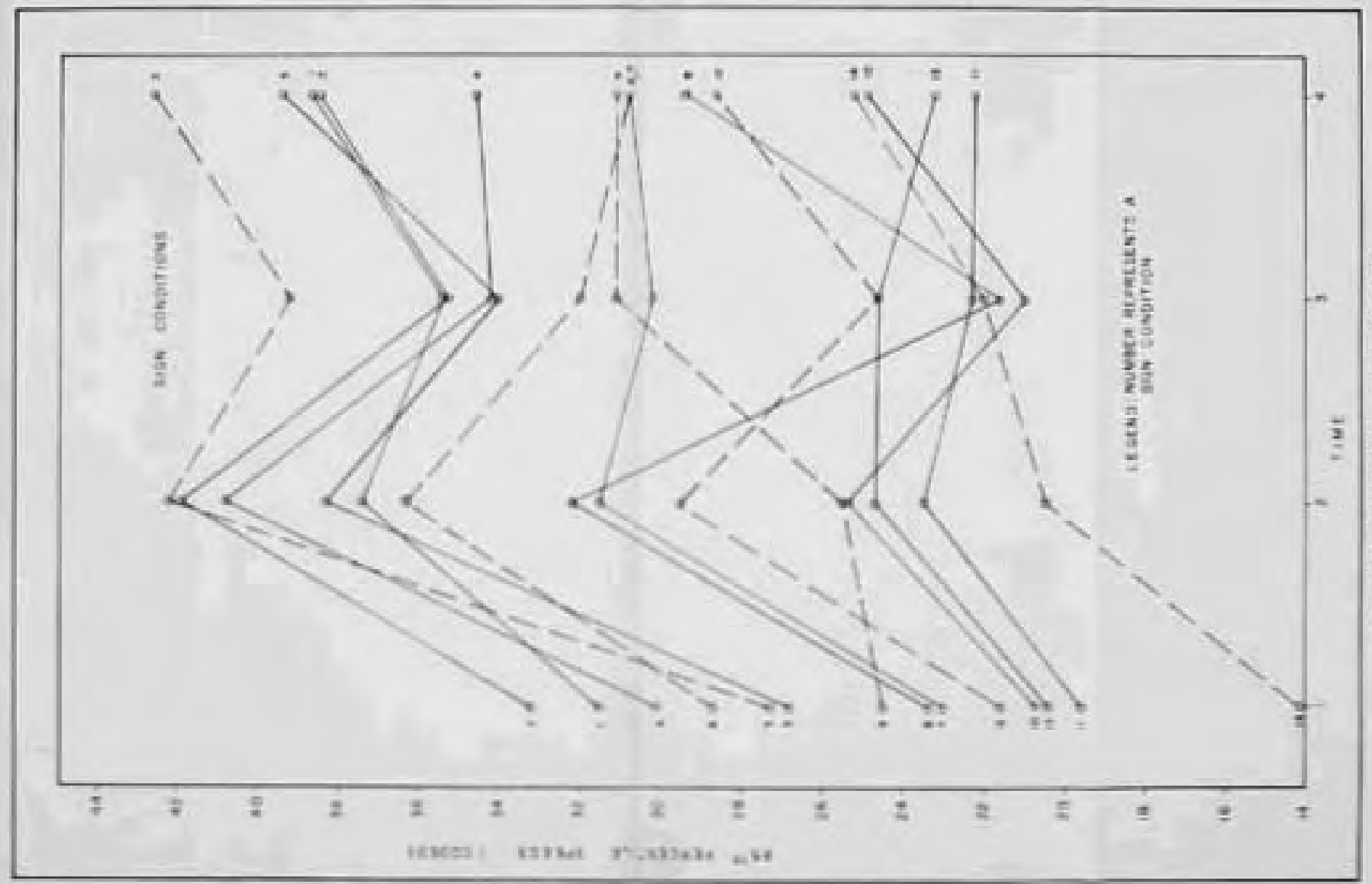


A tabulated sumary of the results of the multiple comparison analysis is given in Table 4, showing significant or not significant differences between the 85 th percentile speeds for the various sign conditions. Those sign conditions having different interaction with the presence of children and/or time of day as shown on Figures 11 and 13 respectively, could not be analyzed by this method. It should be noted that for some sign conditions, where comparisons showed significant differences, they were not significantly different when compared only on the basis of when children were present at the crosswalk.

The sign, "SPEED IIMIT 25 WHEN CHILDREN PRESENT" (sign C), was used In nine of the fourteen sign conditions (see Tables 1 and 2). The ares in which the school crossing is located was zoned at other times for 40 miles per hour. The lowest 85 th percentile speed obtained during the study when children were present and with sign $C$ in use was 32.5 miles per hour, while the highest 85th percentile speed was 43.1 miles per hour. These speeds may Indicate a lack of respect for speed regulatory signs as has also been found by other investigators (11). It may also Indicate that a majority of the motorists feel that a speed limit of 25 miles per hour is too low when children are present.

A limited preliminary study (12) found that when no school crossing signs of any sort were used, the 85 th percentile speed ranged from 39.8 to 41.4 miles per hour when children were not present. When children were present, 1t ranged from 37.9 to 39.5 miles per hour (see Appendix B for data). In the study reported here and when various traffic control signs were used at the school crossing, 85th percentile speeds ranged from 37.0 to 45.7 miles per hour when children were not present and 32.5 to 43.1 miles per hour when children were present. There is an indication 
Table 4

MULTIPLE COMPARISONS

\begin{tabular}{|c|c|c|c|c|c|c|c|c|c|c|c|c|c|c|}
\hline \multirow{2}{*}{$\begin{array}{l}\text { Sign } \\
\text { Condition }\end{array}$} & \multicolumn{14}{|c|}{ Sign Condition } \\
\hline & 1 & 2 & 3 & 4 & 5 & 6 & 7 & 8 & 9 & 10 & 11 & 12 & 13 & 14 \\
\hline 1 & - & - & - & - & - & NS & s & s & s & S & s & s & s & s \\
\hline 2 & & - & - & NS & NS & NS & s & s & $s$ & s & s & s & s & $s$ \\
\hline 3 & & & - & - & NS & - & s & S & s & s & s & s & s & s \\
\hline 4 & & & & - & - & NS & NS & $s *$ & NS & S & $s$ & $S *$ & S* & s \\
\hline 5 & & & & & - & - & NS & s & NS & s & $s$ & s & S & s \\
\hline 6 & & & & & & - & NS & NS & NS & s & s & NS & s & s \\
\hline 7 & & & & & & & - & - & - & NS & S* & NS & NS & $S *$ \\
\hline 8 & & & & & & & & - & - & NS & - & - & - & - \\
\hline 9 & & & & & & & & & - & NS & NS & - & NS & $S^{*}$ \\
\hline 10 & & & & & & & & & & - & - & NS & - & - \\
\hline 11 & & & & & & & & & & & - & NS & - & - \\
\hline 12 & & & & & & & & & & & & - & NS & NS \\
\hline 13 & & & & & & & & & & & & & - & - \\
\hline 14 & & & & & & & & & & & & & & - \\
\hline
\end{tabular}

Not significantly different when compared by $C_{2}$ (children present) only.

- Bither same sign or interaction which could not be analyzed for significance.

that when children were not present, the 85 th percentile speeds increased when certain traffic control signs were used at the school crossing, and slightly decreased for certain other traffic control signs. The same is true when ch1ldren were present, except that the 85 th percentile speed decreased a littlo more under certain sign conditions. 
The morning period, $7: 30-8: 30 \mathrm{a}, \mathrm{m}$., was probably the most critical time period. The highest volume of traffic, during the time children were going to or from school, occurred during this period, and 1t was generally belleved that they would be in a hurry on their way to work. During the winter months it was dark during the early part of this period and, although not true during the study, it was foggy on some days. Speeds were generally lower, however, during this morning period than they were during any of the other school crossing periods of the day. No accidents during the time children were going to and from school have occurred at this school crossing since the road was reconstructed.

\section{Study B}

The results of the study at location $\mathrm{Bl}$ show that during the period of 3:00-4:00 p.m. when children were going home from school, 42.8 per cent of the children used the pedestrian-sctuated signal at the school crossing. The other 57.2 per cent selected their gaps in traffic without the use of the signal. Many times these gaps were not of sufficient length to allow safe crossing, thus leading to undesirable practices. Some of the children dashed across the street while others, especially the larger groups, walked across at a normal pace, and caused traffic to stop. In the process some stood in front of the vehicles and teased the drivers.

Approximately 1.3 per cent of the students pushed the button after they had crossed, causing traffic to stop unnecessarily. Approximately 13 per cent of the veh1cles falled to stop or remain stopped when the signal Indication was red. This may, to a large extent, have resulted from the misuse of the signal by the children, and to a lesser degree from impatience 
on the part of drivers when only a few children crossed during a twentyfive second red indication. It was also found that a few vehicles stopped at the crossing unnecessarily when the signal was not being operated. This confusion may have resulted from not being acqualnted with this type of signal.

The delay to traffic caused by the operation of the signal was greatest during the first fifteen-minute interval of the 3:00-4:00 p.m. period. The total economic cost of the delay to the motorist in this fifteenminute period was 0.667 cents per vehicle as compared to 0.309 cents per vehicle, the average for the total hour during which the signal was used.

Accident records show that since the installation of this signal in September, 1960, to June, 1961, two of the three accidents at the intersection were rear-end collisions during the time children were going to school, and resulted in $\$ 1,160$ property damage. In one case a veh1cle ran Into the rear of three vehicles stopped to let children cross. As a comparison there were no accidents at this school crossing during school crossing periods among the seven accidents occurring during the three previous years before the signal installation.

The results of the study at location $B 2$ showed that during the period of 3:00-4:00 p.m., when children were going home from school, 98.3 per cent of the children used the pedestrian-actuated signal at the school crossing. School patrols are stationed at each nearby intersection prior to the dismissal of the children from school. Practically all of the children using the crossing, used it from 3:15-3:30 p.m. An adult school guard operated the signal from 3:00-3:30 p.m. and allowed children to cross only in large groups. Only 1.7 per cent of the children do not use the facility provided for their protection. These children either 
cross 38 th Street at a non-signalized intersection or Jaywalk, generally after the adult guard has left his post. Adults do not use this pedestrianactuated signal, but jaywalk nearby. On one afternoon three children operated the signal without a desire to use the crosswalk. Only once during the study did a vehicle fail to stop when the signal indication was red.

The delay to traffic caused by the operation of the signal was greatest from $3: 15-3: 30 \mathrm{p} . \mathrm{m}$. The average stop delay was approximately twenty seconds. The total economic cost to the motorist, due to total delay, averaged 0.500 cents per vehicle for the forty-five-minute period of signal operation $(3: 00-3: 45)$ as compared to 0.770 cents per vehicle for the $3: 15-3: 30 \mathrm{p} . \mathrm{m}$. period.

No comparison can be made of the accidents occurring before the installation of the pedestrian-actuated signal in September, 1956, and those occurring since, because the conditions of the roadway were changed at that time. A concrete median strip and separate lanes for left turns were added. Of all the accidents within one-half block of the crossing on 38th Street, two rear-end collisions occurred near the crosswalk during the morning hours when children were probably going to school. The amount of damage is not known.

\section{$\underline{\text { Study C }}$}

The underpass school crossing at location $\mathrm{Cl}$ was used by 100 per cent of the children needing to cross the highway who attended the elementary school nearby. The only enforcement was the threat of punlshment to those who did not use the facility. An adult school guard at a nearby intersection reported those that crossed the street instead of using the facility 
to school officials who then punished the disobedient children. The doors are locked during the night to keep the tunnel from becoming a place of nuisance and crime.

The overpass school crossing at location C2 was used by 100 per cent of the children who needed to cross the highway in order to attend the elementary school near the crossing. Two types of enforcement exist. School patrols are stationed at either end of the structure at the top of the stairs, and the structure is connected to a guard fence which channels the children toward the structure.

The overpass school crossing at location C3 was used by 60.5 per cent of the children needing to cross the highway. The majority of these children were grade-school age. The remaining 39.5 per cent, most of whom were high-school age, crossed elsewhere. Of these, 34.5 per cent crossed at the signalized intersection one block east of the overpass, 3 per cent crossed at the non-signalized intersection one block west of the overpass, and 2 per cent crossed between intersections by fumping over the guard fence. Those crossing at the signalized intersection conflicted with turning novements. The only enforcement consisted of a fence along both sides of the expressway, but with openings at the two intersections, one on each side of the overpass and approximately one block distant.

The overpass school crossing at location $C_{4}$ was used by 100 per cent of the children needing to cross the highway to the elementary school located on the west side of the highway. A teacher escorted the children to the crossing only in the evening as they left school. This was the only enforcement at this crossing. 
At location C5, 74.0 per cent of the children needing to cross the highway used the ground-level school crossing over the depressed expressway while 25.1 per cent crossed at a ground-level signalized intersection one-half block north of the overpass. The remaining 0.9 per cent crossed the depressed expressway by climbing down to the expressway, crossing it and then climbing back to ground level. A small number of adults also used the overpass. Of those children using the overpass, 2.5 per cent played around the structure, especially on their way home from school in the evening. They did such things as crawl under the fence and slide down the embankments to the depressed expressway (see Figure 8) and climb over the guard fence on the overpass and walk on the concrete ledge of the overpass above the traffic below. Both sides of the expressway are fenced and connected to the overpass. At times rail traffic conflicted with the school crossing, and children had to wait as long as fifteen minutes in order to cross the tracks on their way to school.

At location of the underpass school crossing at the hiph school was abandoned because of the nuisances that occurred in the tunnel. It was closed with heavy fence on each end of the tunnel. 


\section{ACCIDENT STUDY OF THE SCHOOLAGE PEDESTRIAN}

There were 1124 deaths and 38,316 infuries in motor vehicle accidents In Indiana in 1960. Of these totals 13.8 per cent, or 155 , of the deaths and 7.0 per cent, or 2,666 , of the infuries were pedestrians. Pedestrians of elementary school age (5-14 years) were 3.3 per cent, or 37 , of the total deaths and 3.3 per cent, or 1,255, of the total injured while b1cycle riders of the same ages accounted for 1.5 per cent, or 17 , of the total deaths and 2.1 per cent, or 791 , of the total infured.

The statistics given in the above paragraph were obtained from the sumary analysis of 1960 motor vehicle accidents which is performed by the Indiana State Police. The data are for the entire year 1960, day and night, school days and weekends, and for the full twelve months. The Indiana State Pollce furnished the study a complete set of the IBM cards for the school-age pedestrian accidents which occurred in 1960. Analysis of these cards determined that 23.8 per cent of the 5-14 age pedestrians involved in fatal or infury accidents occurred during to and from school times on school days in months schools were in session. Thus, approximately 9 deaths and 300 infuries occurred in 1960 in Indiana to child pedestrians 5-14, years old during the approximately four hours when children would be walking to or from school. Undoubtedly some of these deaths and accidents occurred while the child was not actually walking to and from school, but the data on the accident records do not include this information. 
If perfect school crossing protection could have been provided during the approximately four hours when children were walking to and from school in 1960 and the 9 deaths and 300 injuries could have been prevented, the total deaths due to motor vehicles in 1960 would have been reduced by only 0.8 per cent and the total injuries due to motor vehicles would have been reduced only a similar 0.8 per cent. All of the 9 deaths and 300 injuries, of course, could not have been prevented and reduction of motor vehicle deaths and injuries would not have been reduced even the small amount indicated.

It is true, of course, that saving of even a few lives and preventIng a few infuries is desirable, but it is also possible that protection of the school child pedestrian while going to and from school can be overdone and result in children being improperly educated in the crossing of streets, which they must do by themselves at other times of the day. It certainly is true that substantial improvement in the motor vehicle death and infury rate must occur in areas other than at school crossings. 
CONCLUSIONS AND RECOMMENDATIONS

The following conclusions and reconmendations are based on the results of the studies of school crossing protection included in this report :

A. In the study of fourteen sign conditions at the one crossing:

1. The four factors studied--sign condition, time of day, direction of travel, and presence of children--proved to have sufficient interaction in all combinations, except time of day with presence of children, to signiflcantly affect the 85 th percentile speed.

2. The 85th percentile speeds were lowest when children were going to school in the morning than for the other time periods.

3. The presence of children at the edge of the roadway significantly lowered (3-4 miles per hour) the 85 th percentile speed under each sign condition. It was also apparent that the presence of children on the side nearer the vehicle had the greater effect.

4. The 85 th percentile speed was not changed significantly when the size of one warning sign, "SCHOOL CROSSING," was increased from 30 to 36 inches; nor did 1t change signif1cantly when an additional like warning sign was added.

5. The sign, "SPEED LIMIT 25 WHEN CHILDREN PRESENT," did not decrease the 85th percentile speed sitnificantly when placed 
with one or two "SCHOOL CROSSING" signs, but when used in combination with one or two "SCHOOL CROSSING" signs and one or two flashing beacons or with one "SCHOOL CROSSING" sign and a portable "SCHOOL CHILDREN CROSSING" sign, speeds were significantly lower than when only one or two "SCHOOL CROSSING" signs were used.

6. The 85th percentile speed decreased significantly when the portable sign, "SCHOOL CHILDREN CROSSING," was added to one "SCHOOL CROSSING" sign.

7. A single flashing beacon added above one "SCHOOL CROSSING" sign did not significantly lower the 85th percentile speed, but when added above the "SPEED LIMIT 25 WHEN CHILDREN PRESENT" sign and with one or two "SCHOOL CROSSING" signs the 85th percentile speed was significantly lowered. The 85th percentile speed was also significantly lower when a twin horizontal flashing beacon or when a twin vertical flashing beacon was used on the "SPEED LIMIT 25 WHEN CHILDREN PRESENT" sign. However, only the twin vertical plashIng beacon resulted in significantly lower speeds than when a single flashing beacon was used with the same signs.

8. The twin vertical flashing beacon in combination with a 36inch "SCHOOL CROSSING" sign and a "SPEFD LIMIT 25 WHEN CHILDREN PRESENT" sign; and the single flashing beacon in combination with the "SCHOOL CROSSING" sign, "SPEED LIMIT 25 WHEN CHILDFEN PRESENT" sign, and a portable "SCHOOL CHILDREN CROSSING" sign were probably, of the fourteen sign conditions used in this study, the two most effective for reducing 
85th percentile speeds at the school crossing. For the condition of children present the twin horizontal flashing beacon with a "SPEED LIMIT 25 WHEN CHILDREN PRESENT" sign and a "SCHOOL CROSSING" sign was also effective.

9. The use of any of the fourteen sign conditions had a rather small effect on speed. The 85 th percentile speed without any school crossing signs of any kind decreased 2-3 miles per hour when chlldren were present from that when children were not present. Certain sim conditions decreased the speed an additional 3-5 miles per hour. However, the 85 th percentile speed when children were not present for certain sign conditions was up to four miles per hour higher than when no signs existed.

10. In view of the difficulties experienced in keeping the portable sign in place because of wind and vehicles, the fact that someone must place the sign in the roadway at the proper times and remove it when each crossing period ends, the statement of the uniform manual (18) that portable signs in the roadway are prohibited, and the findings of this study that other sign conditions give similar results, it is recomended that the portable "SCHOOL CHILDREN CROSSING" sign not be used.

B. In the study of the two pedestrian-actuated signals it was found that operation by an adult guard was far superior to operation by the school children. Operation by the adult guard resulted In far better use by children of the protection, less delay to 
motorists, fewer accidents, and the minimization of misuse of the signal by playing children. It is recomended where pedestrian-actuated signals are used at school crossings that an adult guard, or at least a school patrol, supervise the actuation during school crossing periods.

C. In the study of underpasses and overpasses which have been constructed for school children crossing in Indiana it was found that:

1. Underpass school crossings are less desirable than overpass school crossings because they have greater potential for nuisance use and even crime. This problem was solved by providing doors to the tunnel which were kept locked during the night in one case, and by abandonment in another case.

2. Overpass and underpass school crossings were more effectively used by elementary school children than high school children. In most cases some form of enforcement was necessary to secure maximum use, with this enforcement more of a necessity for high school children than for elementaryage children. The enforcement was typically adult guards, teachers, school patrols, or fence.

D. It was found from a study of the accident statistics of Indiana for 1960 that the total motor vehicle death or infury rate in the state could be reduced only a maximum of approximately one per cent if all deaths and injuries occurring to elementary school age pedestrians during the hours when they normally walk to and from school, could be prevented. It is evident that a major attack on the motor-vehicle fatality and in jury problem in Indiana must include much more than school child protection. 
BIBIIOGRAPHY 


\section{BIBLIOGRAPHY}

\section{List of References}

1. American Association of State Highway Officials. Road User Benefit Analyses for Highway Improvernents. Washington, D. C., 1960.

2. American Association of State Highway Officials, Committee on Traffic. National Practices for the geration and Protection of School Zones and Crossings. Washington, D. C., 1952.

3. American Automobile Association Foundation for Traffic Safety. "The School Child Pedestrian." Planned Pedestrian Program, 1958, pp. 87-98.

4. American Automobile Association, Traffic Engineering and Safety Department. "Motor Vehicle Speed ... Its Control and Regulation" (pamphlet). Washington, D. C.

5. Anderson, R. I. and Bancroft, T. A. Statistical Theory in Research, first edition. New York: MeGraw-Hill Book Company, Inc., 1952, p. 278 .

6. Box, G. E. P. "Some Theorems on Quadratic Forms Applied in the Study of Analysis of Variance Problems, I. Effect of Inequality of Variance in the Cne-Way Classification." The Annals of Mathematic Statistics, Institute of Mathematical Statistics, Vol. 25, No. 2, June, 1950, p. 290.

7. Brantley, J. Q., Jr. "How Accurate are Radar Meters?" Blectronics, Vol. 28, No. 12, December, 1955, p. 132.

8. Burr, Irving W. Pngineering Statistics and quality Control. New York: McGraw-H1ll Book Company, Inc., 1953.

9. Dier, Robert D. "School Crossing Protection." Proceedings, Institute of Traffic Ingineers, 1959, p. 53.

10. Duncan, Acheson J. Quality Control and Industrial Statistics, revised edition. Homewood, Illinois: Richard D. Irwin, Inc., 1959.

11. Elmberg, Curt M. "Effects of Speed Zoning in Suburban Areas." A thesis submitted to the faculty of Purdue University in partial fulfillment of the requirements for the degree of Master of Science in Civil Ingineering, June, 1960.

12. Elmberg, Curt M. "Speed Patterns at a School Crossing in West Lafayette, Indiana." Report, Purdue University, October, 1959 (unpublished). 
13. "H1 ghway Radar is Watching You." Nation's Business, Vol. 43, No. 8, September, 1955, p. 38 .

14. Hoffman, Lawrence. "School Crossing Protection." Traffic Engineering, Vol. XXV, September, 1955, pp. 494-497.

15. Howie, George W. "Effective Protection for School Crossings." Proceedings, Institute of Traffic Engineers, 1950, pp. 72-77.

16. Lev, Joseph and Walker, Helen M. Statistical Inference. New York: Henry Holt and Company, 1953.

17. Nanual for Electro-Matic Radar Speed Neter. Automatic Signal Division, Eastern Industries, Inc., Norwalk, Connecticut.

18. National Joint Coumittee on Uniform Traffic Control Devices, U. S. Department of Commerce, Bureau of Public Roads. Manual on Uniform Traffic Control Devices for Streets and Highways. Washingtion, D. C., June, 1961.

19. National Safety Council. Accident Pacts. 1953 and 1955 editions.

20. Scheffe, Henry. "A Method for Judging All Contrasts in the Analysis of Variance." Biometrika, Vol. 40, Parts 1 and 2, June, 1953, pp. $87-104$.

21. Snedecor, George W. Statistical Methods, fifth edition. Ames, Iowa : The Iowa State College Press, 1956, pp. 268-271.

\section{General References}

22. Dier, Robert D. "A Study of a School Crossing Hazard." Traffic Quarterly, Vol. VI, No. 1, January, 1952, pp. 102-115.

23. Dier, Robert D. "Determining the Degree of Hazard at School Crossings." Traffic Engineering, Vol. XXv, January, 1955, p. 137.

24. Lawton, Lawrence. "Traffic Controls in the Vicinity of School Zones." Proceedings, Institute of Traffic Engineers, 1953, pp. 108-118.

25. Volk, William. Applied Statistics for Engineers. New York: MeGrawHill Book Company, Inc., 1958.

26. White, James T. "School Crossing Problems," Engineering Bulletin, Purdue University, Vol. XIIV, No. 6, November, 1960, p. 165. 
APFSNDIX A 
$\sigma \quad$ Level of significance

C Presence of children factor

$C_{1}$ Children not present at the edge of the roadway

$c_{2}$ Children present at the edge of the roadway

D Direction of traffic flow

$D_{n}$ Northbound

$D_{s}$ Southbound

df Degrees of freedom

e Error

F Function of the F distribution, used to test hypotheses on variances

f Frequency of vehicles for a specific speed

g Number of replications per cell

H Statistical hypothesis

k Number of cells (samples)

MS Mean square

MS Error mean square

n Number of vehicles whose speeds were recorded for each sample, i.e., sumnation of the frequencies for each speed in a sample

S Sign condition

$S_{1}$ Sign condition 1 (see list of sign conditions)

$S_{2}$ Sign condition 2 (see list of sign conditions)

SS Sum of squares

Study A Study of traffic control signs

A Location in West Lafayette

Study B Pedestrian-actuated signal study

B1 Location in Lafayette

B2 Iocation in Indianapolis

Study C Overpass and underpass school crossing study

Cl Location in East Chicago

C2 Location in Evansville

C3 Location in Clarksville 
C4 Location in Dolltic

C5 Location in Indianapolis

of Location in Richmond

${ }^{5} \times$ Standard deviation for a sample statistic

$\tau$ Tine factor

$\mathrm{T}_{1} \quad 7: 30-8: 30$ a.m.

I $11: 00$ a. m. $-12: 00$ nocn

$\tau_{3} \quad 12: 15-1: 15 \mathrm{p} . \mathrm{m}$.

$\tau_{4}$ 3:00-4:00 p.:m.

$v$ Calculated speed fron a frequency distribution

$\nabla$ Nean speed

$\nabla_{50} 50$ th percentile (nedian) speed

$V_{85}$ 85th percentile speed

$x$ Variable in frequency distribution, e.g., the speed 


\section{GLOSSARY OF STATISTICAL TERMS}

Population: The entire group of elements under investigation.

Samplo: A number of elements selected from the population.

Random Sample: A sample in which each element of the population has an equal chance of being selected for the sample, independent of any other element selected.

Normal Distribution: A symmetrical frequency distribution of the measured variable. The plotted curve of this distribution is bell-shaped.

Population Parameter: A descriptive characteristic of the population, 0.8., the population mean.

Sample Statistic: A function of sample observations used to estimate the population parameter, 0.g., the sanple (observed) mean.

Variance: A measure of the variabillty or dispersion of the values of the random variable. Defined as the average of the squared deviations from the mean.

Standard Deviation: Square root of the variance. Statistical Hypothesis: A statement deliniting the possible values that a population parameter may have.

Sum of Squares: The sum of the squares of the deviations of a set of means from their grand mean weighted by the number of cases in the set.

Mean Square: Sum of squares divided by the degrees of freedom. 
Interaction: The tendency for the combination of factors to produce a result that is different from the mere sum of their individual contributions.

Mean Speed: The average of individual speeds.

pth Percentile Speed: That speed at and below which p per cent of the drivers travel.

Note: Source from references 8 and 10. 


\section{SIGN CONDITIONS}

$\mathrm{S}_{1}$ One 30" warning sign, "SCHOOL CROSSING"

$\mathrm{S}_{2}$ One 36" warning sign, "SCHOOL CROSSING"

$\mathrm{S}_{3}$ Two 36 " warning signs, "SCHOOL CROSSING"

$\mathrm{S}_{4}$ One 36 " warning sion, "SCHOOL CROSSING," and a "SPEED IIMIT 25 WHEN CHILDREN PRESENT" sign

$\mathrm{S}_{5}$ Two 36 " warning signs, "SCHOOL CROSSING," and a "SPEED IIMIT 25 WHEN CHILDREN PRESENT" SIgn

$S_{6}$ One 36" warning sign, "SCHOOL CROSSING," with a single flashing beacon above

$\mathrm{S}_{7}$ one 36" warning sign, "SCHOOL CROSSING," and a single flashing beacon above a "SPEED LIMIT 25 WHEN CHILDREN PRESENT" sign

$\mathrm{S}_{8}$ Two 36" warning signs, "SCHCOL CROSSING," and a single flashing beacon above a "SPEED IIMIT 25 WHEN CHILDREN PRESENT" sign

$\mathrm{S}_{9}$ Two $30^{\prime \prime}$ warning signs, "SCHOOL CROSSING," and a single flashing beacon above a "SPEED LIMIT 25 WHEN CHILDREN PRESENT" sign

$S_{10}$ One 36" warning sign, "SCHOOL CROSSING," and horizontal alternate flashing beacons above a "SPEED LIMIT 25 WHEN CHILDREN PRESENT" sign

$\mathrm{S}_{11}$ One 36" warning sign, "SCHOOL CROSSING," and vertical alternate flashing beacons with a "SPEED LIMIT 25 WHEN CHILDREN PRESENT" sign (one beacon above and one beacon below the sign)

$\mathrm{S}_{12}$ one 36" warning sign, "SCHOOL CROSSING," and a portable "SCHOOL CHILDEN CROSSING" sign

$\mathrm{S}_{13}$ One 36 " warning sign, "SCHOOL CROSSING," and a portable "SCHOOL CHILDREN CROSSING" sign and a "SPEED LIMIT 25 WHEN CHILDREN PRESENT" sign 
$\mathrm{S}_{14}$ one 36" warning sign, "SCHOOL CROSSING," and a portable "SCHOOL CHILDREN CROSSING" sign and a single flashing beacon above a "SPEED LIMIT 25 WHEN CHILDREN PRESBNT" s1gn 
APPDIDIX B 


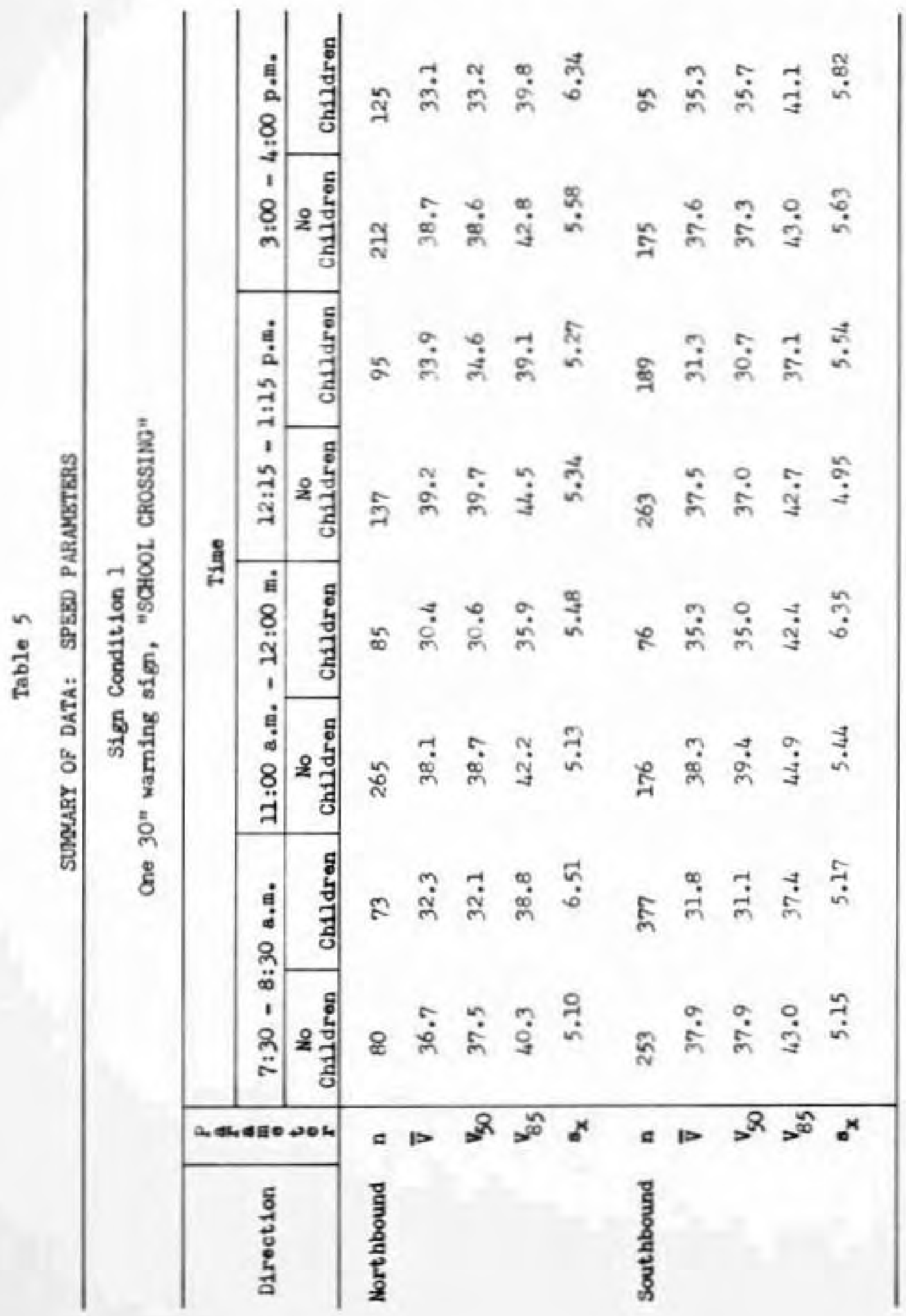




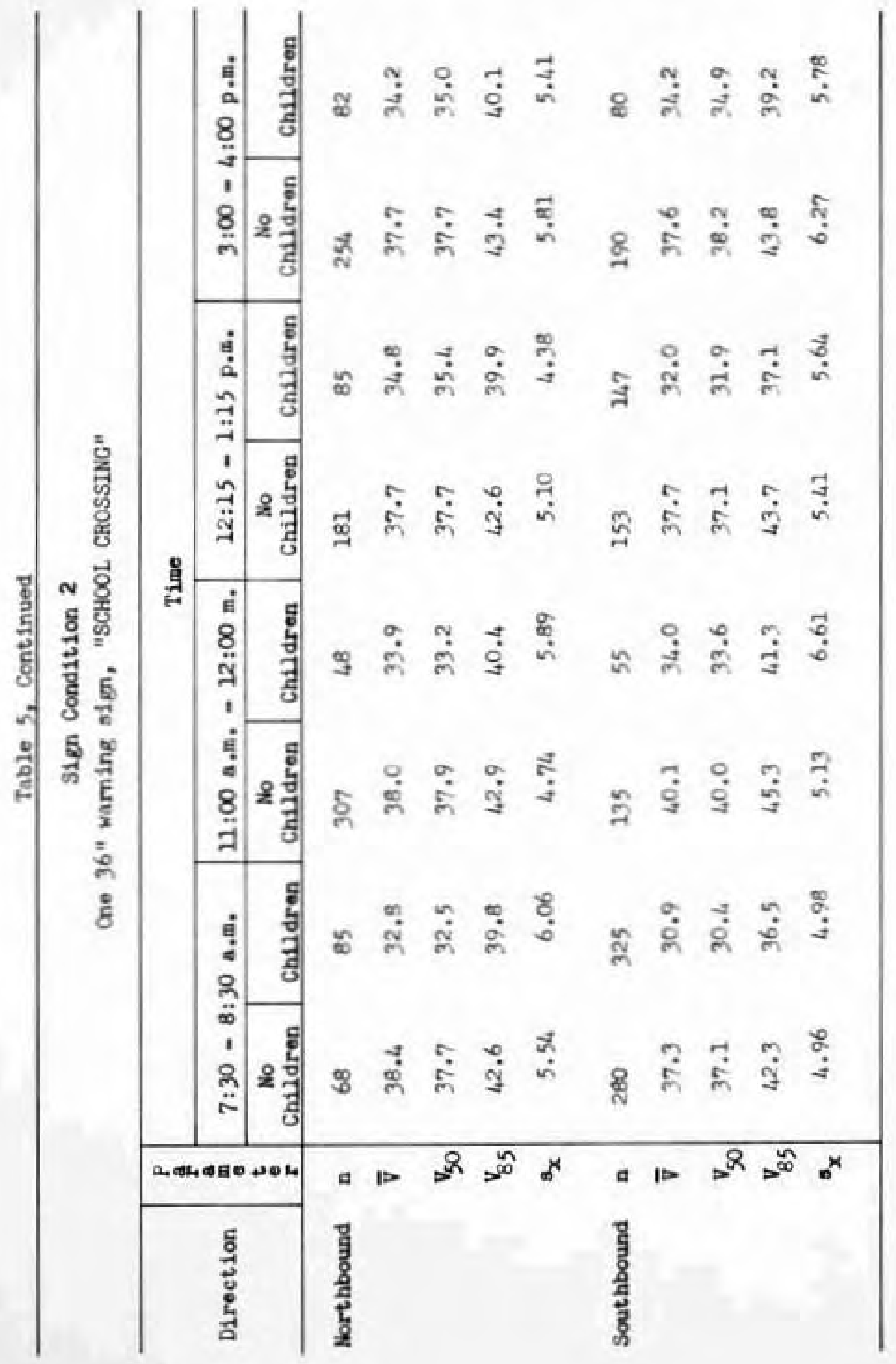




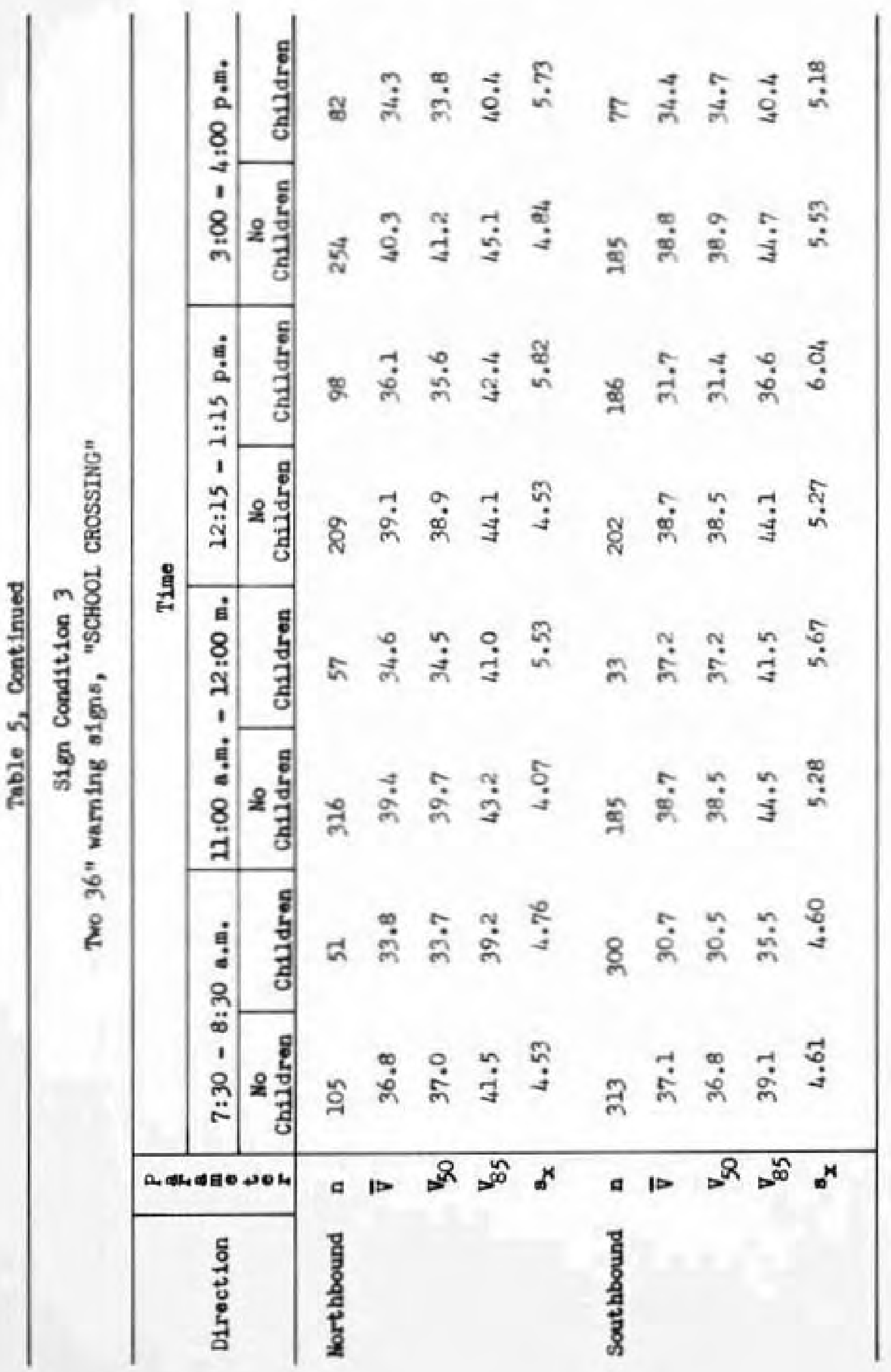




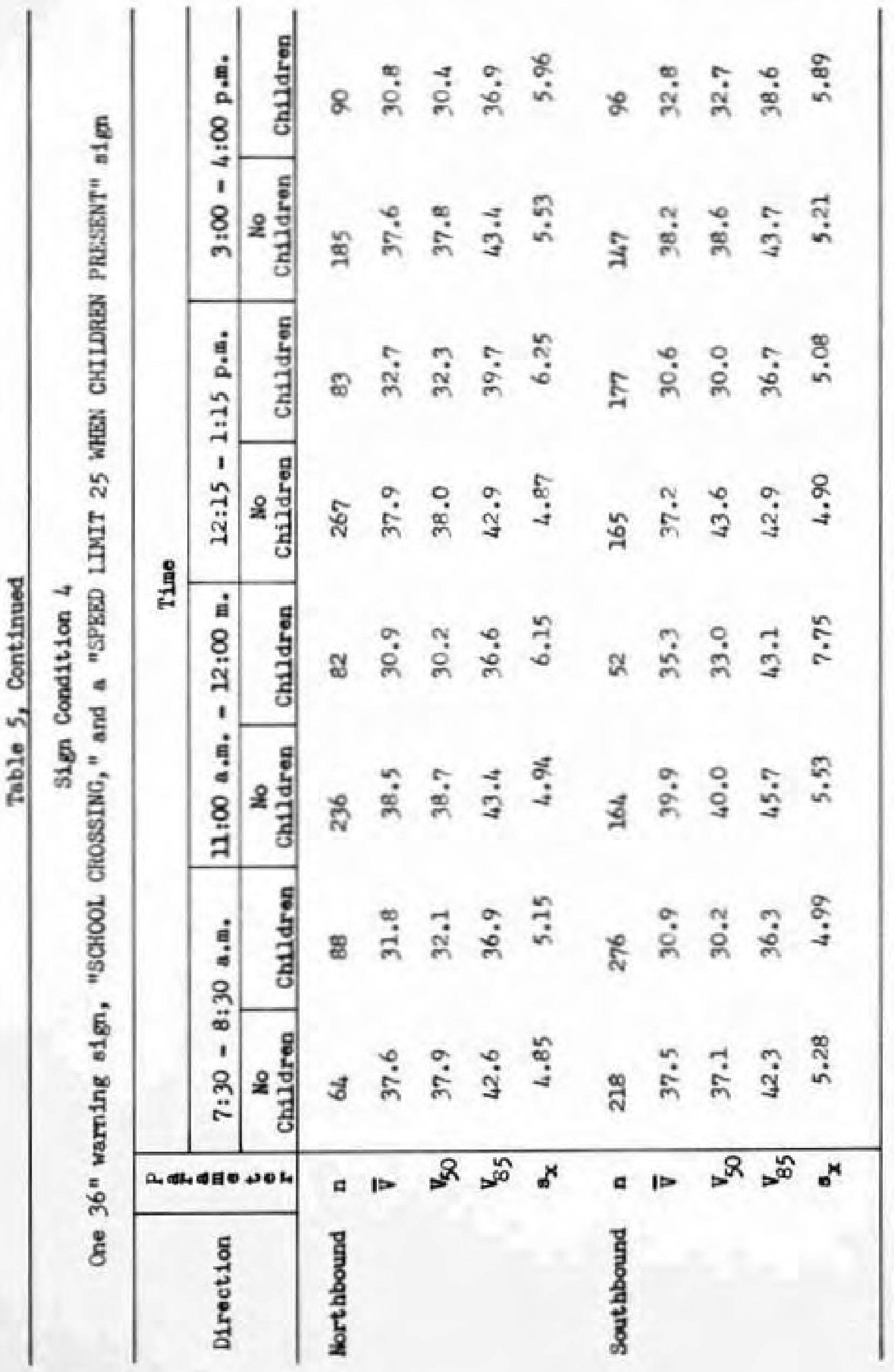




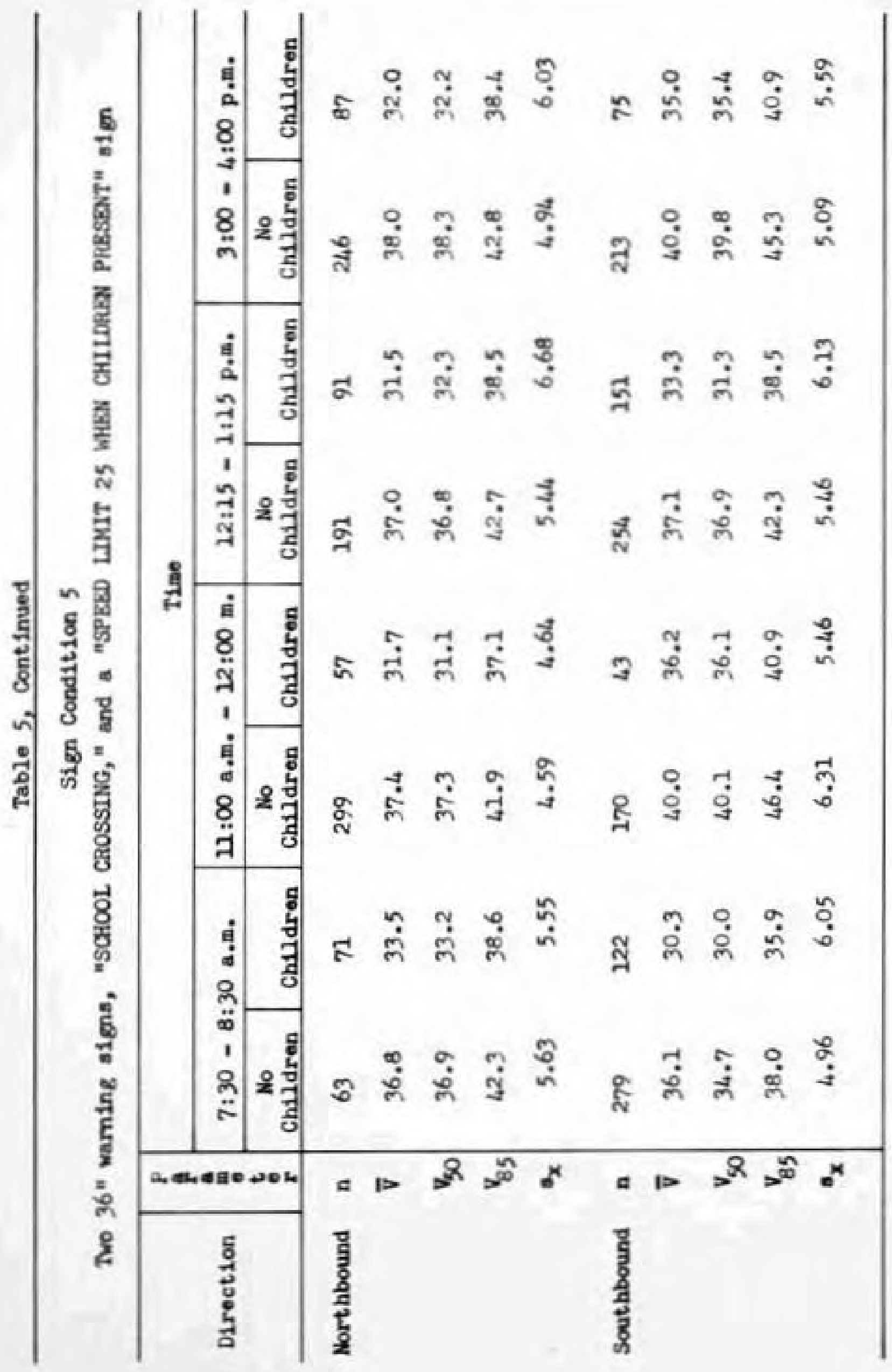




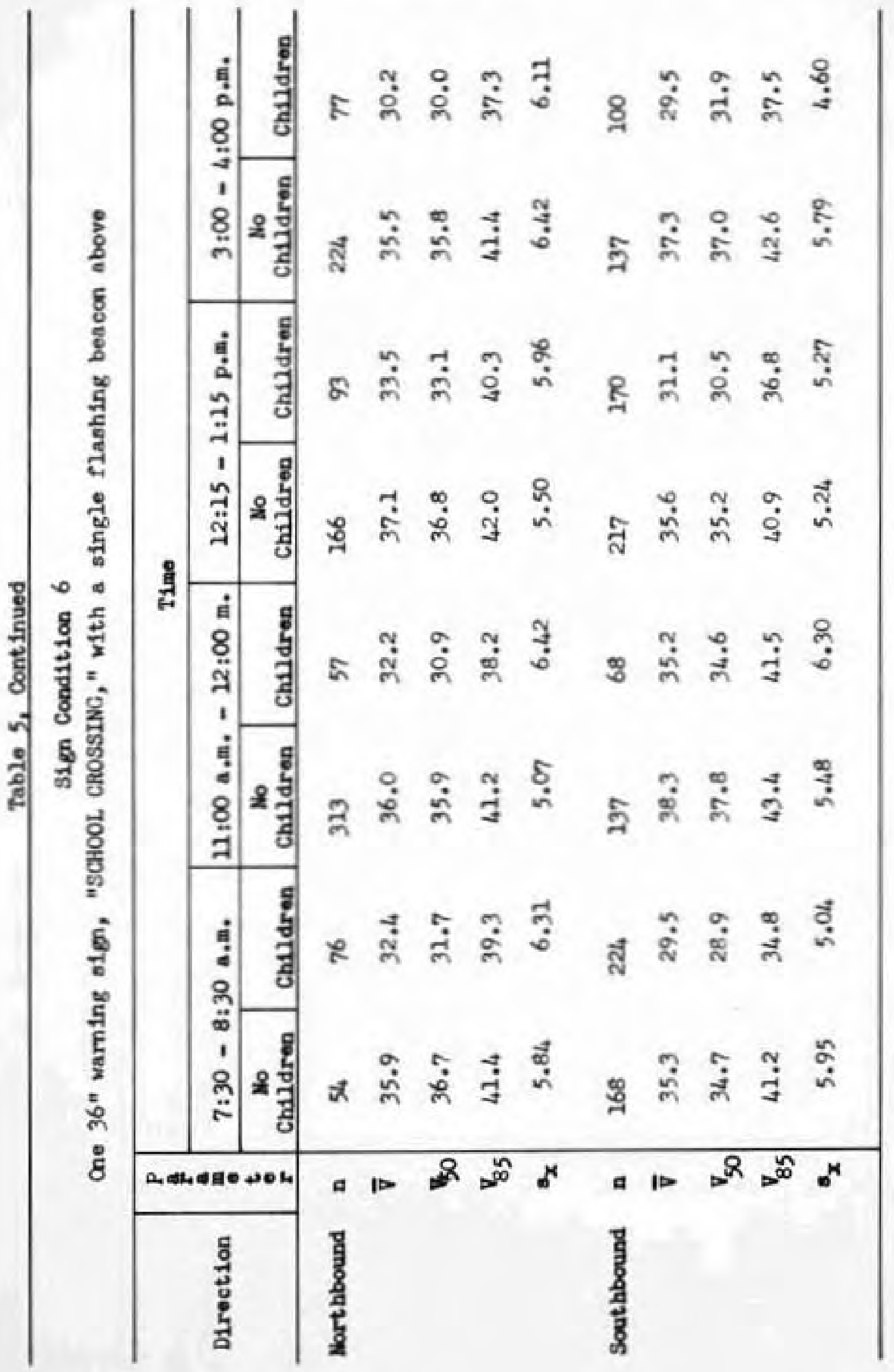




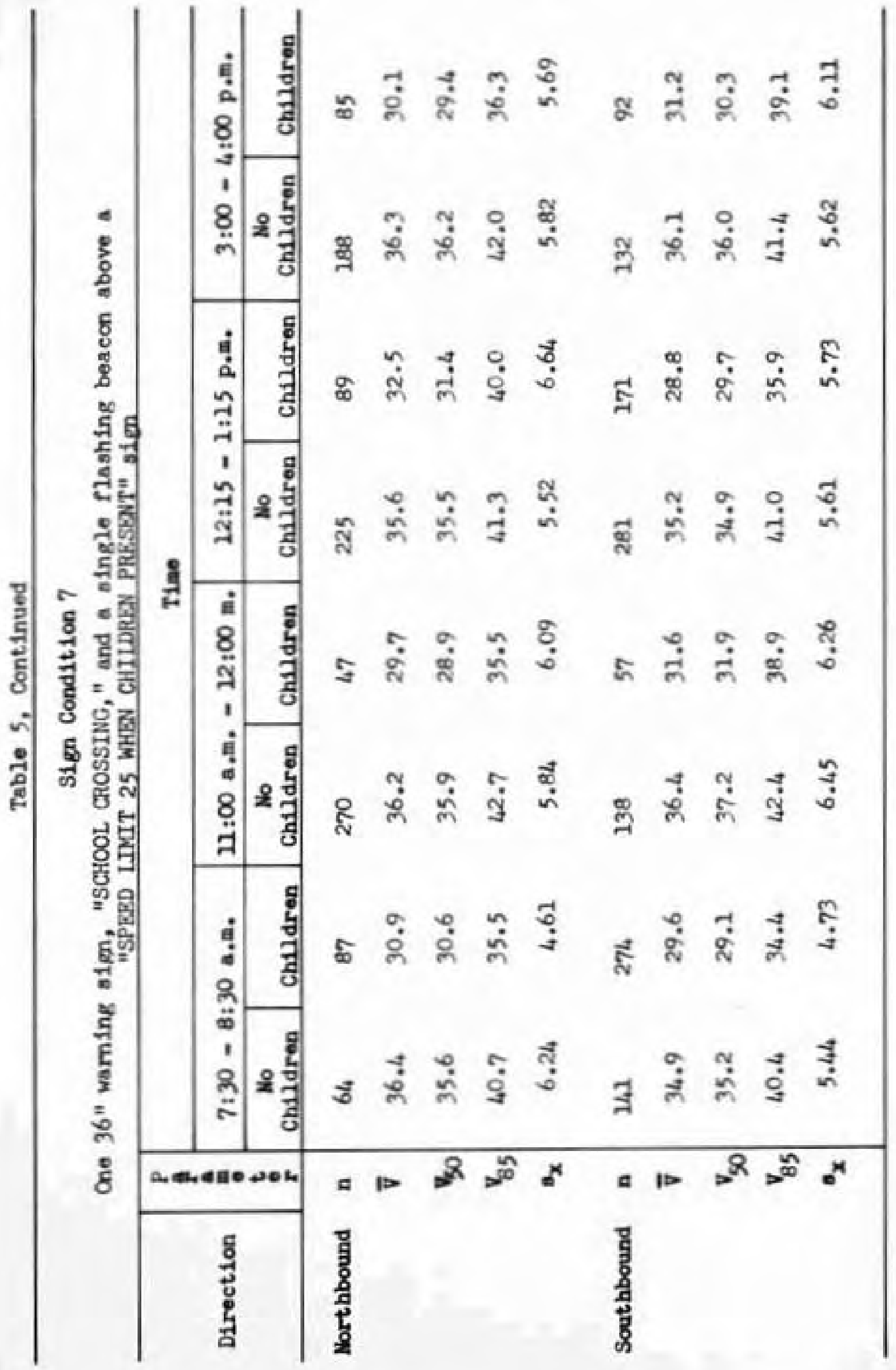




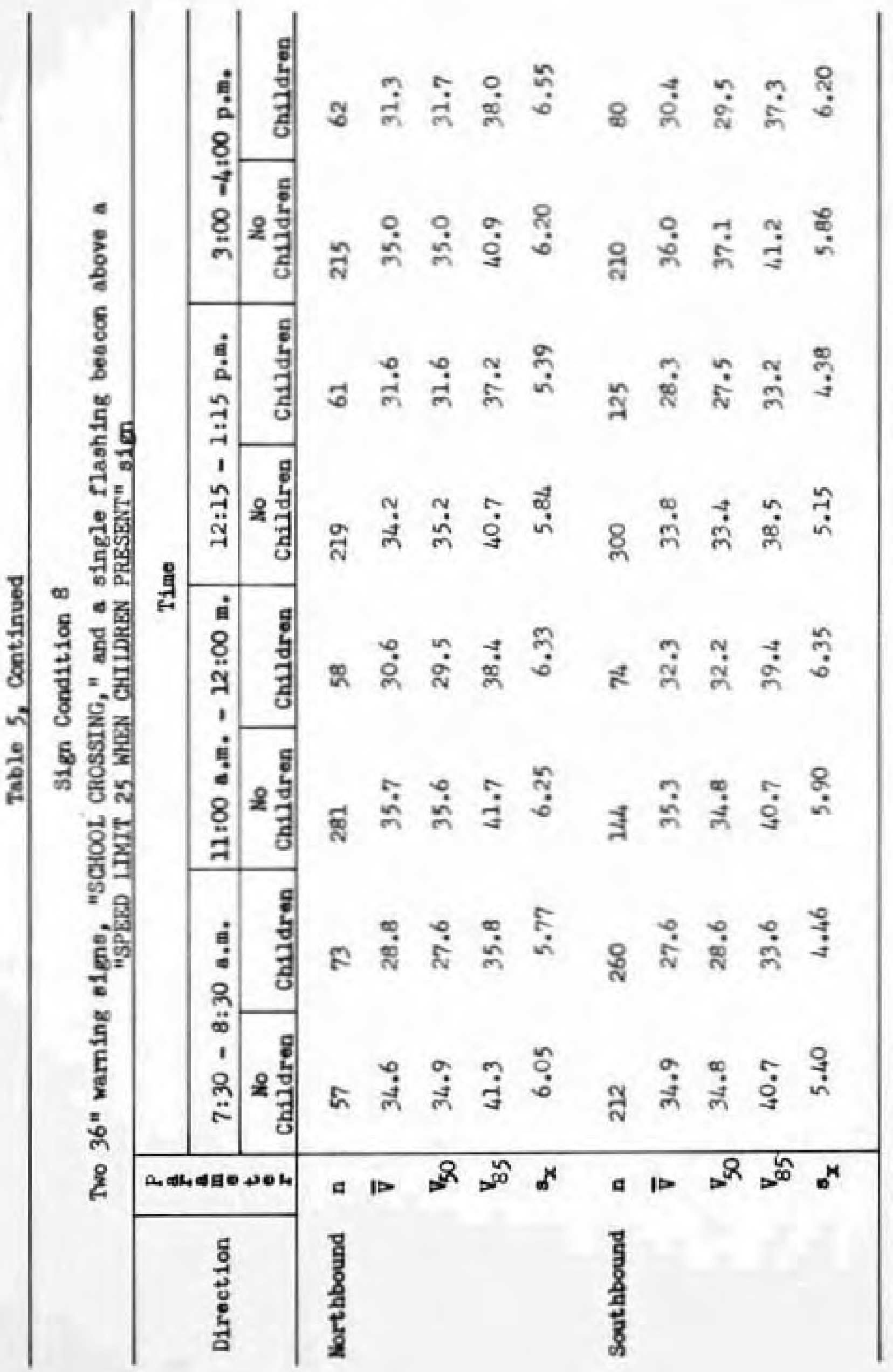




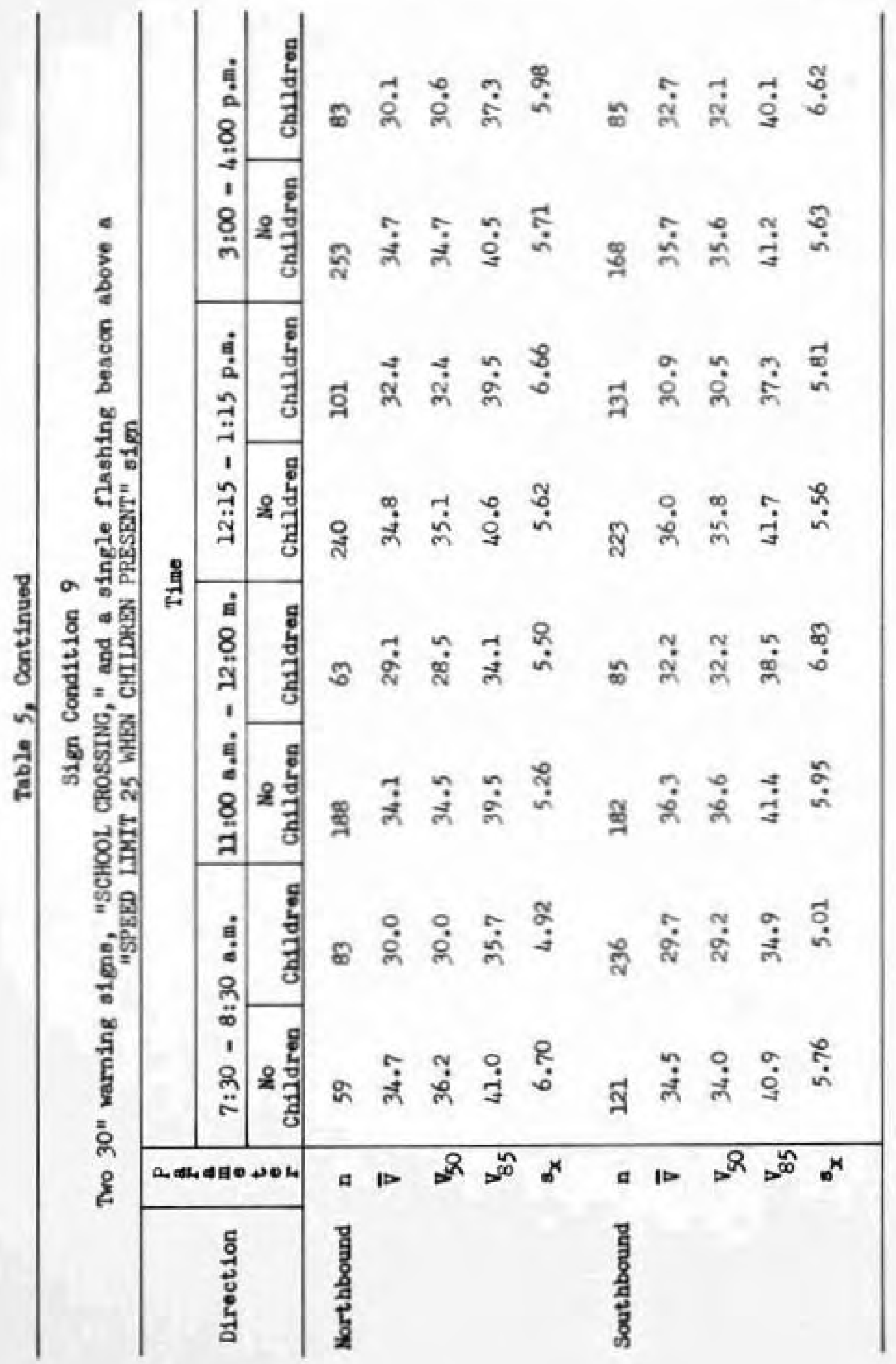




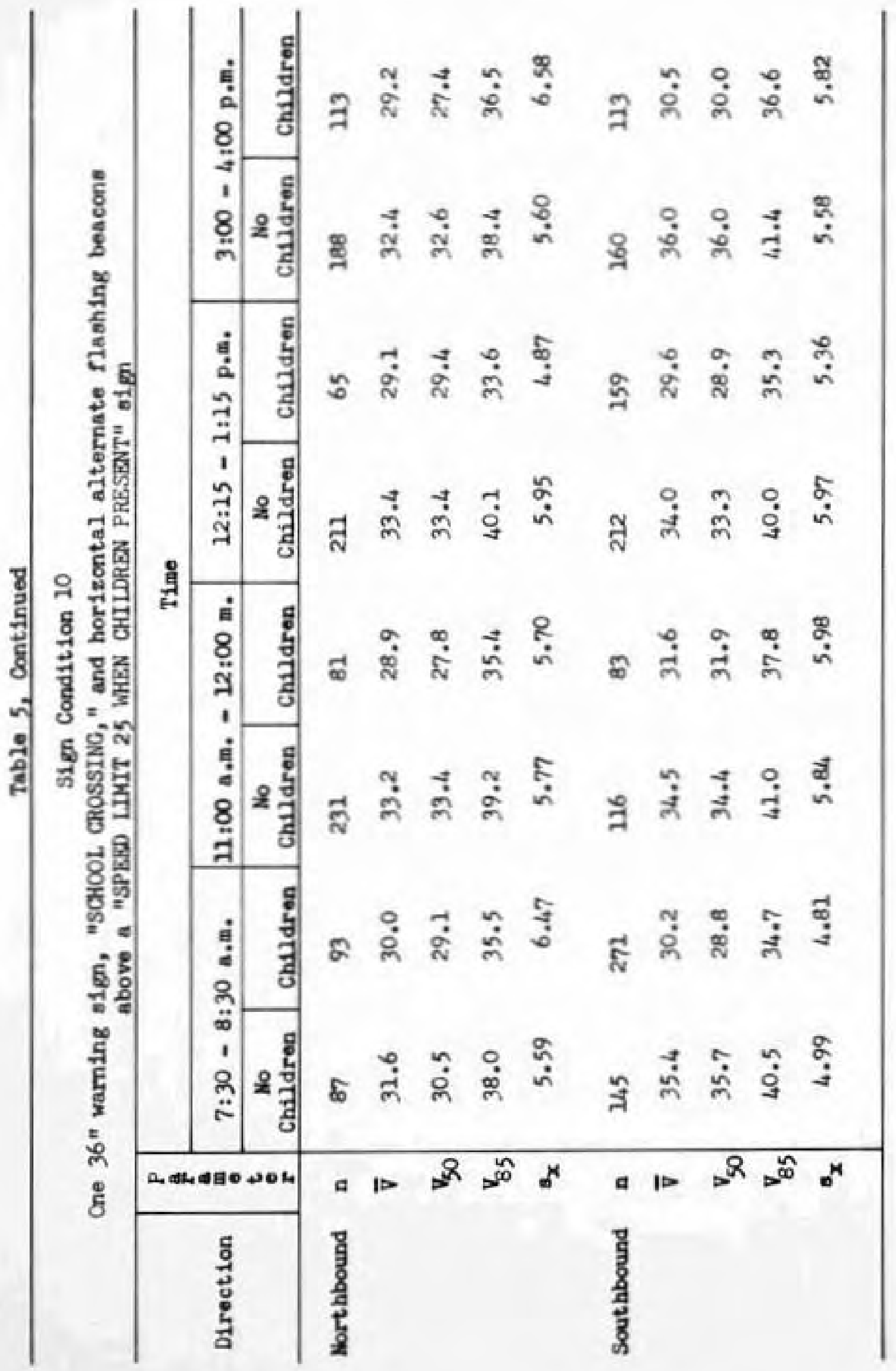




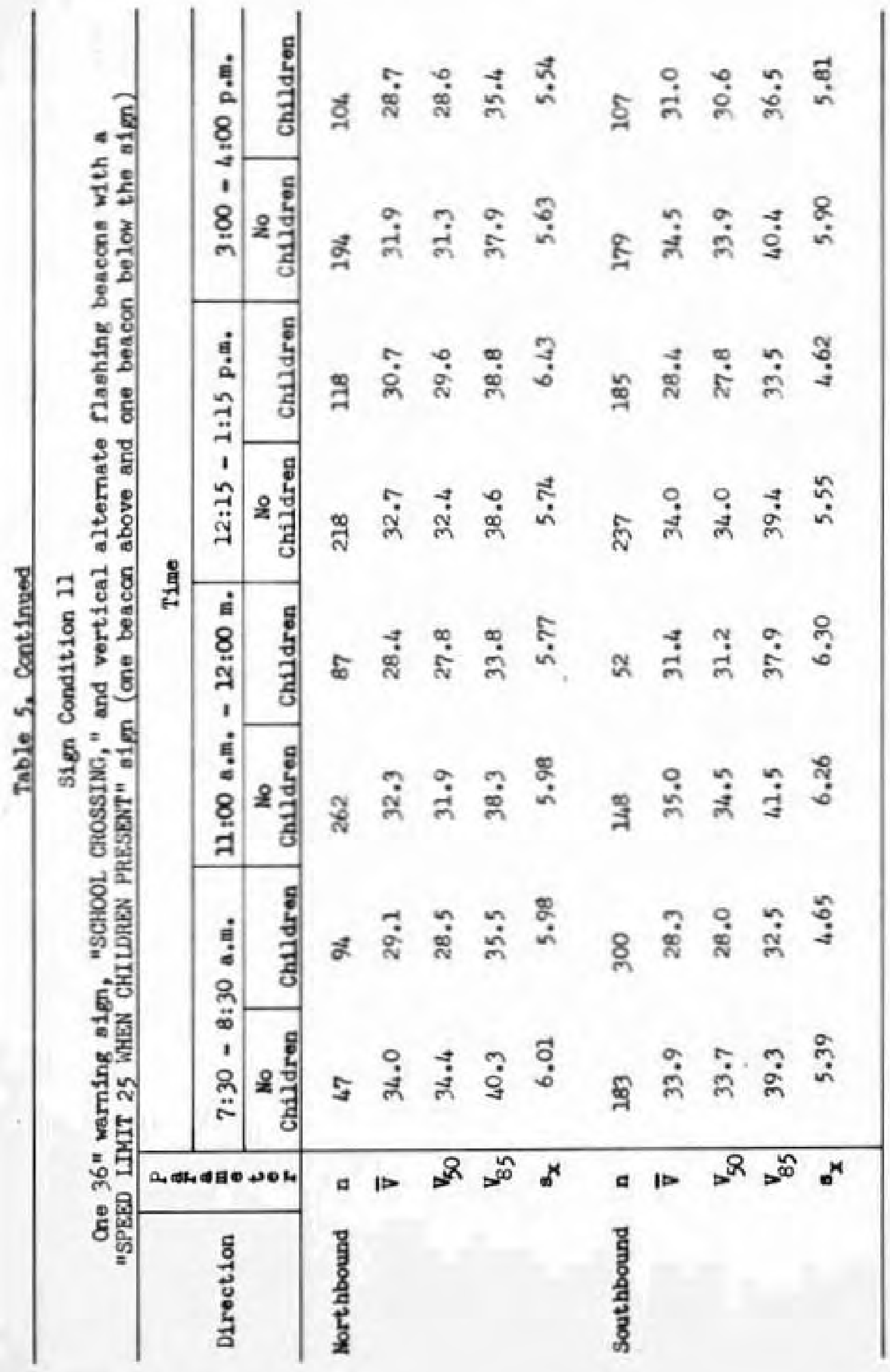




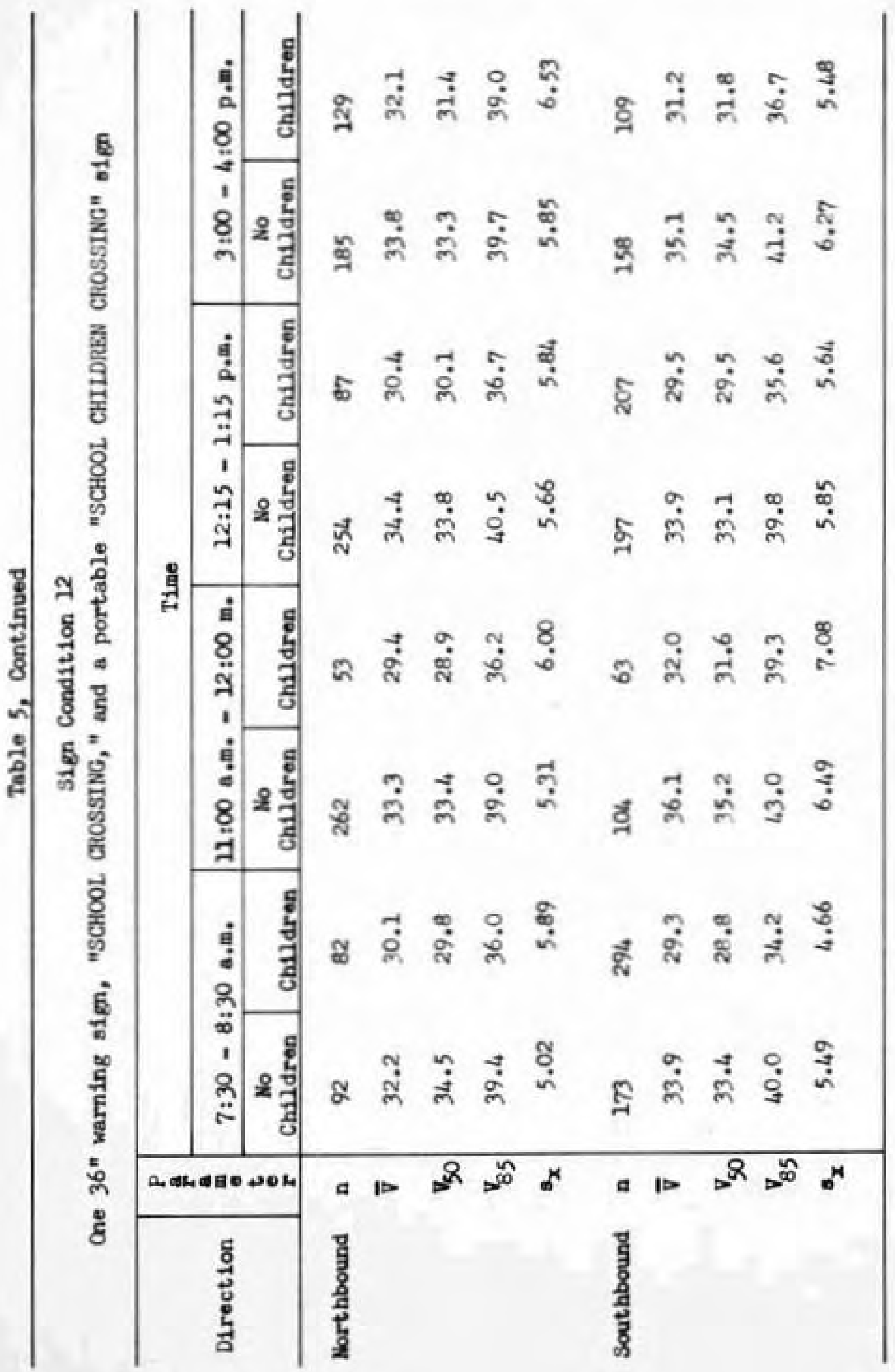




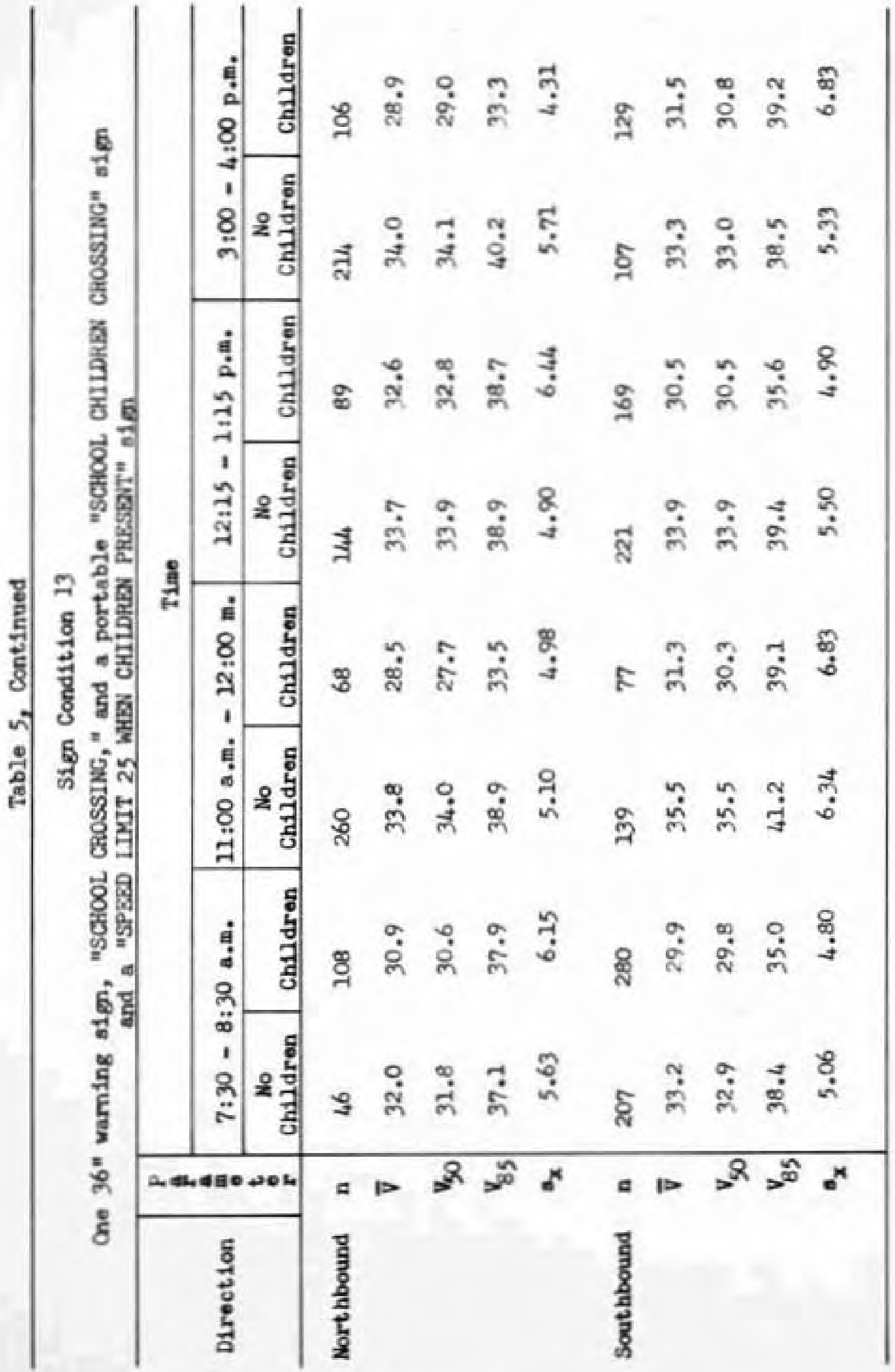




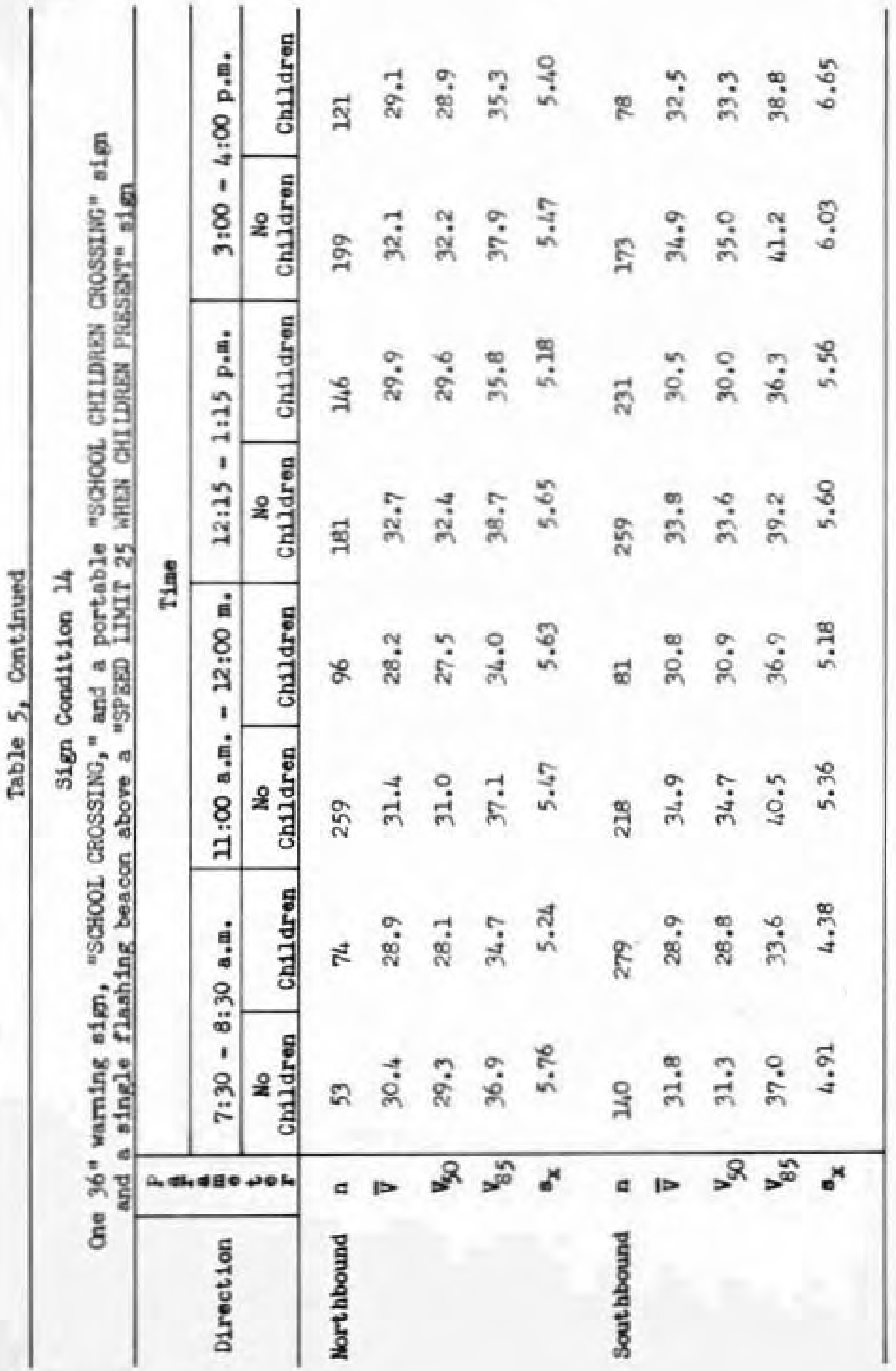


Table 6

SUMMARY OF DATA: MEAN AND 85TH PERCENTILE SPEEDS

Southbound

$7: 30-8: 30$ a.m.

\begin{tabular}{|c|c|c|c|c|}
\hline \multirow{2}{*}{$\begin{array}{c}\text { Sign } \\
\text { Condition }\end{array}$} & \multicolumn{2}{|c|}{ No Children } & \multicolumn{2}{|c|}{ Children } \\
\hline & $\bar{\nabla}$ & $v_{85}$ & $\bar{v}$ & $v_{85}$ \\
\hline 1 & 37.9 & 43.0 & 31.8 & 37.4 \\
\hline 2 & 37.3 & 42.3 & 30.9 & 36.5 \\
\hline 3 & 37.1 & 39.1 & 30.7 & 35.5 \\
\hline 4 & 37.5 & 42.3 & 30.9 & 36.3 \\
\hline 5 & 36.1 & 38.0 & 30.3 & 35.9 \\
\hline 6 & 35.3 & 41.2 & 29.5 & 34.8 \\
\hline 7 & 34.9 & 40.4 & 29.6 & 34.4 \\
\hline 8 & 34.9 & 40.7 & 27.6 & 33.6 \\
\hline 9 & 34.5 & 40.9 & 29.7 & 34.9 \\
\hline 10 & 35.4 & 40.5 & 30.2 & 34.7 \\
\hline 11 & 33.9 & 39.3 & 28.3 & 32.5 \\
\hline 12 & 33.9 & 40.0 & 29.3 & 34.2 \\
\hline 13 & 33.2 & 38.4 & 29.9 & 35.0 \\
\hline 24 & 31.8 & 37.0 & 28.9 & 33.6 \\
\hline
\end{tabular}


Table 6, Continued

Southbound

11:00 a.m. - 12:00 noon

\begin{tabular}{|c|c|c|c|c|c|}
\hline \multirow{2}{*}{\multicolumn{2}{|c|}{$\begin{array}{l}\text { Sign } \\
\text { Condition }\end{array}$}} & \multicolumn{2}{|c|}{ No Chilldren } & \multicolumn{2}{|c|}{ Children } \\
\hline & & $\bar{V}$ & $v_{85}$ & $\bar{V}$ & $v_{85}$ \\
\hline 1 & & 38.3 & 44.9 & 35.3 & 42.4 \\
\hline 2 & - & 40.1 & 45.3 & 34.0 & 41.3 \\
\hline 3 & & 38.7 & 44.5 & 37.2 & 41.5 \\
\hline 4 & & 39.9 & 45.7 & 35.3 & 43.1 \\
\hline 5 & & 40.0 & 46.4 & 36.2 & 40.9 \\
\hline 6 & & 38.3 & 43.4 & 35.2 & 41.5 \\
\hline 7 & & 36.4 & 42.4 & 31.6 & 38.9 \\
\hline 8 & & 35.3 & 40.7 & 32.3 & 39.4 \\
\hline 9 & & 36.3 & 41.4 & 32.2 & 38.5 \\
\hline 10 & & 34.5 & 41.0 & 31.6 & 37.8 \\
\hline 11 & & 35.0 & 41.5 & 31.4 & 37.9 \\
\hline 12 & & 36.1 & 43.0 & 32.0 & 39.3 \\
\hline 13 & & 35.5 & 41.2 & 31.3 & 39.1 \\
\hline 14 & & 34.9 & 40.5 & 30.8 & 36.9 \\
\hline
\end{tabular}


Table 6, Continued

\begin{tabular}{|c|c|c|c|c|}
\hline \multirow{3}{*}{$\begin{array}{l}\text { Sign } \\
\text { Condition }\end{array}$} & \multicolumn{2}{|c|}{$\begin{array}{c}\text { Southbound } \\
12: 15 \text { - } 1: 15 \mathrm{p} . \mathrm{m}\end{array}$} & & \\
\hline & \multicolumn{2}{|c|}{ No Children } & \multicolumn{2}{|c|}{ Children } \\
\hline & $\bar{v}$ & $v_{85}$ & $\bar{v}$ & $v_{85}$ \\
\hline 1 & 37.5 & 42.7 & 31.3 & 37.1 \\
\hline 2 & 37.7 & 43.7 & 32.0 & 37.1 \\
\hline 3 & 38.7 & 44.1 & 31.7 & 36.6 \\
\hline 4 & 37.2 & 42.9 & 30.6 & 36.7 \\
\hline 5 & 37.1 & 42.3 & 33.3 & 38.5 \\
\hline 6 & 35.6 & 40.9 & 31.1 & 36.8 \\
\hline 7 & 35.2 & 41.0 & 28.8 & 35.9 \\
\hline 8 & 33.8 & 38.5 & 28.3 & 33.2 \\
\hline 9 & 36.0 & 41.7 & 30.9 & 37.3 \\
\hline 10 & 34.0 & 40.0 & 29.6 & 35.3 \\
\hline 11 & 34.0 & 39.4 & 28.4 & 33.5 \\
\hline 12 & 33.9 & 39.8 & 29.5 & 35.6 \\
\hline 13 & 33.9 & 39.4 & 30.5 & 35.6 \\
\hline 14 & 33.8 & 39.2 & 30.5 & 36.3 \\
\hline
\end{tabular}


Table 6, Continued

Southbound

3:00 - 4:00 p.m.

\begin{tabular}{|c|c|c|c|c|}
\hline \multirow{2}{*}{$\begin{array}{c}\text { Sign } \\
\text { Condition }\end{array}$} & \multicolumn{2}{|c|}{ No Children } & \multicolumn{2}{|c|}{ Children } \\
\hline & $\bar{v}$ & $V_{85}$ & $\bar{V}$ & $v_{85}$ \\
\hline 1 & 37.6 & 43.0 & 35.3 & 41.1 \\
\hline 2 & 37.6 & 43.8 & 34.2 & 39.2 \\
\hline 3 & 38.8 & $44 \cdot 7$ & 34.4 & 40.4 \\
\hline 4 & 38.2 & 43.7 & 32.8 & 38.6 \\
\hline 5 & 40.0 & 45.3 & 35.0 & 40.9 \\
\hline 6 & 37.3 & 42.6 & 29.5 & 37.5 \\
\hline 7 & 36.1 & 41.4 & 31.2 & 39.1 \\
\hline 8 & 36.0 & 41.2 & 30.4 & $37 \cdot 3$ \\
\hline 9 & 35.7 & 41.2 & 32.7 & 40.1 \\
\hline 10 & 36.0 & 41.4 & 30.5 & 36.6 \\
\hline 11 & 34.5 & 40.4 & 31.0 & 36.5 \\
\hline 12 & 35.1 & 41.2 & 31.2 & 36.7 \\
\hline 13 & 33.3 & 38.5 & 31.5 & 39.2 \\
\hline 14 & 34.9 & 41.2 & 32.5 & 38.8 \\
\hline
\end{tabular}


Table 6, Continued

Northbound

$7: 30-8: 30$ a.m.

\begin{tabular}{|c|c|c|c|c|}
\hline \multirow{2}{*}{$\begin{array}{c}\text { Sign } \\
\text { Condition }\end{array}$} & \multicolumn{2}{|c|}{ No Chilldren } & \multicolumn{2}{|c|}{ Children } \\
\hline & $\bar{v}$ & $V_{85}$ & $\bar{V}$ & $v_{85}$ \\
\hline 1 & 36.7 & 40.3 & 32.3 & 38.8 \\
\hline 2 & 38.4 & 42.6 & 32.8 & 39.8 \\
\hline 3 & 36.8 & 41.5 & 33.8 & 39.2 \\
\hline 4 & 37.6 & 42.6 & 31.8 & 36.9 \\
\hline 5 & 36.8 & 42.3 & 33.5 & 38.6 \\
\hline 6 & 35.9 & 41.4 & 32.4 & 39.3 \\
\hline 7 & 36.4 & 40.7 & 30.9 & 35.5 \\
\hline 8 & 34.6 & 41.3 & 28.8 & 35.8 \\
\hline 9 & $34 \cdot 7$ & 41.0 & 30.0 & 35.7 \\
\hline 10 & 31.6 & 38.0 & 30.0 & 35.5 \\
\hline 11 & 34.0 & 40.3 & 39.1 & 35.5 \\
\hline 12 & 32.2 & 39.4 & 30.1 & 36.0 \\
\hline 13 & 32.0 & 37.1 & 30.9 & 37.9 \\
\hline 14 & 30.4 & 36.9 & 28.9 & 34.7 \\
\hline
\end{tabular}


Table 6, Continued

\begin{tabular}{|c|c|c|c|c|}
\hline \multirow{3}{*}{$\begin{array}{l}\text { Sign } \\
\text { Condition }\end{array}$} & \multicolumn{4}{|c|}{$\begin{array}{l}\text { Northbound } \\
1: \infty \text { a.m. - 12:00 noon }\end{array}$} \\
\hline & \multicolumn{2}{|c|}{ No Chilldren } & \multicolumn{2}{|c|}{ Children } \\
\hline & $\overline{\mathrm{v}}$ & $\nabla_{85}$ & $\overline{\mathrm{v}}$ & $v_{85}$ \\
\hline 1 & 38.1 & 42.2 & 30.4 & 35.9 \\
\hline 2 & 38.0 & 42.9 & 33.9 & 40.4 \\
\hline 3 & 39.4 & 43.2 & 34.6 & 41.0 \\
\hline 4 & 38.5 & 43.4 & 30.9 & 36.6 \\
\hline 5 & 37.4 & 41.9 & 31.7 & 37.1 \\
\hline 6 & 36.0 & 41.2 & 32.2 & 38.2 \\
\hline 7 & 36.2 & 42.7 & 29.7 & 35.5 \\
\hline 8 & 35.7 & 41.7 & 30.6 & 38.4 \\
\hline 9 & 34.1 & 39.5 & 29.1 & 34.1 \\
\hline 10 & 33.2 & 39.2 & 28.9 & 35.4 \\
\hline 11 & 32.3 & 38.3 & 28.4 & 33.8 \\
\hline 12 & 33.3 & 39.0 & 29.4 & 36.2 \\
\hline 13 & 33.8 & 38.9 & 28.5 & 33.5 \\
\hline 14 & 31.4 & 37.1 & 28.2 & 34.0 \\
\hline
\end{tabular}


Table 6, Continued

Northbound

12:15 - 1:15 p.m.

\begin{tabular}{|c|c|c|c|c|}
\hline \multirow{2}{*}{$\begin{array}{l}\text { Sign } \\
\text { Condition }\end{array}$} & \multicolumn{2}{|c|}{ No Children } & \multicolumn{2}{|c|}{ Children } \\
\hline & $\overline{\mathrm{V}}$ & $v_{85}$ & $\bar{v}$ & $v_{85}$ \\
\hline 1 & 39.2 & 44.5 & 33.9 & 39.1 \\
\hline 2 & 37.7 & 42.6 & 34.8 & 39.9 \\
\hline 3 & 39.1 & 44.1 & 36.1 & 42.4 \\
\hline 4 & 37.9 & 42.9 & 32.7 & 39.7 \\
\hline 5 & 37.0 & 42.7 & 31.5 & 38.5 \\
\hline 6 & 37.1 & 42.0 & 33.5 & 40.3 \\
\hline 7 & 35.6 & 41.3 & 32.5 & 40.0 \\
\hline 8 & 34.2 & 40.7 & 31.6 & 37.2 \\
\hline 9 & 34.8 & 40.6 & 32.4 & 39.5 \\
\hline 10 & 33.4 & 40.1 & 29.1 & 33.6 \\
\hline 11 & 32.7 & 38.6 & 30.7 & 38.8 \\
\hline 12 & 34.4 & 40.5 & 30.4 & 36.7 \\
\hline 13 & 33.7 & 38.9 & 32.6 & 38.7 \\
\hline 14 & 32.7 & 38.7 & 29.9 & 35.8 \\
\hline
\end{tabular}


Table 6, Continued

Northbound

3:00 - 4:00 p.m.

\begin{tabular}{|c|c|c|c|c|}
\hline \multirow{2}{*}{$\begin{array}{l}\text { Sign } \\
\text { Condition }\end{array}$} & \multicolumn{2}{|c|}{ No Chilldren } & \multicolumn{2}{|c|}{ Children } \\
\hline & $\overline{\mathrm{V}}$ & $v_{85}$ & $\bar{V}$ & $v_{85}$ \\
\hline 1 & 38.7 & 42.8 & 33.1 & 39.8 \\
\hline 2 & $37 \cdot 7$ & 43.4 & 34.2 & 40.1 \\
\hline 3 & 40.3 & 45.1 & 34.3 & 40.4 \\
\hline 4 & 37.6 & 43.4 & 30.8 & 36.9 \\
\hline 5 & 38.0 & 42.8 & 32.0 & 38.4 \\
\hline 6 & 35.5 & 41.4 & 30.2 & $37 \cdot 3$ \\
\hline 7 & 36.3 & 42.0 & 30.1 & 36.3 \\
\hline 8 & 35.0 & 40.9 & 31.3 & 38.0 \\
\hline 9 & 34.7 & 40.5 & 30.1 & $37 \cdot 3$ \\
\hline 10 & 32.4 & 38.4 & 29.2 & 36.5 \\
\hline 11 & 31.9 & 37.9 & 28.7 & 35.4 \\
\hline 12 & 33.8 & 39.7 & 32.1 & 39.0 \\
\hline 13 & 34.0 & 40.2 & 28.9 & 33.3 \\
\hline 14 & 32.1 & 37.9 & 29.1 & 35.3 \\
\hline
\end{tabular}




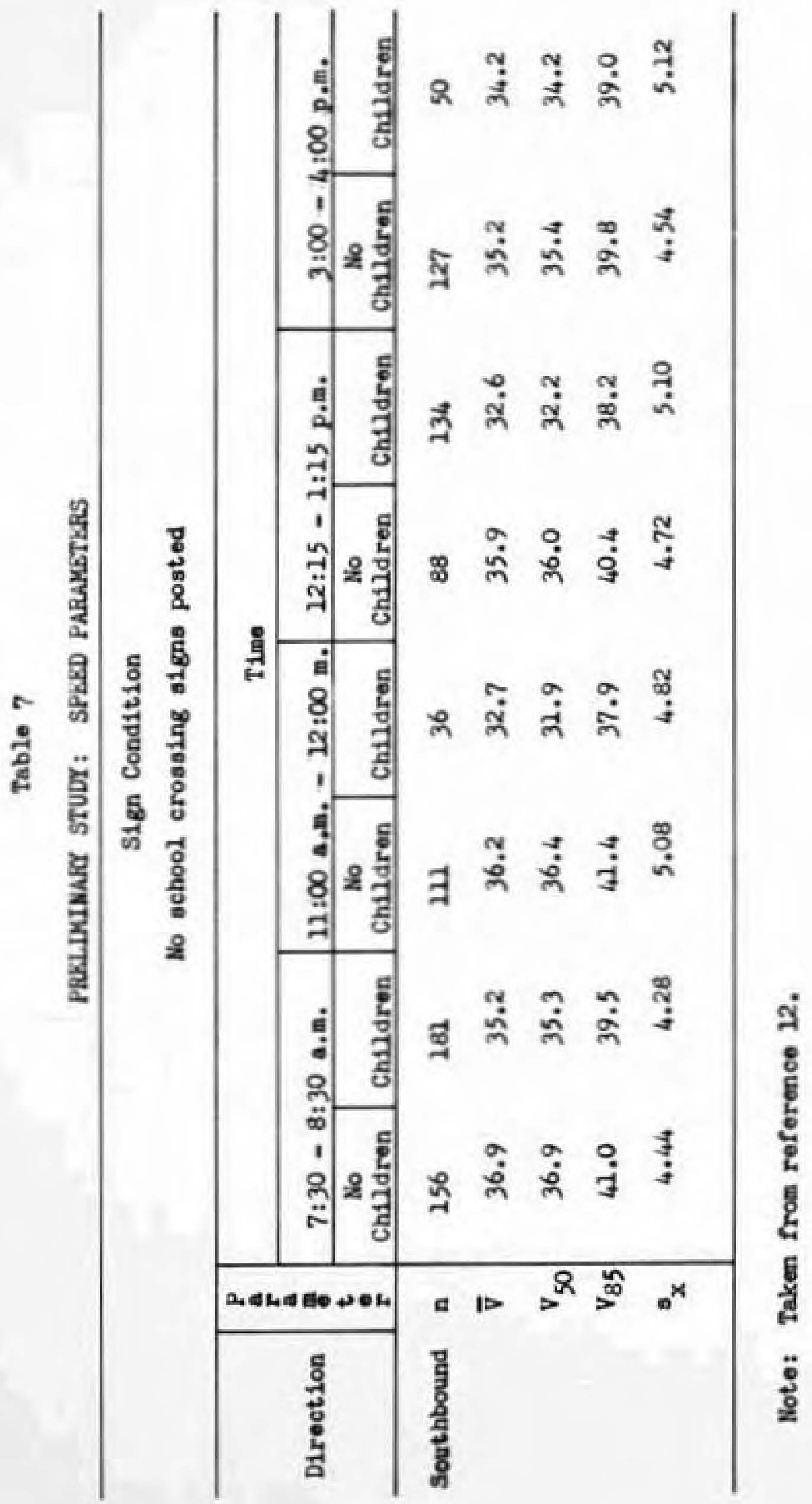


Table 8

SUMARY OF DATA: TRAFFIC DELAY RBSULTING FROM PEDESTRIAN-ACTUATED SIGNALS Total Location Tine Average Number of Bconomic Average Travel Stops per Cost in Volume Tine* Vehicle Cents per (sec.) Vehicle

B1.

$\begin{array}{lll}2: 00-3: 00 \mathrm{p} \cdot \mathrm{m} . & 390 & 56.4 \\ 3: 00-3: 15 \mathrm{p} \cdot \mathrm{m} . & 124 & 57 . \\ 3: 15-3: 30 \mathrm{p} \cdot \mathrm{m} . & 134.5 & 59.5 \\ 3: 30-3: 45 \mathrm{p} \cdot \mathrm{m} . & 176 & 55.9 \\ 3: 45-4: 00 \mathrm{p} \cdot \mathrm{m} . & 128 & 54.6\end{array}$

36.4

B2

$$
\begin{array}{r}
2: 30-3: 00 \mathrm{p} \cdot \mathrm{m} . \\
\text { and } \\
4: 00-4: 30 \mathrm{p} \cdot \mathrm{m} . \\
3: 00-3: 15 \mathrm{p} \cdot \mathrm{m} . \\
3: 15-3: 30 \mathrm{p} \cdot \mathbf{m} . \\
3: 30-3: 45 \mathrm{p} \cdot \mathrm{m} .
\end{array}
$$$$
1,741
$$$$
72.2
$$$$
400
$$$$
80.3
$$$$
0.036
$$$$
0.228
$$$$
378.5
$$$$
92.4
$$$$
0.365
$$$$
0.770
$$

437

81.7

0.166

0.519

$$
\text { hverage }=0.500
$$

-Based on a distance of 2,165 feet for Iocation Bl and 2,415 feet for Location B2. 


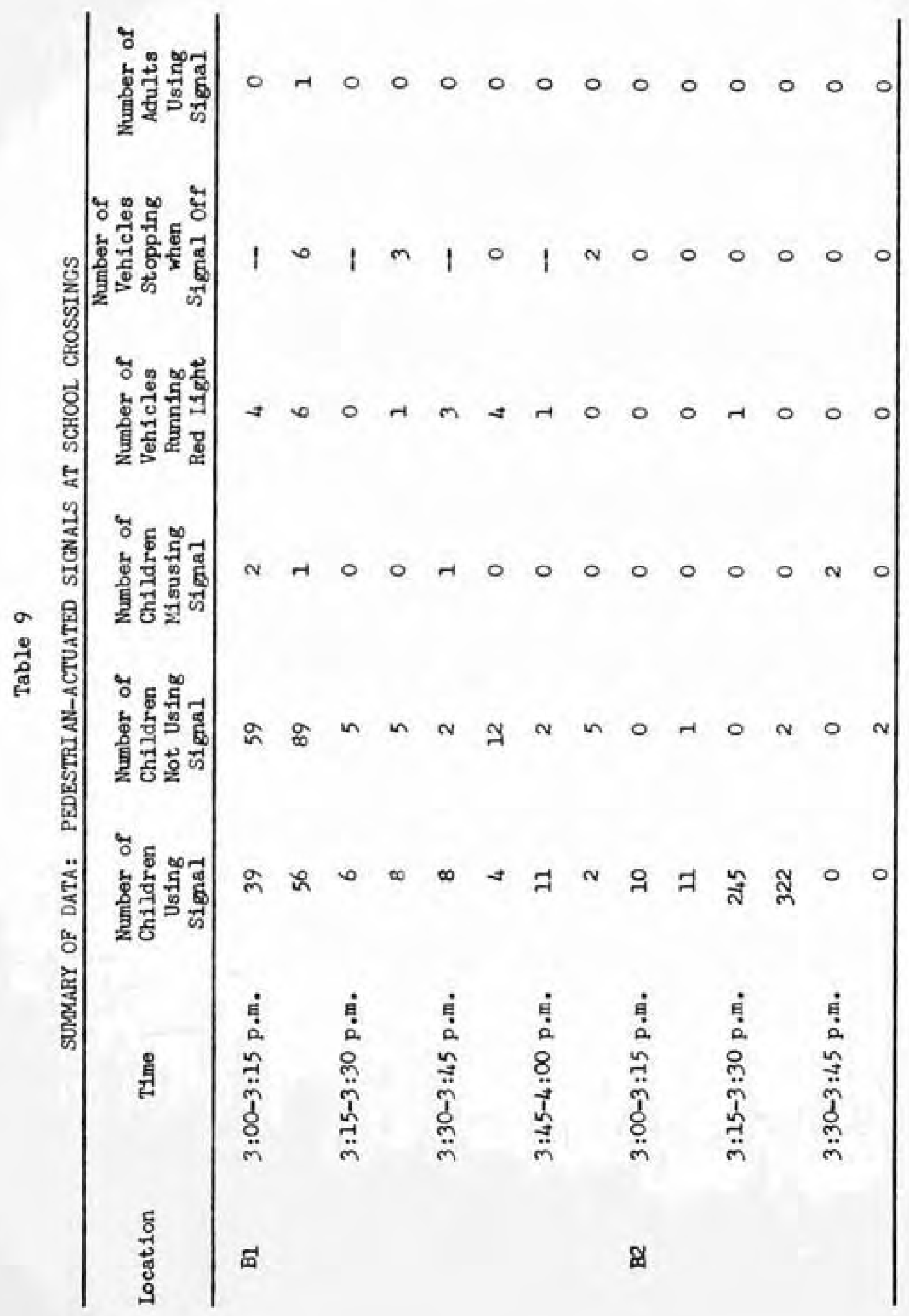




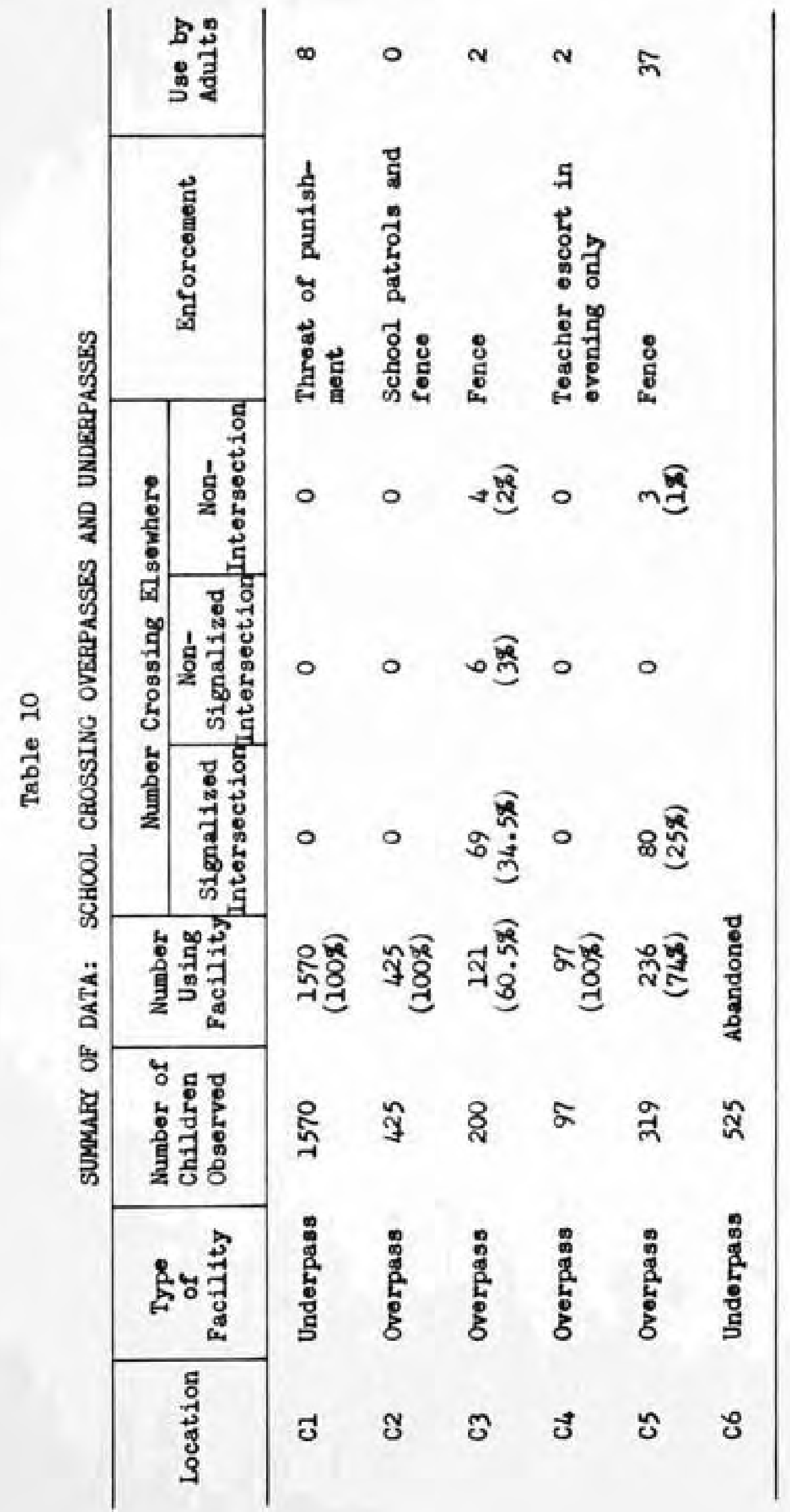




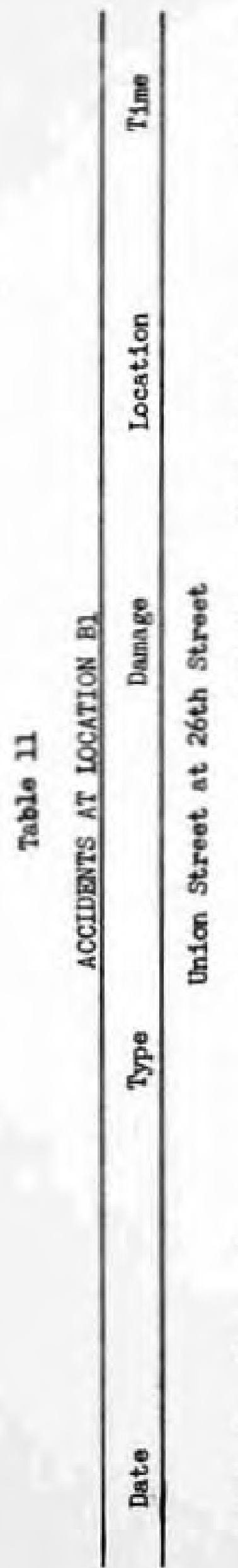

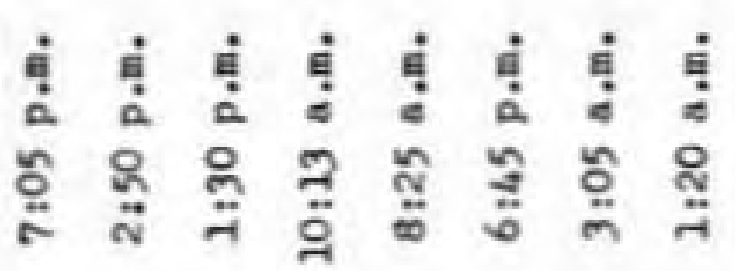

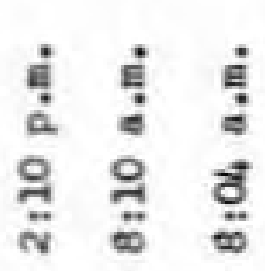

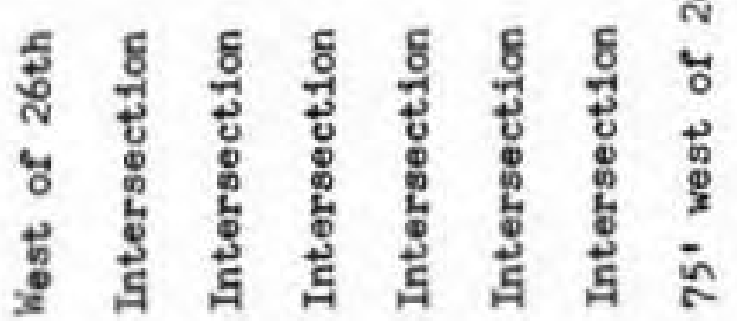

돈

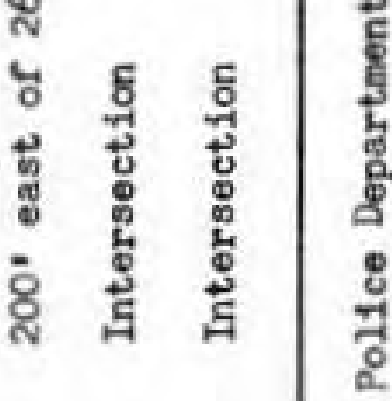

88 8

용

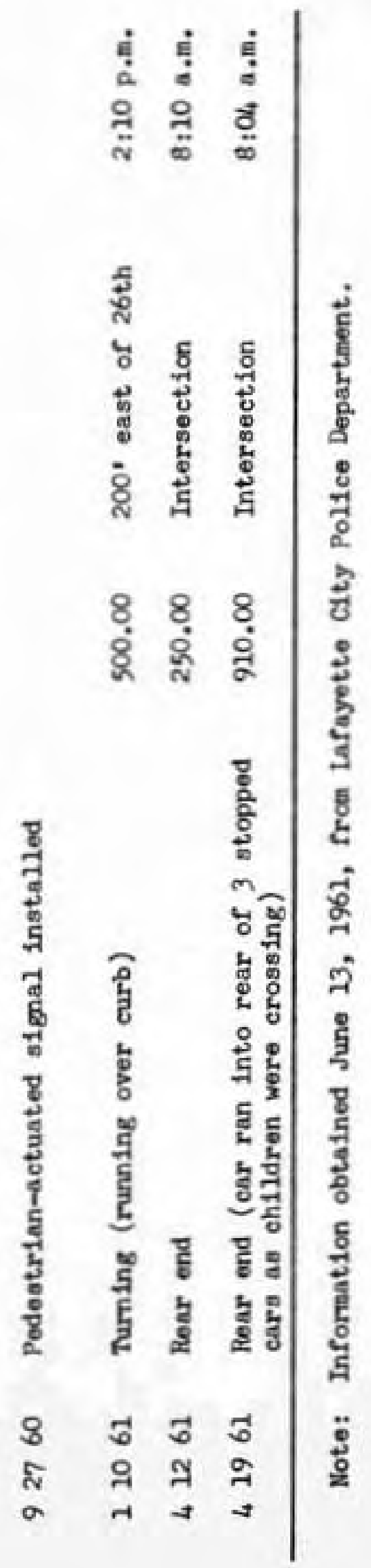




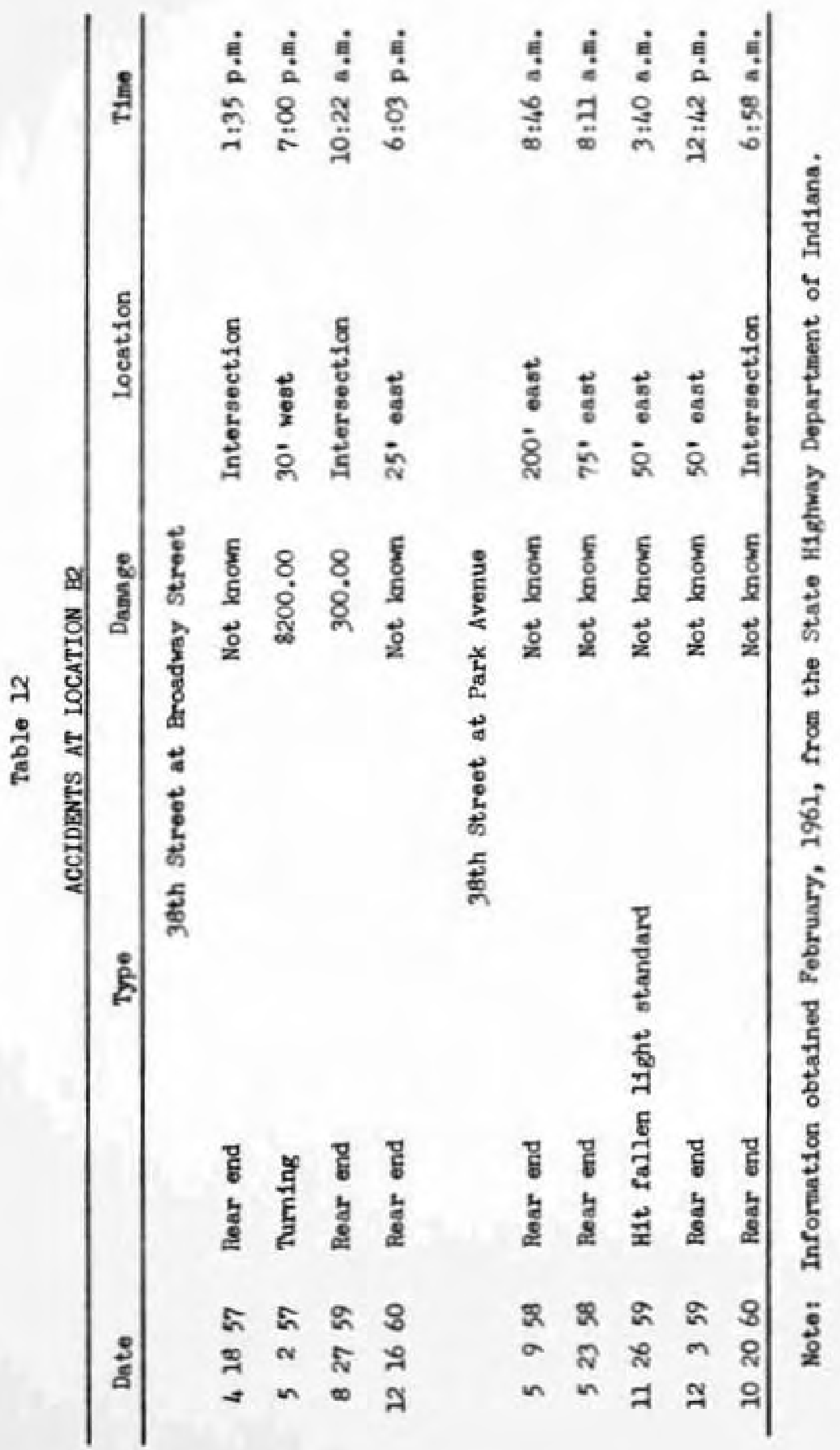





\section{ILUSTRATIVE EXAMPLES}

In order to understand the method used in the statistical analysis, parts of the method will be illustrated by examples.

Since the number of replications per cell were unequal, the summation of the sum of squares within each individual cell had to be divided by the average sample size or harmonic mean (5) to obtain the total sum of squares within all cells.

$$
s_{\mathrm{k}}=\frac{\sum_{\mathrm{k}} s_{\mathrm{g}}}{\overline{\mathrm{n}}}=\frac{1,038 \cdot 331 \cdot 8}{114.106}=9,099 \cdot 712
$$

where $\overline{\mathrm{n}}=$ harmonic mean of all the $\mathrm{n}_{1}$ 's within the cells.

$$
\bar{n}=\frac{1}{\frac{1}{k} \sum_{k} \frac{1}{n_{1}}}=\frac{1}{\frac{1}{224}[1.963]}=124.106
$$

Since the 85th percentile speed was used for analysis instead of the mean speed, another correction factor (16) had to be applied. The error mean square was calculated as it would have been for mean speeds and then multiplied by the correction factor to obtain the error mean square for 85th percentile speeds,

$$
\text { MSe }=K_{\mathrm{p}}^{2} \frac{S S_{k}}{d . f_{.}}=2.347\left[\frac{9.099 .712}{33,980}\right]=0.6285
$$

where d.f. $=\sum_{k}(g-1)=$ sum of degrees of freedom for each cell.

Correction factor, $K_{p},=\frac{\sqrt{p(1-p)}}{p(\zeta)}$

$p=0.85=$ the percentile in decimal form

$F(\xi)=0.2331$ a ordinate on a normal curve below which the area is equal to $p$

$K_{p}=1.532=$ correction factor for the standard deviation

$k_{p}^{2}=2.347=$ correction factor for the variance and error mean square 
The error mean square was compared with the mean squares of the various factors and interactions in the F-test as shown in the ANOVA table (see Table 3).

Multiple comparisons were then made of the 85th percentile speeds of various sign conditions to deternine if significant differences existed. The Scheffé Test (20) was used to make the comparisons. $Y_{1}$ and $Y_{f}$ are significantly different at level $\sigma$ if:

$$
\left|Y_{1}-Y_{j}\right|>\sqrt{(k-1) F_{\sigma}} \sqrt{M S e\left(\frac{1}{n_{1}}+\frac{1}{n_{j}}\right)}
$$

where $F_{\sigma}$ is the $100 \sigma \%$ point from the P-distribution with $(k-1)$ and d.f. degrees of freedom. $Y_{1}=$ the 85 th percentile speed (coded) of a sign condition from ANOVA.

$$
\left|\mathrm{Y}_{L}-\mathrm{Y}_{11}\right|=\frac{139.7-87.6}{16}=3.26
$$

$$
\begin{aligned}
\mathrm{P}_{0.05} & =1.13 \\
\text { MSe } & =0.6285 \\
\text { d.f. } & =33,980 \\
\mathrm{k} & =32 \mathrm{Ll}
\end{aligned}
$$

$$
\begin{gathered}
\sqrt{(k-1) P_{0.05}} \sqrt{\operatorname{MSe}\left(\frac{1}{n_{4}}+\frac{1}{n_{11}}\right)}= \\
\sqrt{(223)(1.13)(0.6285)(0.01071+0.00969)}=1.80
\end{gathered}
$$

Since $3.26>1.80$, the 85 th percent1le speeds under $S_{11}$ were significantly lower than those under $s_{4}$. 